\title{
CASEFILE
}

HYDROGEN-OXYGEN SPACE SHUTTLE ACPS

THRUSTER TECHNOLOGY REVIEW

by John W. Gregory and Paul N. Herr

Lewis Research Center

Cleveland, Ohio

TECHNICAL PAPER proposed for presentation at

Eighth Propulsion Joint Specialists Conference sponsored

by the American Institute of Aeronautics and Astronautics and the Society of Automotive Engineers

New Orleans, Louisiana, November 29 - December 1, 1972 


\section{HYDROGEN-OXYGEN SPACE SHUTTLE ACPS THRUSTER TECHNOLOGY REVIEW}

by John W. Gregory* and Paul N. Herr**

Lewis Research Center

National Aeronautics and Space Administration Cleveland, Ohio .

\section{Abstract}

A comprehensive program, sponsored by NASALeRC during the past few years, has provided the technology groundwork for the use of hydrogenoxygen propellants in the Space Shuttle Attitude. Contral Propulsion System (ACPS) thrusters. This work has concentrated on generation of technology for injectors, cooled thrust chembers, valves and ignition systems. The thrusters are designed to meet a unique and stringent set of requirements, including: long life for 100 mission reuses, high performance, light weight, ability to provide long duration firings as well as small impulse bits, ability to operate over wide ranges of propellant inlet conditions and to withstand reentry heating.

$\rightarrow$ The program has included evaluation of thrusters

i designed for ambient temperature and cold gaseous propellants at the vehicle interface. The cula mination of the component technology work is the incorporation of the best component designs into a complete integrated thruster assembly for evaluation of interaction effects, life, and performance.

This paper summarizes the results of the above programs.

\section{Introduction}

For the past few years, NASA has been sponsoring, through the Orfice of Aeronautics and Space Technology, an extensive program to advance the technology of hydrogen-oxycen thrusters applicable to the Space Shuttle Attitude Control iropulsion System (ACPS). This thruster technolory program has been managed by the Lewis liesearch Center. Related feed system technolocy work has been handled jointly by Manned Spacecraft Center and Marshall Space Flight Center. At the time this effort was initiated, hydrogen-oxygen propellants were baselined for the Space Shuttle AClS f'or both the Orbiter and Booster stages. The se propellants were selected because of their high performance, relatively low cost, clean exhaust, and nontoxic, noncorrosive nature, which is vitally important for a fully reusable system. Additional benefit was expected from comonality of propellants with the main engines and Orbital Maneuvering System (OMS). Subsequently, the Shuttle concept changed from the reusable flyback Booster and internally tanked Orbiter to the present external-tank Orbiter configuration with twin solid rocket motor boosters. These changes eliminated hydrogen-oxygen camonality with the Booster and greatly reduced the total system impulse required of the ACPS for the Orbiter (rrom over $2 \times 106$ Ib-sec to approximately 1.0-1.5\%106 1b-nes). Consequentiy, earth atoruble propellants (nitrogen tetroxlde-amine fuel) or monopropellant hydrazlne were selected as baseline for the orbiter in preference to hydrogen-oxygen. Since then, the hydrogen-oxygen technology work has been continued on a reduced scale to provide an alternate or backup approach for Shuttle as well as to fully eveluate the technology areas of importance so that the concepts would be avallable for other possible applications, such as Space Tug. It is the purpose of this paper to present a comprehensive review of the state-of-the-art of hydrogen-oxygen ACPS thruster technology, with principal emphasis on the gas/gas thruster area. Discussion of the relative merits of the various competing propellant comblnations, which requires an extensive and detailed trade-off study of system weight, volume, operational problems, cost, and reliability will not be presented herein.

Attitude Control Propulsion System (ACPS) Concepts and Considerations

The Shuttle Orbiter ACPS must provide both angular and translational control from the time of main engine shutdown after launch until reentry into the earth's atmosphere where aerodynamic control surfaces become capable of vehicle attitude control. The ACPS also provides roll control during main engine firing and translation maneuvers in three axes in space for rendezvous and docking.

of the various types of systems studied involving the use of hydrogen-oxyeen propellants for the ACPS, the most promisine are the gas/gas, gas/ liquid, and liquid/liquid systems, shown schematically in Figures 1,2 and 3 , respectively.

The gas/gas feed system (fig. 1) has received the greatest amourit of attention and technology effort. In this system, the propellants are stored at low pressure as cryogenic Iiquids, pumped to high pressure by centrifugal pumps and passed through heat exchangers where they are "conditioned." The gases are stored in high pressure accumulators, from which they are fed on demand through a distribution network to the many thrusters. Small $\mathrm{H}_{2}-\mathrm{O}_{2}$ gas generators, which also draw gases from the accumulators, are utilized to provide the hot gases to drive the turbopumps and to heat the incoming liquids. Various configurations of this basic system concept have been studied, including some where a single gas generator is employed to power the turbopump and heat the propellants.

The gas/gas feed system offers the advantages of versatility, flexibility, reasonably light weight, and the ability to be developed into a reliable, high performance, fully reusable systep with excellent thruster pulsing performance. (I) Its disadvantages are complexity, large propellant oturage volume, and high development cost. The system performance is degraded from the thruster performance of $435 \mathrm{lb}-\mathrm{sec} / 1 \mathrm{~b}_{\mathrm{m}}$ to about $380 \mathrm{lb} \mathrm{f}^{-}$ $\mathrm{sec} / 1 b_{m}$ speciflc Impulse because of the losses as-? sociated with the gas generator exhaust gases. The 
system also imposed severe requirements on the turbopumps and the gas generator/heat exchanger thermal conditioning unit. Technology contracts were undertaken by NASA-MSC and NASA-MSFC to solve the problems associated with the high performance and long iife required of these components. $(2,3)$

The gas/liquid feed system (fig. 2) was devised as an approach that eliminates some of the undesirable aspects of the gas/ges system by subst1tuting a liquid propellant feed system on the oxygen side. In the simplest approach of this kind, the oxygen is stored supercritically and fed directly to the thrusters at moderate pressure and near liquid oxygen saturation temperatures. This eliminates the need for the turbopump, accumulator, and gas generator/heat exchanger on the oxygen side making the total system simpler and less costly to develop. It does, however, introduce the requirement for distributing a cryogenic fluid throughout the vehicle to all the thrusters.

A further step in the direction of simplification is made by going to the liquid/liquid feed system (fig. 3). In this concept, both the hydrogen and oxvgen are fed to the thrusters as cryogenic liquids. The propellants would be stored as liquids, pumped by centrifugal or positive displacement pumps to moderate pressure, stored in liquid accumulators (bellows tanks), and distributed throughout the network of manifolds and lines to the thrusters. (4) Thus, the gaseous accumulators and gas generator/heat exchangers used for gasifying the liquids are eliminated, making a simpler, lighter weight, lower volume system that would be cheaper to develop. The problem areas associated with this system are ignition of the cryogenic liquids, pulsing operation performance with liquid propeilants as opposed to gases, possible combustion instability, and distribution of the cryogens without excessive heat leaks causing off design operation. 'This latter question has been stuaied in detail (5) to determine the temperature rise of liquid hydrogen and liquid oxygen in typical distribution lines and manifolds and to ascertain whether vacuum jacketed lines are necessary. The results of this analysis indicated that relatively small, controllable temperature increases would occur even without vacuum jacketed lines, making the concept appear quite feasible fram this standpoint. Also, the study considered various types of $\mathrm{LH}_{2}$ pumps and various means of driving the pumps, including the gas generator/hot gas turbine drive (shown in fig. 3), hydraulic and electrical drive. The questions concerning ignition of liquid hydrogen-liquid oxygen and thruster steady-state and pulsing performance are being investigated presently in a technology contract started in 1972. (6) The thruster technology for the Iiquid/Iiquid and gas/liquid systems is not as far advanced as the gas/gas system, and they will not be discussed further in this peper: Evaluation of the above problems, ao well as expertmential uyotem demonatrations are needed before the viabillity of these approaches will be fully establ1ahed.

Thmaster Requirements

The Shuttle operational characteristics and the characteristics of the reer systems described above imposed a unique and rather stringent set of requirements on the ACPS thrusters, lncluding high performance, long life, rouadility, abli1ty to provide both long duration firings and short impulse bits, exposure to reentry heating and atmospheric conditions, and abllity to operate over a wide range of propellant inlet conditions. The thruster operating conditions and design requirements that were evolved from these general require and used for the various technology programs are given in Table I for the gas/gas feed system. The ranges of chamber pressure, mixture ratio and propellant inlet temperature over which the thrusters were tested are also given.

The various nominal values listed in Table I were selected as a design point at which to examine thruster technology problem areas and were considered reasonably close to correct values for the original Shuttle concept. System studies $(7,8)$ of various hydrogen-oxygen ACPS were conducted to select the most promising system concept and to provide trade-off studies of various thruster operating parameters to select the optimum values. The nominal values of thrust, chamber pressure, mixture ratio, nozzle expansion ratio, and propellant inlet conditions listed were selected based on these studies and supporting NASA documentation of ACPS requirements. ( 9 ) The propellant temperatures were initially specified to be $540^{\circ} \mathrm{R}$ (ambient) and were later reduced to the colder temperatures listed.

The specification of thruster life was considered to be of Ereat importance and is one of the truly distinguishing features of this type of encine. The design life requirement specifled for a]1 the technolosy programs was that the thrusters should be capable of 100 mission reuses with a minimum of maintenance or refurbishment. Assumed firing rates of 1000 pulses/mission plus $50 \mathrm{rull}$ thermal cycles/mission were used. A safety factor of five was employed to arrive at the design life. because of the uncertainties of thermal fatigue analysis techniques and the sparsity of reliable basic materials data upon which to base the analysis. The precise thruster firing schedule for the various types of Shuttle missions is not well defined at present. Obviously, not all thrusters will be utilized equally; this will depend on the number of thrusters (approximately 30-40), their location on the Orbiter, level of redundancy, and control techniques. The selected life requirements were, therefore, chosen to provide a measure of conservatism but were considered to be reasonable design values with which to demonstrate the effects of long life requirements on thruster performance and design details. These effects will be further described in the section on Thrust Chamber Iife.

The specifled values of minimum impulse bit and response are necessary to provide precise Orbiter attitude control and minimize propellant usage when controlling attitude to a tight deadband. These values are achieveable with the hydrogen-oxygen thruster provided valve response is rapld (see section on Valves) and manifold volumes are kept small. The gas/gas thruster is particularly adept at providing high specific impulse at small impulse bits.

Certain thrusters will be exposed to severe reentry heating, particularly the down firing and forward flring englnes, if protective doors are not provided. The specifiad exposure time and 
temperatures are based on preliminary estimates; firm values have yet to be determined. These requirements were not imposed upon the early technology programs but have been applied more recently as more information on reentry heating effects on the thrusters became available. The effect of this requirement is to legislate against the use of low melting point materials, such as copper, in the expansion portion of the nozzle. Another factor that dictates against the use of copper is repeated exposure to atmospheric conditions when hot, which causes surface corrosion and severely degrades thermal fatigue life.

The specified thruster assembly weight was not imposed upon the initiel thruster programs but was applied to the Integrated Thruster Assembly (see Thruster Assembly Section). After consideration of all the requirements, the critical component technology areas were identified and specific programs formulated to evaluate them. Included in the overall technology programs were: investigations of the problems of injector design and performance; thrust chamber cooling, life, and fabrication techniques; ignition of ambient temperature and cold gaseous propellants; valve design, cycle life, and leakage; and thruster assembly steady-state and pulsing performance, heat soak back and component interaction effects. These subjects are discussed in detail in the following sections of the paper.

\section{Component Technology}

\section{Injectors}

The thruster design and operating requirements listed in Table I dictated that injector designs be developed that were capable of providing high combustion performance (over $97 \%$ energy release efficiency) and combustion stability at both steady-state and pulsing conditions, that would provide a benign combustion chamber environment with a minimum of temperature striations, that would have $10 \mathrm{w}$ face temperatures to promote long life and minimum heat soak back, and that would be relatively low in cost to fabricate. Another somewhat unique requirement was the use of gaseous fuel and oxidizer in the injector, whereas most rocket injectors are designed for either gas/liquid. or liquid/liquid propellants.

A number of parallel ACPS thruster contracts $(10,11,12,13)$ were initiated in which different approaches to injector design were pursued in order to provide alternate solutions to the injector design problem and avoid direct duplication of effort. A number of injector types were evalvated analytically and by cold flow tests using simulant fluids to determine the basic element designs best able to meet the above requirements. This preliminary screening resulted in selection of the element types shown in Figure 4 which were used for full scale injectors for hot firing tests.' These included: (a) concentric tube (coaxial) element, (b) premix, (c) triplet (with raised center post), (d) trislot, and (e) reverse flow/ vortex cup.

The various injectors were tested initially in instrumented heat sink thrust chembers to obtain energy release efficiency and heat transfer data. Tests were made both with no film cooling and with up to $37 \%$ fuel film cooling, since many of the thrust chamber cooling schemes involved the use of varying amounts of film cooling. A comparison of the energy release efficlency (ERE) performance of the various injectors is shown in Figure 5 in which ERE is presented as a function of mixture ratio $(O / F)$ for the cise of no film cooling. The raised post triplet injector provided very high performance for these operating conditions, which is typical for this type of element. The coaxial and premix injectors provided high performance also and proved to be rugged, durable destgns well suited to the long life requirements of the ACPS thrusters. The tri-slot injector was slightly lower in performance and also caused hot streaks in the chamber due to 1ts rather coarse pattern. Consequently, it was not used for the cooled thruster testing. The reverse flow/vortex cup injector date shown is somewhat mlsleading alnce with this concept there is always some film cooling of the chamber occurring, which tends to reduce performance. Because of this, delivered specific irnulse of the reverse flow thruster was better than would be predicted based upon the injector performance curve and met the performance requirements.

Performance data was obtained with the various injectors with varying film coolant flow, propellant inlet temperatures, and chamber pressure to determine the effects of these variables. The effect of percent film cooling on performance is presented in Figure 6 for the coaxial, triplet, and premix injectors. The performence differences are small and are partly due to the differences in thruster mixture ratio at which these data curves were taken. The trend of decreasing performance with increasing film coolant flow is consistent with predictions and was typically exhlbited by all the infectors tested. The injectors also showed consistent trends of decreasing performance with decreasing chamber pressure and decreasing performance with decreasing propellant temperatures.

Chamber heat transfer data were obtained with the various infectors using copper chambers instrumented with thermocouples. Typical throat heat flux data obtained with a coaxial injector (10), a premix injector(I1), and a triplet injector(12) are presented in Figure 7. Throat heat flux, referenced to a $5000 \mathrm{~F}$ design point wall temperature, is shown as a. function of percent fuel film cooling. As would be expected, the throat heat flux was reduced as film cooling flow was increased. Data curves are shown for the premix injector for two different film cooling rings, one of essentially zero length (equivalent to film coolant injection from the injector face) and one which extended 2.5 inches downstream from the injector face. It can be seen that the 2.5 inch ring was more effective in reducing throat heat flux than the zero length ririg. This result would be expected since the film coolant has less length in which to mix with the hot gas core flow and, therefore, is more effective in cooling the throet. The data shown are not intended to provide generalized results in terms of the heat flux produced by the different injectors, since there were differences in film cooling. injector design, chamber length, and chamber contour (all) of which have subtle influences on throat heat flux and film cooling effectlveress). It is shown only to 1llus. 
trate the type of data obtained and present some typical results. Similar results were obtained with the other injectors.

Face patterns of the various injectors are shown in Figures 8 through 12. The coaxial injector developed by Rocketdyne Division of North American Rockwell (10) is shown in Figure 8 . The design shown resulted from extensive cold flow testing of different element configurations and hot fire testing of two different injectors. The highest performing coaxial element design (shown in fig. 4(a)) incorporates an oxidizer tube flush with the injector face which contains a $7^{\circ}$ tapered outlet to enchance mixing between the oxygen and hydrogen. The injector contains 54 coaxial elements and has the igniter port in the center of the injector face. The injector has a copper faceplate and Nickel-200 oxidizer posts. The body and manifolds are of $304 \mathrm{~L}$ stainless steel.

The premix injector developed by Aerojet Iiquid Rocket Company (17) is shown in Figure 9 and the element detail is shown in Figure $4(\mathrm{~b})$. In this novel approach, the propellants are premixed in a "cup" behind the injector face. Oxygen enters the cup region of each element through a central tube and is impinged upon by two hydrogen streams from the two sides of the cup. A number of different injector designs were tested in which the cross-sectional shape of the hydrogen orifices was varied. Rectangular, $\mathrm{T}$-shaped, and I-shaped orifices were investigated and an I-shape was finally proven to be optimum. These variations in the hydrogen orifice shape are achieved by the unique fabrication method employed. A stack of thin (0.010 in.) nickel plates, in which the appropriate holes are photoengraved, are brazed together and brazed to the stainless steel body of the injector. This method provides very accurate control of tolerances for the small flow passages involved and provides great flexibility in designing the shape and size of the passages. The faceplate is cooled by a multiplicity of small hydrogen bleed holes. This injector has 72 premix elements and has the igniter port in the center of the injector face.

The raised post triplet injector developed by TRW Systems, Inc. $(10)$ is shown in Figure 10 and the element detail is shown in Figure 4(c). The injector has three circular rings containing a total of 144 oxidizer-fuel-oxidizer triplet elements. The orifice diameters were varied for each ring to provide a relatively uniform mass distribution across the injection plane. The injector faceplate (rings) are OFHC copper and the injector body and manifolds are $304 \mathrm{~L}$ stainless steel.

The trislot injector design developed by Rocketdyne (10) is shown in Figure 11 and the element detail is shown in Figure 4(d). The trislot injector consisted of 18 elements in each of which hydrogen flow from two rectangular slots impinged upon oxygen flow fram a central rectangular slot. The objective of this approach was to provide an injector concept that would be low in cost to fab'ricate, provide high performance, and be well suited for gav/pars propellante. The elote ware fahrlcated by olectrical duchurge machinine. (Hid) into a copper faceplate core, which was the: electron beam welded onto a 304I stainless steel body.

The reverse flow injector concept developed by Bel1 Aerospace Company $(13)$ is shown in Fig- ure 13 and Figure 5(e). In this unique approach, the hydrogen is injected in a reverse direction in the convergent portion of the nozzle and used to film cool the spherical chember. The oxygen is injected from the head end of the engine through a vortex cup which causes the oxygen to spray radially outward and impinge with the fuel coming off the chamber wolls. The objective of this design approach was to provide low temperature chamber walls, thereby allowing use of common materials and reducing manufecturing cost, and to separate the fuel and oxidizer which normally are in close proximity in the injector. This injector design will be covered in more detail in the section on thrust chambers to follow since in this concept, the injector and chamber are combined.

All of the above infector concepts, except the trislot, were utilized for testing of cooled thrust chambers. As stated earlier, the trislot was eliminated because of its tendency toward streaking.

\section{Thrust Chambers}

To arrive at the most attractive thrust chamber concepts for the ACPS thrusters, a number of cooling schemes were analyzed, such as regenerative, film, dump, ablative, radiation, and combinations of these. The analysis included tradeoff studies of performance, weight, inlet pressure required, cost, external wall temperature, ability to withstand reentry heating and repeated exposure to atmosphere, nozzle scarling, and most particularly, chamber life.

Ablative chamber cooling was quickly discarded because of life limitations and excessive weight. Radiation cooling cannot be used effectively in buried installations. and it also is somewhat life limited by the refrectory metals normally used in the construction of radiation cooled chambers. It was, however, selected for the nozzle skirt in one of the chamber designs. Detailed study of the remeining cooling methods by the various contractors led to selection of the concepts shown in Figure 13 for fabrication of cooled thrust chamber hardware and testing.

The selected chamber configurations all feature combined use of three basic cooling methods, all of which employ active cooling with the fuel as coolant: (a) regenerative, (b) dump, and (c) film. To avoid confusion, definitions were established for these cooling methods, as follows:

(a) Regenerative cooling refers to forced convective cooling of the hot thrust chamber wall by passing the coolant first through coolant channels or tubes built into the chamber walls and: then routing the coolant to the injector after it leaves the chamber. Thus, the fuel flows through the chamber coolant circult and the injector in series.

(b) Dump cooling is simllar to regenerative in that it employs forced convective cooling and uses a double wall or channel-wall design to provide coolant passages. It differs from regeneratilve cooling in that the coolant does not pans

through the injector and chamber in serles, but instead these flow circutts are in parallel, 1.e., after convectively cooling the chamber, the coolant is dumped directly into the combustion chamber or nozzle, where it may then be employed as film 
coolant. Depending upon the chamber design, the dump coolant may be partially or fully "regenerative" in the sense of a thermodynamic cycle in which heat is removed from the combustion process and absorbed by the incoming working fluid (fuel).

(c) Film cooling refers to the cooling of a single chamber wall (as opposed to double or channeled wall) by injecting a cooler fuel flow along the wall which acts us a barrier to heat flow from the hot gas' core to the metal wall. In several of the designs, fuel is used first for regenerative or dump cooling and then for film cooling.

These three cooling methods are well known in the rocket industry, but occasionally the terms are used differently. Hence, the above more or less arbitrary definitions are provided. Regenerative cooling has the advantages of no performance loss, long chamber life, and cool outer chamber walls, but the disadvantages of high pressure drop, high weight, and high fabrication cost. Dump cooling has similar advartages and disadvantages to regenerative cooling, but has lower pressure drop and lower delivered performance. Film cooling has the advantages of low pressure drop, simple, low cost chamber design, and relatively light weight, but the disadvantages of performance loss, higher wall temperatures which, therefore, limit chamber life. The advantages of film cooling were a good choice for the skirt of the ACPS thruster from a nozzle area ratio of about 18-20:1 to the exit plane. As may be seen in Figure 13 , all of the thrust chamber cooling concepts used film cooling for the skirt. This jrovided a lightweight, single wall nozzle design that facilitates scarfing of the nozzle and makes excellent use of materials such as stainless steel or Haynes 188 which can withstand the high temperatures due to cambustion heating with very little film cooling needed, as well as reentry heating without active cooling.

Th six chamber concepts shown in Figure 13, all of which were fabricated and tested, differed significantly in the cooling approaches used for the chamber and nozzle up to the nozzle area ratio of 18-20:1. These different approaches represented a deliberate attempt to provide $a$ broad technology background. In the chamber design considerations, variation among the desirable attributes of performance, life, and cost, resulted in quite different design approaches to achieving the performance and life goals of the technology efforts. These chambers are generally characterized or referred to first by the method used to cool the throat, since this is the most critical region, and then by the method used to cool the combustion chamber or nozzle expansion section.

In the next few paragraphs, each of the six thrust chamber concepts will be described in detail as to the materials and construction techniques employed. Following this, a brief description will be given of the considerably different methods used to aralyze the life of two typical chambers, a regenerative design and a f1lm cooled design. Delivered performance obtained with four of the thrust chambers is described in the section on Thruster Assemblies, to rollow.

(1) Regenerative/Dump Cooled Chamber. - In Figure 1415 shown a one-half-pass regeneratively cooled thrust chamber designed, fabricated, and experimentally tested by Rocketdyme $(10)$, which was shown conceptually in Figure 13(a). This design employed regenerative cooling for the combustion chamber, throat, and divergent section of the nozzle to an expansion area ratio of 3 . Drmp cooling was employed from an area ratio of 3 to 18 , and film cooling from an area ratio of 18-40. The chamber is of channel wall construction from the injector face to a plane 1.7 inches upstream of the throat. From this plane to a nozzle area ratio of 3 , the chamber is of double wall construction (closure not attached to liner). From area ratio 3 to 18 , channel wall construction is used, followed by the film cooled nozzle extension. The chamber, from the injector face to an area ratio of 18, used a NARloy-Z (copper/silver/ zirconium alloy) liner with an annealed electroformed nickel closure, while the film cooled coni-: cal nozzle extension was made of 310 stainless steel. The double wall chamber region was designed to decrease the stresses imposed on the inner wall by the restraint of the outer wall when the inner wall is heated, thereby increasing the cyclic life (thermal fatigue) of the chamber. In this chamber, the hydrogen flow enters the manifold located near the throat and is split. Approximately $15 \%$ of the fuel flows downward to dump cool the nozzle from an area ratio of 3 to 18 and film cool the skirt, while the remainder of the flow is routed upward to regeneratively cool the throst and combustion chamber. The nozzle film coolant was injected through small two-dimensional. nozzles designed to provide supersonic injection of the coolant at a pressure matching the free stream static pressure in the nozzle. F1gure 16 shows the NARloy-Z chamber liner after the coolant channels were machined but prior to electroforming the nickel outer well. The $\mathrm{fllm}$ coolant injection nozzles are clearly evident. This chamber also had provision for the use of film coolant injection from the injector end to supplement the regenerative cooling and reduce the chamber wall temperatures.

(2) Regenerative/Film Cooled Chamber. - A second thrust chamber design classified as regenerative/film, shown in Figure 16, was developed by Aerojet. (9) This chamber design was shown conceptually in Figure 13(b). The design consists of a single pass counterflow regeneratively cooled copper chamber which extends from the infector face to a nozzle area ratio of 3 , a short dump cooled downpass flow section from area ratio 3 to 8 , and a spun stainless steel fllm cooled nozzle expansion section from area ratio 8 to 40 . A novel fabrication approach was used which featured the use of 60 photoctched precontoured stainless steel truss members to close out the coolant channel slots and provide coolant man1folds in the throat region. Final channel and manifold closeout wes accamplished by use of a shrunk-flt and brazed stainless stcel cylindrical jacket for the chamber region and several match machined conlcal stalnless steel sections for closing out the channels in the divergent section. The film coolant flow was injected through 100 small two-dimensional nozzles formed by photoengraving a 0.015-in. thick copper strip which was brazed in place between the copper inner wall and a match machined stainless steel closeout section. The spun stainless steel skirt was electron beam welded to the aft end of the facket. The hydrogen 
flow enters this chamber at the manifolds near the throat with $10 \%$ of the fuel flowing downward to dump cool the short section from an area ratio of 3 to 8 and film cool the skirt and the remainder flowing upward to regeneratively cool the chamber.

(3) Drmp/Film Cooled Chamber. - In Figure 17 is shown a dump/film cooled thrust chamber developed by Rocketdyne(10), which is illustrated schematically in Figure $13(\mathrm{c})$. This chamber consists of an uppass dump cooled section from an area ratio of 3 to the injector end, a downpass dump cooled section from an area ratio of 3 to 18 , and a film cooled skirt. In this design, $35 \%$ of the fuel enters the manifolds located near the throat while the reminder is routed directly to the injector. Fifteen percent of the fuel is used. to downpess dump cool the nozzle expansion section. and film cool the skirt and $20 \%$ is utilized to uppess dump cool the throat and chamber and is then dumped into the chamber as film coolant. Because of the splitting off of the coolant flow, the injector is designed to operate at a mixture ratio of 6.1 whereas the overall thruster mixture ratio is 4.0. The construction details for the dump cooled chamber are very similar to concept (1) above, except that no double wall section was employed. The chamber is of channel wall construction throughout having a NARIoy-Z liner into which the coolant channels were machined and which were closed out with electroformed nickel. The manifolds and boited on nozzle skirt are of $304 \mathrm{~L}$ stainless steel.

(4) Film/Regenerative Cooled Chamber. - A chamber concept featuring the use of film cooling for the throat and nozzle expansion and regenerative cooling of the cylindrical chamber, developed by Aerojet(11), is shown in Figure 18. This chamber was shown conceptually as Figure $13(\alpha)$. In this design, the fuel enters the chamber at the manifolds located near the start of nozzle convergence. Twenty percent of the fuel flows downward through a short dump cooled section and is injected as film coolant 1.3 in. upstream of the throat. The remainder of the fuel flows upward through a short cylindrical regeneratively cooled copper chamber section and discharges into the injector fuel manifold. The cylindrical chamber liner was fabricated of OFHC or zirconium copper (one of each were built) into which $80 \mathrm{cool}-$ ant slots were machined. The coolant slots were closed out by a $304 \mathrm{~L}$ stainless steel jacket, brazed in place. The throat section was fabricated by spinning Haynes 188 on a mandrel. The nozzle skirt, of $304 \mathrm{I}$ stainless steel material, was also spun to shape and welced to the Haynes 188 thraat section. The conical shaped film coolant injection ring was made of copper.

(5) Film/Drmp Cooled Chamber. - Shown in Figure 19 is a unique film/dump cooled chamber that was designed, fabricated, and tested by TRW Systems, Inc. (13) This chamber is shown conceptually! in Figure 13(e): In this concept, $32 \%$ of the fuel is injected between a copper inner sleeve (or duct) and the stainless steel chamber. This fuel cools the duct in a downpass dump mode and is then: injected as film coolant in the convergent portion: of the nozzle. The throat and entire nozzle expansion section are film cooled. The duct is fab-i ricated of Berylco copper with coolant channels machined into the outer wall. The combustion chamber/nozzle assembly is of spun A-286 steel. The duct is mounted within the chamber so that it is free to grow slightly axially and radially when heated. This concept has the unique advantages of: (a) a simple, ilghtweight, inexpensive chamber, (b) the stmuctural looding imposed on the inner duct wall is low and, therefore, cyclic life is high, and (c) response and coolant pressure drops are minimal.

(6) Reverse Flow Chamber. - The reverse flow chamber concept shown in Fisure 21 was developed by Bell Aerospace Company. (13) This concept, as shown in Figure $14(f)$, actualiy consists of a regeneratively cooled throat section, a spherical shaped, film cooled combustion chamber, and a film cooled nozzle expansion section. In this chamber, the fuel enters the manifold near the throat and flows upward from a nozzle area ratio of 10 through coolant channels machined into the copper liner. The fuel, thus, regeneratively cools the throat region and is injected into the nozzie convergent section in the reverse direction to film cool the spherical combustion chamber section. This throat cooling mode is regenerative (according to our earlier definitions) rather than uppass dump since the main fuel injector located in the nozzle con- : vergence is in series with the coolant circuit. In this chamber design, the vortex cup oxygen injector parts and spherical combustion chamber are $304 \mathrm{~L}$ stainless steel. The throat liner is OFHC copper with coolant channels machined into the outer wall. Closeout of the coolant passages is achieved by two aluminum shroud half shell members that are held in place by the 304L stainless steel fuel manifold assembly. A film cooling mainfold is incorporated into the aft end of the fuel manifold and throat section assembly fram which $7.5 \%$ of the fuel is injected downward to film cool the nozzle extension. The bolted on nozzle extension section is of Columblum $\mathrm{All}$ oy $\mathrm{ClO} 3$ with a sllicide coating on the inner wall and a Dynaflex insulation blanket on the outer wall. The Columbium nozzle is essentielly radiation cooled with supplemental film cooling. A chamber insulating blanket is provided to reduce the radiation heat transfer to the vehicle.

\section{Thrust Chamber Iife}

The advent of reusable vehicles, such as the Space Shuttle, wherein the components should ideally be capable of 100 mission reuses, places a! premium on thrust chamber life. The ACPS thruster life requirements, as listed in Table $I$, lncluded 500,000 pulses, 25,000 ful thermal cycles, and 50 hours of operation. These are stringent requirements for a small, high performance rocket engine which require careful design considerations to produce a truly long-life engine. Compromises in engine performance and materials selections had to be made in some cases to meet the life require-1 ments.

The entire technology related to rocket thrust chamber life is a new and difficult field that is essentially in its infancy. Reliable predictions of chamber life require extensive basic materials data on thermal fatigue, such as that shown in Figure 21, detailed analysis of the cyclic stress and strain behavior of each portion of tho chamber, and Intimate knowledge of the temperaturo profile throughout the chamber durling tho 
transient and steady-state phases of each firing cycle. To experimentally verify chamber life requires extensive testing at known operating conditions with avoidance of extraneous failures due to facility malfunctions, chamber fabrication discrepancies, or the like. Correlation of experimental results with theoretical predictions is also complicated by the inaccuracies in such areas as heat transfer analysis and material property. data.

The fundamental theory used in life analysis is that failure prediction depends on the accumulation of fatigue damage and creep damage. The analysis involves the evaluation of the material's capability to resist damage from exposure to steady stresses, cyclic stresses, and elevated temperatures for the specified service life. Mansion's universal slopes method, adjusted for elevated material properties or actual experimental thermal fatigue property data were used to calculate fatigue damage. Stress rupture data were used to estimate creep damage.

A complete discussion of the methods and theory used for chamber life predictions is beyond the scope of this paper. However, a brief discussion is included of the approach used for two different chamber types, a film cooled (throat) chamber and a regenerative chamber. These chambers differ not only in the materials used and the allowable temperatures, but also in the wall temperature behavior under transient conditions. As shown in Figure 22 , the hot side and back side wall temperatures for a film cooled chamber wall initially diverge when an engine firing begins and then converge as the heat pulse is absorbed and the wall cames to thermal equilibrium. The maximum temperature difference across the wall, and consequent maximum thermal strain, occurs very early in the firing, perhaps within 100 milliseconds. For a regeneratively cooled chamber, where a channeled wall construction is used and the wall is actively cooled, the hot side and back side wall temperatures continually diverge until thermal equilibrium is established. This occurs later in the firing than for the film cooled case and, consequently, the worst case condition, i.e., the maximum temperature difference, occurs only in a longer duration firing. Thus, the life limiting condition for film cooled chambers is any pulse of greater than say 100 miliiseconds, whereas the life limiting case for the regenerative chamber is a full thermal cycle, i.e., a riring longer than about 2-3 seconds. This, of course, neglects other stress imposing factors, such as pressure loads, and creep, which tend to be secondary effects for the ACPS thruster operating conditions.

For the film cooled chamber, shown in Figure 18, the cyclic and creep rupture life of the single wall throat and skirt was computed based on experimental temperatures and transient heating rates measured during a test firing. (11) The anaiysis begins at the film coolant injection station and extends through the Haynes 188 throat and $304 \mathrm{~L}$ stainless steel skdrt to an area ratio of 40 . Figure 23 shows the effective stress in the laynes 188 thront region at 0.10 seconds after the thruster is started from a cold condition. The major component of this stress is due to the radial Gradient through the wall. For the 0.045 in. thick wall Haymes 188 tiroat, the peak stress of
72,000 ps1 results in a strain of $0: 27 \%$ which converts to a cycle life of $4.6 \times 10^{5}$ (rig. 21). The Iffe at the chamber throat could be Increased by, using more film cooling or a thinner chamber wali: The region $0.4 \mathrm{in}$, upstream and downstream of the throat operates in the elastic region and has much greater life. (i]) For longer firine times, the radial temperature gradient through the wall is greatly reduced and the remaining structural loads are due to thrust, internal pressure; and axtal temperature gradients. These steady-state stressea are considerably below the 50-hour creep rupture limits of the chamber materials throughout the film cooled portion of the chamber.

Life predictions for the regenerative chamber designs are generally based upon steady-state measured temperature profiles throughout the chamber wall at or just upstream of the throat cross section obtained with heat-sink chambers. These data are then correlated with analytical predictions using two-dimensional heat transfer computer prosrams. For this analysis, the chamber wall cross section is divided into a grid network and the temperature at each nodel point is calculated. From these calculations, en average circunferential chamber wall temperature is established for which the material stress and strain in the chamber walls are colculated at various axial stations. Life predictions are then made laking into account thermal fatigue damage and creep damage.

Experimental data were obtained with a regenerative chamber of the type show in Figure 16 at chamber pressures from 100 to 500 psia and with varying propellant inlet temperatures. The effect of these variables on the chamber inner wall temperature difference and the chamber life are shown in Fig. 24. The temperature measurements were made at a point 0.6 in. upstream of the throat, which is the most critical point for this chamber. The life predictions shown are for thermal fatigue damage alone, neglecting long term creep effects, which are of secondary importance. These predictions are based upon minimum properties for zirconium copper and are, therefore, conservative. The curves show that chamber pressure has a dramatic effect on chamber life while changes in fuel inlet temperature have little effect.

\section{Ignition Systems}

No clear-cut choice of the ignition system to accommodate the stringent ignition requirements of a smell, pulsing hydrogen/oxygen thruster was evident. Spark ienition systems, for fixed-point operating condition hydrogen/oxygen engines have been successfully developed in the past for both the $\mathrm{RI}-10$ and $\mathrm{J}-2$ engines. However, the requirements for the Shuttle ACPS thrusters are more severe in that the igniter must have fast rosponse, high cycle life, be capable of operating over a wide range of corditions, and tho total number of igniter systems required is very high (\$38); therefore, power requlrement for coch 1 gnt tor aystem must be very low. Table II lists the requirements that the 1gnition system must meot in addition to the general thruster requirements $B$ iven in "lable $I$.

In order to provide an adequate 1gnition system concept to fulfill the requirements of the 
ACPS application, a number of different ignition schemes were considered. Some of the more attractive candidates that were selected for experimental testing as part of the LeRC technolosy program were: (1) electric spark plug/torch ${ }^{* *}$ igniter, (2) electric plasma/torch ${ }^{*}$ igniter, (3) direct electric spark nlug ignition (combustion chamber wall-mounted), (4) heterogeneous cataIytic torch ${ }^{* *}$ igniter, and (5) auto ignition torch.

(1) Electric Spark Plug/Torch Igniter. - The primary objective of the electrical spark plug/ torch igniter investigation was to obtain a highly reliable ignition device capable of operating over the wide ranges of operating conditions given in Table II, while also achieving significant reductions in spark plug and exciter package input energy requirements, reduction in exciter weight and size; and minimum radio frequency interference (RFI). Elimination of the high-tension pressurized cable assembly between the exciter package and the spark plug, such as used on the J-2 and RL-10 engines, was an important design goal to reduce RFI and eliminate voltage loss and leakage problems associated with such cables.

A technology program was conducted by Rocketdyne(14) on igniter systems, which included extensive analytical and desien effort, to fully delineate the effects of major variables on the ability to obtain fast reliable ignition of the spark igniter/torch itself and of the complete thruster. This effort began with analysis of the basic chemical and physical variables involved in the ignition process for various mixtures of gaseous hydrogen and gaseous oxygen over a range of temperatures.

Cold flow tests were conducted with scale model hardware from which evolved design critera for the igniter injector, igniter torch chamber, and spark plur, location. 'l'he design which evolved for the spark plue/torch igniter is shown in Figure 25. Extensive tests were performed with the spark/torch igniter over ranges of propellant temperatures and pressures, fuel lead and lag, environmental temperature and pressure, and mixture ratio. Variations were also made in spark rate and energy, spark plug gap, electrode type and material, and plus location. Tests were made to verify that the RFI output was within the MIL-STD461 specification.

A flight type exciter package was designed that features an integral spark plug, as shown in Figure 26, and weighs only $0.6 \mathrm{lbs}$. The exciter provides an inductive electrical circuit to provide energy to the spark discharge, as opposed to a capacitive discharge device. The exciter package requires only 8 watts electrical power input, and complies with the $\mathrm{RFI}$ requirement.

As a result of the testing done on the igniter and excitor unit, a complete liat of nominal les-

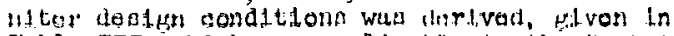
Table III, wh1ch are applicable to the Rocketuyne unit. (14) The test results indlcated that reliable Igrition was obtained over all of' the operating condition ranges except at low propellant temperatures (below $380^{\circ} \mathrm{R}$ ) where same nonignitions oc: curred. Typical response data for this leniter design indicated that ignition usually occurred on the fifth spark 16 milliseconds (1gnition delay) after inception of oxidizer flow, 25 milliseconde after start of fuel flow, and 33 milliseconds after electrical start signal. A fuel lead of 10 milliseconds was intentionally used to avoid autoignition. Thus the local spark plus mixture ratio had to E, through a ruel-rich transient. Without a fuel lead, the response could be less than 25 milliseconds from electrical start to ignition.

A second electrical spark plug/torch igniter design concept was generated under contract by Aerojet.(15) Although the objectives and design requirements (Table II) of this effort were the same as discussed above, several noticeable differ-: ences are evident in the approaches taken. As may be seen in Figure 27, this igniter uses an air-gap spark plug and a cooled igniter body. Oxygen is injected around the plue center electrode so that the spark discharge occur:s in an oxidizing atmosphere. Fuel is injected radially inward just downstream of the plug tip and provides a controlled mixing environment for reliable ifnition. The reminder of the fuel passes through coolant channels in the double-walled body and is injected at the igniter $t i p$ giving an overall $0 / F$ of 6.5 , whereas the core $O / F$ is $45: 1$. Other characterlsties of the Aerojet design include: an exciter spark rate of 500 sparks per second, capacitive discharge cxciter unit, nickel electrodes, and electrical enerey delivered to the spark plug of 5 millijoules. The ignliter uses $20 \mathrm{kV}$ breakdown valtage and a spark gap of: 0.050 inches.

Expcrimental results with this electrical spark/torch i.gniter, employing the higher $0 / F$ in both the igniter core and overall igniter flows in conjunction with a higher spark rate, provided reliable ignition over the cntire range of operating conditions tested and was also within the standard RTI requirements. Another significant experimental result with this igniter design was that optimm ignition with no pressure spikes was obtained with simultaneous injection of the main propellants. Both fuel leads and lags caused ignition overpressures, but fuel lags caused the more severe spikes. From the data from all tests conducted with this igniter assembly under vacuum conditions, it was determined that the average response time for the torch ignition to occur was $10 \mathrm{mill}$ iseconds from electrical start. Durability tests of both steadystate (10 seconds of operation) and pulse mode (1000 pulses of $1 \mathrm{sec}$ duration) operation on the igniter assembly revealed no operational or physical degradation.

(2) Electric Plasma/Torch Ignition. - Another electric ignition system very similar to the spark/ torch igniter was also evaluated by Aerojet(15) for potential ACPS thruster applications. This concept. thiown in l'lowre 20 , has the potential advantages over the upark/toruh upproach of longer electrode Ilfe and lower input power required. Tho basic alft :

\footnotetext{
* *orch means an ifnlition device that bringe together lenttaule mixtures of guseous hydrogen and oxygen, in the prescrice of an lenition cnerfy source, and expelis the products of this combustion (offluent) into the maln combustion chanber of the thruster to lenste the main propellant flow.
} 
ference between the two concepts is in the primary ignition zone (ignition kernel area).

In the plasma pulse igniter, a portion of the hydrogen is passed through the plasma gap and is ionized by a pulsing electrical energy source of 0.2 millijoules at 5000 volts to provide the ignition source. In the spark plue igniter system, oxygen is passed through the spark sap or in some designs the spark discharge occurs directly in a gas mixture. The enerey level of the spark plug system is much higher. This approach requires 5 millijoules of energy at 20,000 volts. The oxygen is injected in an ennulus around the plasma plug tip. As in the spark plug/torch ieniter, most of the hydrogen (85\%) is used to cool the torch chamber wall. This coolant hydrogen then mixes and further reacts with the igniter core effluent at the igniter exit plane to provide a very hot torch for thruster main stage ignition. The core $O / F$ is $45: 1$ while the overall $O / F$ is 6.5 for plasma/torch igniter. Test results demonstrated that the plasma/torch igniter operates reliably over the ranges of operating conditions given in Table II. Best results again were obtained with simultaneous propellant valve sequencing. A portion of the testing was concerned with evaluation of candidate electrode materials. Based on electrode durability tests, copper was selected for the anode and $2 \%$ thoriated tungsten for the cathode.

(3) Direct Electric spark Plue Innition. - The possible use of a conventionil aircrurt ensine air(ap) :ipark plug, simply mounted through the combustion chumber wall, was eveluated as a part of the hydrogen/oxygen thruster techuoloty work performed under NASA-LeRC contruct, with BelI Aerospace Company. (13) The ignition effort performed was orly that necessary to develop a workable ignition system to be used in thruster tests. A conventional G.L.A. spark plug exciter package and Champion Al4-1-395-1 aircraft spark plug were used. The spark plug was mounted through the combustion chamber wall, as shown in Figure 28. Provision was made in the spark plug mounting arrangement to provide oxygen augmentation on the upstream side of the spark plug to enhance the ignition process. It was found that some chamber wall erosion occurred if the quantity of oxygen used was not very accurately controlled. This ignition scheme is somewhat simpler than the spark/torch or plasma/ torch systems and apparently worked sufficiently well to complete the overall thruster evaluations, but does not provide the well controlled environment at the spark plue tip so necessary for reliable ignition, particularly over the range of propellant inlet temperatures and mixture ratios set forth in Table $I$.

(1) Heterosencous Cntalytic Torch Igniter. For muny years, rocket enpineers have sought a reliable passive lenition systom for the hydrogen/ oxygen propellant systems (i.e., one requiring no external power input). Since the interest arose in hydrogen/oxygen propellant for the shuttle ACPS thrusters, NASA-LeRC intensified this search for a passive ignition system. Two passive ignition systems have been investigated during the 19691971 time period under Lewis sponsorship. These two, to be discussed in the next two sections,

i are: (1) heterogeneous catalytic itnition, and (2) autoigntion torch/resonance tube ignition.
Ey 1969 , the use of noble metal catalysts had been demonstrated to create spontaneous ignition of both ambient temperature and chilled axygen/ hydrogen mixtures in a single thermel bed reactor. $(16,17)$ However, the response time required for the spontaneous reaction to occur (from the measured time of arrival of both propellant species at the catalyst active sites unt 11 roaching $90 \%$ of steady-state chember pressure) appeared to vary drastically with variations in both initial propellant temperature and reactor operating pressure (chamber pressure). Also, the Ignition response was never faster than approximately 200-250 milliseconds. Additional investigation was, therefore, undertaken to reduce the ignition delay. time at low propellant temperatures and to find possible means of significantly improving ignition response times under all conditions. $(18,19,20)$ Catalytic igniters were designed to minimize thermal and pneumatic lag and tests were made to evaluate the relative importance of several factors, such as pneumatic las, bed thermal mass, reactor body thermal mass, and initial $O / F$ entering the reactor, in causing long ignition delay times.

In the search for f'uster responsc of the thermal reactor bed type igniter, high initial $O / F^{\prime \prime}$ s up to 10:1 were allempted, which only created flashbacks. Reducing the thermin inertia of the reactor body by means of insulation and isolating the catalyst bed irom the reactor body brought about no appreciable improvement in response time. A speci.t liatalytic ieniter design finally cvolved (fib. 30) which used downstream injection of pure oxygen into the effluent from the catalytic reactor. 'J'his approach produced sienificant ignition response improvement. Figure 31 shows the ignition response of the same type of $\mathrm{H}_{2} / \mathrm{O}_{2}$ reactor with and without downstream oxygen injection. This technique brought about an order of magnitude change in the ignition response - from 250 inilliseconds to approximately $25-30$ milliseconds just by the use of downstream $\mathrm{O}_{2}$ injection. The 25-30 millisecond response of this igniter still fell short of the 10 millisecond goal set forth in Table II however. With cold temperature propellants $\left(-250^{\circ} \mathrm{F}\right)$, the overall reactor response remained very good - approximately 40-50 milliseconds.

Durability tests, including both pulging and steady-state firings, were also conducted (18) to establish the cyclic and steady-state life potential of two key noble metal based catalysis Shell 405 and Engelhard MFSA. It was clearly established that both of these catalysts were very durable for steady-state firings up to $4000 \mathrm{sec}$ onds duration and continuous pulse mode operation up to 5000 thermel cycles without significant physical or chemical degradation. Ultimate durability of catalyst beds has not been f'irmly established.

(5) Autoignition Torch (Compression-Resonance Tube). - The second passive ignition system concept evaluated for potential Space Shuttle ACPS thruster applications was the autoignition or compression-resonance tube igniter.(14) This concept requires minimal electrical power and no high voltage but does require a gaseous propellant. llydrogen gas was used becouse of 1 tis avallubility and because it provldes rapld heating to tempora- 
tures above the autoignition temperature of hydrogen/oxygen mixtures.

The physical principle upon which the resonance tube igniter operates is the use of a resonating gas column to heat the hydrogen gas to the $\mathrm{H}_{2} / \mathrm{O}_{2}$ autoignition temperature. As shown in Figure 32 , the hydrogen was injected at 350 psia through a sonic nozzle and impinges directly upon the resonance tube entrance. Gas trapped in the resonance tube is quickly heated by repeated adiabatic compression to temperatures of $1500 \circ \mathrm{F}$ (Mode 1). The hydrogen is introduced about 5-10 milliseconds before the oxygen to allow time for the resonant heating to occur. Oxygen is then injected into this hot hydrogen and ignites (Mode 2 ). Combustion is sustained in the larger diameter tube, fram which it flows out into the thruster, thus providing a torch for thruster ignition. The concept requires no external power other than for valve operation and, therefore, is a passive system.

During the autoignition technology program, several resonance cavity configurations and other igniter/resonance tube variables (gap ratio and pressure ratio) were evaluated. Ignition responses, from electrical signal to $90 \%$ of igniter chamber pressure, of 20 to 30 milliseconds were obtained. The basic feasibility of the concept was demonstrated with work horse hardware and relatively rapid ignition response appears to be directly related to the high igniter operating pres. sure (350 psia).

Several hundred hot tests were conducted with an optimized resonance tube igniter assembly, shown in Figure 33, of which 2? were igniter/ thruster ignitions in a 1500 lv. ACrs linuster it:sembly. $(14)$. The overull response of this iqnilion system in the thruster asscmbly was determined to be approximately $50 \mathrm{milliseconds}$ from valve sitrial to $90 \%$ thruster chamber pressure. Ihe resonance tube igniter generally pcrformed well but needs further investigation to optimize the design for low propellant temperatures and reduce its sensitivity to pressure ratio and valve sequencine. From the amount of testints performed with this; itniter concept, the only durability limiting device is the propellant valve assembly since the basic igniter assembly contains no moving parts.

From the array of ignition data produced and the variety of ignition schemes, it is evident that a number of viable ignition system candidates exist for the ACPS thrusters. Final selection of the ignition system for flight use will depend to some extent upon the relative emphasis placed upon various requirements, such as power required, redundancy, reliablity level, life, etc. At this polnt in lime, the alectrili spark/torch ayitem appears moot uthractive bocause ol' i.ts bilph experience level, rellablilliy, nuwlblvenomi, this respunse, likht welfht, low power ira.ln, and low

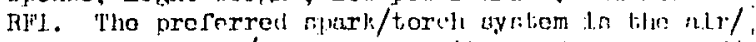

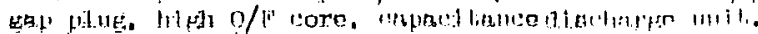

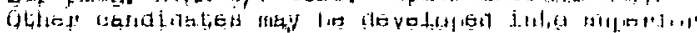
systems with additional work, but would have airf'iculty competing with the high experience level of a spark plug system. In the selection of a spark Plug torch or Direct Spark Plug igniter system, the spark rate (spark per second) and the thruster response requirements must be closely matched in order to provide spark availability overlap during rapid pulse mode thruster operation to preclude unduly delayed thruster ignition or excessive pro pellant accumulations. A summary of all five 1gnition system design and operational characteristics is shown in Table IV.

\section{Propellant Valves}

Another critical ACPS thruster component area that needed technology improvement was the thruster propellant valves. Existing propellant valve designs of the required size were not capable of meeting the long life, low leakage, and rapid response requirements of the ACPS thruster application.

In order to provide propellant valve design and materials selection criteria for the ACPS thruster propellant valves, two parallel contracts (21 and 22) were sponsored by NASA-LeRC in 1970. The se programs included analysis and conceptual design of propellant valve subcomponents, including fluid shutoff devices, actuators, linkages, and seals. The design requirements for the propellant shutoff valves, which applied to both contracts, are listed in Table $V$. Following the analytical phase, selections were made of the more promising sealing techniques, materials, and actuation methods, and screening tests were performed. Based on this data, preliminary designs were completed for complete valves and more extensive cycle life tests performed on valve test rixture assemblies. The lcakage specification set forth in Table $V$ was based upon values of total propellant loss tor the entire one-week Shuttle mission considered acceptable, considering that leakage would be occurring from 30-40 thruster fucl and oxidizer valves. The operating temperature rantse specificd assumes that valve temperatures may reach $850^{\circ} \mathrm{R}$ due to heat soakback from the thruster after a firing. This requirement necessitated considerution of all metallic valve seats or the use or thernal. jeolation to bllow sal't use of: nonmetallics. both metrlitic and nonmetrlicic scals were studied in the valve programs.

The types of fluid shutoff devices included in the studies were: ball valves, butterfly, poppet, blade, and diaphragm valving concepts. Conceptual designs were completed for each type to establish sizing and seat load requirements. Both impact and sliding seal closures, singly and in cambination, were included in the conceptual designs. The results of these analyses were compared and rated in terms of pressure. drop, leakage, response time, cycle life, contamination sensitivity, actuation forces, weight, envelope, degree of fabrication difficulty, assembly and inspection difficulties, and cleaning and handling requirements.

'I'he valve techrolowy contracts also included study of vurlous methods of actuating the valve, includine meumulile, lydraulic, and clectrical.

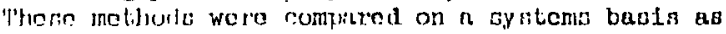

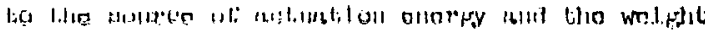

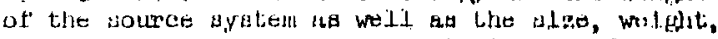
response, and operating characterlatics of the valve actuators themselves.

Based on these studies, both contractors selected poppet type valves and pneunatic actu- 
ation using the hydrogen or oxygen (propellant) gas as the actuating media. The poppet type sealing closure was selected because this type of closure requires the least amount of sliding between the sealing surfaces. This reduces the effects of wear and enhances the cyclic life of the seal closure.

The poppet-type seal is sensitive to misalinement, however. The amount of misalinement between the sealing surfaces at closure results in varying degrees of clamshelling and scrubbing actions, which produce sliding wear. The amount of wear for a given length of sliding varies greatly for different seal materials. 'The selection of the proper seal material is, therefore, equally as important as the actual seal design configuration.

Pneumatic actuation was selected for the valves because gaseous propellants would normally be available for use as an actuation medium and this approach offers, system simplicity and low weight while meeting the valve's fast response requirement. $(21,22)$

In order to select the internal sealing closure for the valve, screening tests of many seal closure configurations and seal materials were conducted for impact and sliding concepts.

Rocketdyne $(22)$ tested the following seal closures in a specially designed seal test fixture:

1. Flat $440 \mathrm{c}$ (stainless steel) seat on flat $440 \mathrm{C}$ poppet.

2. Grooved gold seats on flat $440 \mathrm{c}$ and tungsten carbide poppets.

3. Hard sharp tungsten carbide seat on flat tungsten carbide poppet.

4. Captive plastic seat on flat $440 \mathrm{c}$ poppet.

5. Elgiloy disc seat on $440 \mathrm{c}$ poppet.

The hard sharp tungsten carbide and the captive plastic seal configurations, shown in Figure 34, were selected for testing, in a valve test f'ixture. The captive plastic seal successfully achieved more than 100,000 cycles under all test conditions and the leakage remained well below specifications. The other seal closure/material configuration tested failed by leaking excessively.

The preferred propellant valve design concept generated by Rocketayne, shown in Figure 35 , is a hydrogen gas actuated poppet valve employing the captive plastic seal arrangement. The valve incorporates a solenoid actuated pilot valve. The pressure unbalanced poppet is designed so that the solenoid valve vents pressure behind the actuator piston to open the valve and pressurizes this cavity to close the valve using a return spring for assistance.

The objectives of the propellant valve technology effort conducted by Marquardt (21) were identical to the previously discussed Rocketdyne effort but the approach and design configurations differed.

In order to select the internal sealing closure for the valve, screening tests of many seal closure configurations and seal materials were again conducted for impect and sliding concepts. The following seal closures were tested:

1. Spherical and flat polyimide seats on tungsten. carbide poppets.

2. Spherical and flat teflon seats on tungsten carbide poppets.

3. Flat tungsten carbide seat and poppet.

4. Flat teflon coated and gold plated lip seal seats on tungsten carbide poppets.

Based on these test results, the flat polyimide (Vespel 21) seat on tungsten carbide poppet and the gold plated lip seal on tungsten carbide poppet were selected. The flat polyimide scat conflguretion successfully met the leakage specification in hot, cold and ambient temperature tests after 100,000 opening/closing cycles. The gold lip seal seat configuration only slightiy exceeded the original leakage specification, therefore, it is still considered a viable candidate for a final valve design. The other seal closure configurations tested exhibited excessive leakage and werc deemed unacceptable. Based on valve test fixture cycle testing with these seal concepts, a preferred flightweight valve concept was designed that is shown in Figure 36. This is a coaxial poppet valve with a single solenoid actuated pilot valve and.uses the flat polyimide seat and an Inconel 718 poppet. It is a vent-to-open, pressurize-to-close design.

The valve concept is bosed upon a previous design which was built as a valve test fixture and met the leakage, response, and cycle life requirements of previous technology efforts.

In summary, the NASA-LeRC sponsored propeliunt valve technology effort indicates the poppet type, propellant actuated valve to be the most promising concept to meet the Space Shuttle ACPS thruster shutoff valve requirements, which include: fost response, low lcakage, high cyclic life, minimum weight and envelope, simplicity, and reliability. The valve test f'ixture tests have produced data for two sealing design configurations (flat polyimille and captive plastic seal) which appear capable of meeting the stringent APS life and leakage requirements.

Thruster Assembly Experimental Evaluation

Within the thruster contract programs, specific components (i.e., injectors, thrust chambers igniter assemblies, and propellant valves) were selected from the many component designs evaluated for use in testing of complete ACPS thruster assemblies. Four of these specific thruster assemblies will be discussed in this scction. Except as noted below, these assemblies used spark/torch igniters and modified off-the-shelf valves that were readily available. The thrusters were subjected to extensive hot firing tests to establish the actual delivered performance, chamber cooling, and ignition behavior in both steady-state and pulse mode operation under simuiated altitude conditions using 40:1 area ratio nozzles. Propellant inlet temperatures ( $250^{\circ} \mathrm{R}$ to $\left.800^{\circ} \mathrm{R}\right)$, chamber pressure ( 100 psia to 500 psia), overall thruster mixture ratio ( 3.0 to 5.5 ), coolant flow rates, 
and pulsing duty cycles ( $10 \%$ to $90 \%$ were the primary operating parameters that were varied during these tests. A comparison chart of the four selected thruster assemblies showing typical operating and design characteristics is shown in Table VI.

The four thruster assemblies discussed below are: (1) Regenerative/Dump Cooled, (2) Film/Dump Cooled, and (4) Reverse Flow.

(1) Regenerative/Dump Cooled Thruster Assembly. - The regenerative/dump cooled thruster assembly, shown in Figure 37, consisted of a concentric tube injector assembly (fig. 8), a channel wall thrust chamber assembly (fig. 14), an electrical spark-plug/torch igniter assembly (fig. 25), and modified, facility-mounted, butterfly-type main propellant valves. It was first tested at nominal steady-state design point conditions: 300 psia chamber pressure, mixture ratio of 4.0 , with ambient temperature propellants. The fuel coolant flow rates and thruster mixture ratio were varied to determine the effects on delivered performance and chamber wall temperatures. Also, the chamber pressure, overall mixture ratio, and propellant inlet temperatures were varied with coolant flowrate held con:itunt at a silected lixed value. One 500-sccond duration test was conducted with the thruster assembly at nominal design point conditions with no evidence of chamber degradution.

The steady-stale perl'ormance obtained with this thruster is shown us a function of mixture ratio and propellant irlet lemperature in $\mathrm{Fig}-$ ure 38. Thruster performance decreased as mixture ratio was increased; performance ilso decreased as propellant inlet temperature decreased. Chamber pressure effects on performance were very small over the range of 100-500 psia. This factor leaves an option open to the vehicle designer of operating this thruster at a lower chamber pressure to gain increased chamber life (see fig. 24). The performance effects of mixture ratio and propellant temperature variations show the importance of a well controlled propellant feed system.

A vacuum specific impulse of $447 \quad \mathrm{lb}_{\mathrm{f}} \mathrm{sec} / 1 \mathrm{~b}_{\mathrm{m}}$ was consistently demonstrated at the nominal design point (ambient temperature propellants) operaiting conditions with approximately $17 \%$ of fuel film cooling for the nozzle. Tests were also! conducted with this same thruster (not reoptimized for cold propellants) to obtain the effects on delivered performance by the use of low temperature propeliants $\left(320^{\circ} \mathrm{K} \mathrm{O}_{2}\right.$ and $\left.283^{\circ} \mathrm{R} \mathrm{H}_{2}\right)$. A vacuum specific impulsc value of approximately $4251 b_{-s e c} / 2 b_{m}$ was obtained at the nominal operation condition of $P_{c}=300$ and M.R. of 4.25 .

Severel series of pulsing, tests were conducted with the refenerative/ilump cooled thruster assembly to determine ils delivered pulse mode performance, ignition transients, thrust transients and thermal characteristics. This design was selected for pulse testing because very little experimental data existed on the effects of coolant jacket volume, on pulse mode performance, and start-up and shutdown transients (resnonse). The pulse mode tests covered various duty cycles, ranging from $30 \mathrm{milliseconds} \mathrm{(ms)} \mathrm{"on"} / 1 \mathrm{sec}$ "off" to $1 \mathrm{sec}$ "on"/30 sec "off". Fuel and oxidizer leads and lags were also varied to determine the effects of propellant sequencing on thruster response and pulsing performance. These tests covered a range of oxidizer leads to simultaneous propellant entry to a tiel lead, and it was concluded from these tests that a fuel or oxidizer lead of $4 \mathrm{~ms}$ or less was the most desirable mode of operation for this thruster design.

A definite performance $\left(I_{s p}\right)$ trend with impulse bit was established during the duty cycle test series. The delivered specific impulse was reduced as the thruster on time was decreased as shown in Figure 39. At the minimum impulse bit (MIB) of less than $50 \mathrm{lb}-\mathrm{sec}$, the $I_{\mathrm{sp}}$ was $\cong$ $4121 b-\mathrm{sec} / 1 b_{m}$.

A thruster durability test series of 2547. pulses at a duty cycle of $20 \%$ (100 ms "on" and "400 ms "off") was also conducted with no noticeable physical degradation of the thruster and with excellent pulse repeatability. Considerably more pulse testing would be required to verify the 500,000 cycle life of the chamber; the 2500 pulse test was made primarily to evaluate pulse repeatability.

(2) $\mathrm{Film} /$ Regenerative Cooled Thruster Assembly. - The film/regenerative cooled thruster as sembly shown in Figure 40 consisted of an "I" triplet premix injector assembly ( $\mathrm{flg} .9$ ), a filmcooled thrust charaber assembly (fig. 18), and a spark-plue/torch igniter (fig. 27). Pneumatically: actuated propellant valves that were poppet type and facility mounted, were used for propellant flow conlrol durine all thruster tests. Variations in propellant inlet temperatures, chamber pressure, and overall thruster mixture ratio were made during these tests. All test data were acquired under simulated altitude conditions using a 40:1 nozzle.

Several series of steady-state hot firing tests were conducted to establish the amount of film coolant required to satisfy the desired equilibrium wall temperatures of the chamber. Fuel film coolant flow was varied from $13.9 \%$ to $30 \%$ of the total fuel flow. It was determined that $20 \%$ fuel film cooling was required to meet the limiting wall temperature at the throat of $500^{\circ} \mathrm{F}$ during the startup transient at $0.05-0.10$ seconds after start-up. This Iimit was dictated by chamber thermal fatjoue life requirements. At nominal conditions of chamber pressure, $O / F$, and propellant temperature, with $20 \%$ film cooling, the steady-state throat wall temperature was maintained at $8000 \mathrm{~F}$ and the maximum skirt temperature at $14000 \mathrm{~F}$, which were well below the limiting volues for 50 hour creep life of $12500 \mathrm{~F}$ and $1800^{\circ} \mathrm{F}$, respectively.

The effects of chamber pressure, mixture ratto, and percent film cooling on delivered vacuum apecitise impulse are shown in Figure 41 for the film/regenerative thruster. All of the performance curves have a similar trend of decreasing performance whth increasine thruster mixture rat1o indicating the gains in thruster apecific impulac available by operation at $O / F^{\prime} s$ of $3-4$. Comparison of the two upper curves indicates that the performance gain obtained by increasing $P_{c}$ from 300 to 500 psia is small (about $31 b_{f}-\mathrm{sec} / 1 b_{m}$ ). Comparison of the two curves for 300 psia chamber shows that performance is degraded fram 
$4441 b_{f}-\sec / 1 b_{m}$ with $20 \%$ film cooling to $434 \mathrm{lb}-\mathrm{sec} / \mathrm{lbm}$ with $30 \%$ film cooling. The curve for performance obtained with cold propellants shows $435 \mathrm{lb}_{\mathrm{f}}-\mathrm{sec} / 1 \mathrm{~b}_{\mathrm{m}} \mathrm{I}_{\mathrm{sp}}$ at an $\mathrm{O} / \mathrm{F}$ of 4 due to use of cald propellants. The performance value obtained at the nominal design conditions of $P_{C}=300$ psia, 20\% film cooling, $O / F$ of 4 and cold propellants meets the contract goal with the thruster reoptimized for low temperature propellants.

The same film/regenerative cooled thruster assembly as discussed above was also evaluated in a series of pulse mode tests. These tests had the objectives of evaluating the transient behavior of the film/regenerative cooled thruster on start-up and shutiown, as well as the thermal soak-back, minimum impulse bit (MIB) capability and specific impulse variation with impulse bit. A durability demonstration of this chumber, under pulse mode operatine conditions, was also demonstrated by accumulating 2813 total pulses on the thruster harcware with valyine pulse widths. Other operating variables such as cliamber pressure, mixture ratio, valve sequencing and film coolant flow rate remained fixed. After the 2813 pulse test series was completed using ambient temperature propellants, approximately 100 pulses of varying pulse widths were conducted using low propellant inlet temperatures, $170^{\circ} \mathrm{R}$ hydrogen and $280^{\circ} \mathrm{R}$ oxygen.

The bit specific impulse obtained with the film/regenerative chamber is show as a function of bit impulse in Figure 42. The minimum impulse bit (MIB) obtained was about 50 Ib-sec which occurred at an electrical signal "on" time of about 50 milliseconds. The limit on $M \square B$ was caused by the slow response of the valves (approximately 35-45 milliseconds f'rom signal to full open or closed) and is not truly a characteristic of the thruster design. The actual ignition delay time of the thruster was less than 2 milliseconds. 'The delivered specific impulse decreased as impulae bit was reduced. At an impulse bit of $1001 \mathrm{~b}-\mathrm{scc}$, the specific impulse was about $3901 b^{-}-\sec / 1 b_{m}$.

(3) Filn/Drmp Cooled Thruster Assembly. - The film/dump cooled thruster assembly shown in Figure 43 consisted of a raised-post triplet injector (fic. 10), a film/dump cooled thrust chamber (fig. 19), two interchangeable igniter assemblies (electrical spark plug or catalytic reactor) (fig. 29), and two Marquardt propellant valve assemblies (similar to fig. 36). Evaluation of this thruster assembly consisted of both steady-state and pulse mode tests to thoroughly evaluate the concept over a range of typical operating conditions.

Approximately 40 steady-state firings of the $\mathrm{film} /$ dump cooled thruster assembly were conducted to establish delivered performance and chamber cooling characteristics. After the first few. firings to establish the optimum main propellant valve sequencing, the electrical spark plue igniter assembly was replaced by the catalytic itniter assembly, which was used in all subsequent thrustex testing. During the steady-state thruster test series, overall thruster mixture ratio was

i varied from 3.6 to 4.8 , film coolant flowrate was varied from $25 \%$ to $37 \%$ of the fuel, and propellant inlet temperatures were varied from ambient down to $250^{\circ} \mathrm{R} \mathrm{H} 2$ and $350^{\circ} \mathrm{R} \mathrm{O}$. Figure 44 shows the performance obtained for various mixture ratios at 300 psia chamber pressure, ambient propellants and $32 \%$ film cooling. The delivered specific impulse at naninal $0 / F$ of 4.0 was 432 seconds: These tests showed dramatically the performance penalty incurred with this chamber design because of the high percentage film coolant needed to keep wall temperatures within the limits specified by chamber life requirements. Also shown on this flgure is the delivered impulse for this thruster with propellant inlet temperatures of $250^{\circ} \mathrm{R}$ for the $\mathrm{H}_{2}$ and $3000 \mathrm{R}$ for the $\mathrm{O}_{2}$, using $25 \%$ f1lm cooling. Results of these tests indicated that the use of lower temperature propellants actually raised the delivered impulse level of this thruster design by allowing use of lower hydrogen film coolant flow rate. 'The measured throat wall temperature was $12000 \mathrm{~F}$ with a film coolant flow of $25 \%$ which met the life requirements. The delivered impulse of the chamber meets the perfiormance gool of

$4351 b_{f}-\mathrm{sec} / 1 b_{m}$ at an $0 / F$ of 4.0 with cold propellants. This thruster hardware was not reoptimized for low temperature operation.

Long duration tests (up to 290 seconds) were completed with $32 \%$ film cooling at nominal chamber pressure and mixture ratio wherein the chamber wall temperatures were successfully maintained at $1200^{\circ} \mathrm{F}$ at the throat and a maximum of $1550^{\circ} \mathrm{F}$ in the nozzle at an expansion ratio of 10 .

Pulse mode testing on the film/dump cooled thruster assembly consisted of duty cycle variations only. Propellant temperatures were amblent and all other thruster operating parameters $\left(\mathrm{P}_{\mathrm{C}}\right.$, $O / F$, and film coolant (low) were held at nominal values. The range of thruster "on" and "of $f$ " times (duty cycle percentages) covered "on" times of 50 , 75 and $100 \mathrm{~ms}$ and "of "times of 100 and $200 \mathrm{~ms}$. "These values of "on" and "orf" times were selected in various combinations to evaluate thruster duty cycles of $25 \%, 50 \%$ and $75 \%$. The MIB achievable with this design was found to be 33 lb-sec. All pulse traces (thrust v:: time curves) were repeatable. 'Ihe response of the catalytic igniter was about $25 \mathrm{~ms}$ during each startup.

A series of igniter-only thruster tests were conducted to establish the MIB capability of the thruster assembly when only the igniter is flring and to determine whether supplemental coolant flow is necessary for the thrust chamber, duct, and nozzle when only the igniter is operating: In these igniter-only tests, no propellant was flowing in either the main injector assembly or the "duct" coolant passages during the time the igniter was firing.

This type of thruster operation could possibly be used for spacecraft reaction control maneuvers that require very low thrust or $M I B$ levels (e.g., 10 lb thrust or 1.0 lb-sec impulse bits).

The catalytic igniter assembly used in the previous pulse mode tests was used for the igniter-only test series with a copper thrust chamber assembly. Tests were made both with and without the use of film coolant in the coolant passages and with both ambient and low temperature propellants.

The results of the "igniter-only" tests clearly indicate that extermely low thrust and 
MIB values" (as low as $10 \mathrm{lbs}$ and $2 \mathrm{lb}$-sec, respectively) can be obtained with a $1500 \mathrm{Ib}$ thruster assembly using cold propellants and no supplemental film cooling is required in the main thruster coolant passages.

(4) Reverse Flow Thruster Assembly. - The reverse flow thruster assembly, shown in Figure 45, was tested in both pulsing and steadystate altitude tests to verify several design features unique to this particular concept and to determine its steady-state and pulse mode performance. This thruster configuration consisted of the reverse flow cambustor/nozzle assembly (fig. 20), and electric spark plug (surface mounted) ignition system (fig. 31), and two balltype main propellant valves that were thruster mounted.

Steady-state tests were made on the reverse flow thruster to determine the effect on performance and chamber wall temperatures of variations in mixture ratia, chamber pressure, propellant inlet lemperatures, and nozzle film coalant llow rates. Figure 46 presents the data obtained at 300 psia chamber pressure with ambient temperature propeliants. The performance trend of decreasine $I_{5}$ with increasing $O / F$ is similar to the other thrusters tested. The reverse flow thruster delivered approximately $4401 \mathrm{~b}_{\mathrm{r}}-\mathrm{sec} / 1 \mathrm{~b}_{\mathrm{m}}$ impulse with up to $6 \%$ nonzle f'ilm cooling, which exceeds the contract goal performance level. When $9 \%$ nozzle film cooling wa: empioyed, however, the $I_{s}$ dropped sigrnilicantly, as shown in liti. 46. A nominal design condition of $7.5 \%$ film cooling was selected based on the wall temperature roquired for chamber design life time. Chamber pressure variations from 100 to 500 psia affected the delivered $I_{s}$ by less than $1 \%$. lowever, the use of low propellant temperatures $\left(250^{\circ} \mathrm{R} \mathrm{H}_{2}\right.$ $350^{\circ} \mathrm{R} \mathrm{O}_{2}$ ) reduced performance by approximately $30 \%$, indicating that the reverse flow chamber designed for ambient propellants needed to be optimized for operation with cold propellants.

The durability of the reverse 1'low thruster was demonstrated by one 500-second duration firing at nominal design point conditions. No eviderice of thrust chamber or nozzle skirt overheating or other degradation was detected.

Several series of pulse mode firings were conducted with the reverse flow thruster assembly. Pulse width variation sequences were conducted in which thruster "on" times were varied from $30 \mathrm{~ms}$ to $I$ second and "of' $f^{\prime \prime}$ times from 100 ms to 30 sec- : onds. As shown in Figure 47, this thruster design exhibited typical specific impulse vs. electrical "on" time (pulsc width) characteristies, i.c.,

Ionger "on" times produced hicher specif'ic impulse. The MIB achieved with this thruster design was (it) Ib-sec at $30 \mathrm{~ms}$ "on" time, which was limited by "Jow valve response. A "pulce train" of 2500 pulacs completed the pulise mode test activity for this thruster design. Data f'rom these teats revealed the pulses to be very repeatable in terms of shape and total impulse bit.

\section{Integrated Thruster Assembly}

The integrated thruster assembly (ITA), show in Figure 48 , is a new design under investigation by Aerojet(23) in a contract placed in 1972. The ITA represents the culmination of all of the com- ponent technology for gas/gas pydrogen-oxygen thrusters into an integrated, flightweight design. This thruster will be labricated and extensively tested during the next year to verify its ability to rully meet the design requirements set forth in Table I. In the ITA concept, greater emphasis will be placed upon meeting vehicle interface and Shuttle operational requirements than heretofore. For example, the thruster will not use copper material downstream of the throat in order to assure its ability to meet the stringent reentry heating and life requirements. Also, lightweight materlei and design features, such as a welded-on injector, will be employed to assure a iruly flightweight design. The test program will emphasize evaluation of chamber life and operational problems such as heat soakback from the thruster to the igniter and valves. A series of 50,000 pulse firings are planned plus a minimum of 5,000 full thermal cycles, which will exercise the thruster to 10-20\% of its design life.

Completion of the ITA program will provide a strong technology vacluground for gas/gas hydrogenoxyeen thrusters so that their application to the Space Shuttle or other velicles can proceed with a minimum of development risk.

\section{Concluding Remarks}

The NASA-Lewis sponsored technoloby program on hydrosen-oxyeen thrusters for Space Shuttle ACPS has included extensive work on injectors, thrust chambers, ignition systems, valves, and thruster assemblies. A surmary of the technolocy status in each area is given below. Also provided are comments pertainine to the epplication of hydrogenoxygen auxiliary propulsion systems.

1. Injectors - of the injector types tested, the extent to which each concept was tesled, and the cooling concept cach was tested with, the concentric tube and promix types best demonstrated the attributes of performance, durability, and acceptable heat transfer to the thrust chamber wall. llowever, acceptable combution efliciency and stable combustion were obtalned with all of the gas/Eas injectors tosted.

2. Thrust Chambers - A variety of thrust chamber designs were evaluated which used comblnations of regenerative, $11 \mathrm{~m}$, and dump cooling. All of these destgns were found to be capable of meetine the performance requirements at operating conditions consistent with the predicted life requirements. The film cooled desiens provide a lighter weight, potentially lower cost chamber but are also somewhat lower in delivered specific impulse than a regenerative design.

3. Ignition Systems - The spark/torch igniter with air gap plug, high mixture ratio core, and capacitance discharge exciter was most successful in providing rapid, reliable ignition at all test conditions. The plasma/torch and resonance tube igniters are also promising ignition methods, but require further testing and optimization before application. The catalytic igniter with downstream oxyen infection meets the overoll thruster response requirements but is limited in its ability to ignite low temperature propellants (below $250^{\circ} \mathrm{R}$ ). 
4. Valves - For the requirements of the gas/ gas thruster, the poppet type, propellant gas actuated valve concepts were perferred. Both the captive plastic seal and flat polyimide seat on tungsten carbide poppet appear capable of meeting the cycle life, leakage, and response specifications. These concepts are capable of providing lightweight, compact, and reliable valves suitable for flight application.

5. Thruster Assemblies - The thruster assemblies tested provided delivered specific inpulse ranging from 432 to $447 \mathrm{lb}$ - $\mathrm{sec} / 1 \mathrm{~b}_{\mathrm{m}}$ at 300 psia chamber pressure and an $O / F$ of 4 with ambient temperature propellants. However, if vehicle volume and weight allocations could permit the use of slightly larger hydrogen tanks, operation of any of the thruster assemblies at mixture ratios $(O / F)$ at values lower than 4.0 would increase the delivered specific impulse values simif'icantly (see figs. $38,41,44$ and 46). T'he regenerative chamber delivered highest performance and the film cooled chambers the lowest for the rame design Iife. The best pulsing performance of 41 ? $1 \mathrm{~b}_{\mathrm{r}}$-scc/ $1 b_{m}$ at; 50 Ib-sec impulse bit was also obtained with a regenerative chamber. (10)

6. System Consideriztions - There are presently no critical cas/gas lin-on thruster techulogy problem arcas outstandiry; that would prevent the use of this syslem. 'Niter asicssment of the above rosults, it was concluded that lurther work was required to optimize thruster periormance with cold ( $250^{\circ} \mathrm{R} \mathrm{H}_{2}-375^{\circ} \mathrm{K} O \mathrm{O}$ ) propellants and demonstrate the long life required of the thrusters has yet to be experimentally proven. (23) Some of the components of the gas/gas feed system, such as the turbopumps and gas generator/heat exchangers are being investigated in technology contracts sponsored by MSC and MSFC, as previously mentioned, and this work has not yet been completed. The liquid/liquid $\mathrm{H}_{2}-\mathrm{O}_{2}$ system has the potential of providing a simpler, lighter weight system and deserves further consideration. Liquid/liquid thruster technolocy problems, such as ienition and pulse mode. oneration, are presently under investifration. (6) Additional technolory work is necucd on the system componentis, such as liquid accumulators, vacuum jacketed lines, and pumps.

1. "Space Shuttle Auxiliary Propulsion System Dcsign Study," McDonnell Douglas Corporation, Contract NAS9-12012, Interim Systems Definition Review, October, 1971.

2. "LH⿰ 2 and $\mathrm{LO}_{2}$ Turbopump Assemblies Program," Design Review, ASR 71-344, Rocketdyne Div. of NAR, Contract NAS8-27794, November, 1971.

3. "Shuttle APS Propellant Thermal Conditioner Study,". Monthly Proeress Report No. 11, Rocketdyne Div. of NMR, Contract NAS9-12046, May, 1972.

1. Nkkcrmas, jamen $W .:$ Shuttle Raretion cortrol Siyotem Cryogendic I Iqufel Diatribution iyotem study. Auxillury lropulsion and Pyrotechnies Branch Internal Note, Propulsion and Power Division, Manned Spacecraft Center, September, 1971.
5. "Space Shuttle Auxiliary Propulsion System Design Study," McDonnell Douglas Corporation, Contract NAS9-12013, Systems Def'in1tion Review, February, 1972.

6. Schoeman, L.:- Extended Temperature Range Thruster Investigation. Monthly Report No. 1, NASA Contract NAS3-16775, Aerojet Liquid Rocket Co., Sacramento, Calif., JuIy, 1972 .

7. Herm, T. S., and Houte, F. W., "Space Shuttle High Pressure Auxiliary Propulsion Subsystem Definition Study. Design Handbook," MDC-E0300, NASA CR-103110, Feb. 1971, MeDonnell-Douglas Astronautics Co., St. Louis, Mo.

8. Benson, R. A.; Shaf'fer, A., and Burge, H. L., "Space Shuttle High Pressure Auxiliary Propulsion Subsystem Defirition," NASA Cli-11516i, Mar. 1971, TRW System Group, Reiondo Beach, Colir.

9. "Space Shuttle Vehicle Description and Requircments Document, Space Shuttle Nuxlliary Iropulsion System Design Study," Iuly 1, 1971, NASA-MSC, Propulsion und Power Division.

10. Paster, R. D.: Hydrogen-Oxygen APS Eng,ines. NASA-CR-120805, 1972, Volure 1, NASA Contract NAS3-14352, Rocketdyne Div. of NAR, Canoga, Fark, Calif.

17. Schoenman, L.: Hydrogen-Oxygen Auxiliary Propulsion Investigation. NASA-CR-120895, volume 1, NASA Contract NAS3-14354, Acrojet Liquid Rocket Company, Sacramento, Calif.

12. Johnson, R. J., Heckert, B. and Burge, II. L.: Itydrogen-oxygen Catalytic Ignition und Thruster Investiration. NASA-CR-120870, 1972, Volume II, NSA Contract NAS3-14347, TRW Systems, Redondo Beach, Calif.

13. Senneff, J. M.: High Prosisure Reverse l'low APS Eneine. NASA-CR-120881, 1972, NASA Contract NAS3-14353, Beli Aerospace Compary, Buf'falo, N.Y.

14. Lauffer, J. R.: Spece Shuttle Auxiliury Propulsion IEnition System. NASA-CR-72972. NASA Contract NAS3-14351.

15. Rosenberg, S. D., Aitken, A. J., Jassowski, D. M. and Royer, K. F.: Ignition Systems for Space Shuttle Auxiliary Propulsion System. NASA-CR-72890, 1972. NASA Contract NAS3 -14348 .

16. Johnson, R. J., "Investigation of Thrusters for Cryogenlc Reaction Control Systems. Vol. I," TRW-09849-6001-RO-00-Vol. 1, NASA CR-72781, Nov. 1970, TRW Systems Group, Redondo Beach, Calif.

17. Johnson, R. J., "Investigation of Thrusters for Cryogenic Reaction Control Systems. Vol. II: Appendices," TRW-09849-6002-RO-00Vol. 2, NASA CR-72785, Nov. 1970, TKW Systems Group, Kedondo Beach, Calif. 
18. Johnson, R. J., Heckert, B. and Burge, H. Hydrogen-Oxygen Catalytic Ignition and Thruster Investigation. NASA-CR-120869, 1972, Volume I, Contract NAS3-14347, TRW Systems, Redondo Beach, Calif.

19. Kesten, A. S., Study of Catalytic Reactors for Hydrogen-Oxyeen Ignition," UARL-H91072l, NASA CR-72567, July 1969, United Aircraft Corp., East Hartford, Conn.

20. Kesten, A. S., and Sangiovanni, J. J., "Iransient Model of Hydrogen/Oxygen Reactor," UARL-K910962-12, NASA-CR-120799, Feb. 1971, United Aircraft Corp., East Hartford, Conn.
21. Wichmann, H.: Space Shuttle Auxiliary Propellant Valves. Monthly/Quarterly Progress Reports. Contract NAS3-14349, 1971/1972.

22. Smith, G. M.: Space Shuttle Auxiliary Propellant Valves. Monthly/Quarterly Progress Reports. Contract NAS3-14350, 1971/1972.

23. Blubaugh, W.: Integrated Thruster Assembly Investigation. Monthly Report No. 1, NASA Contract NAS3-15850, Aerojet Liquid Rocket Company, Sacramento, Calif. July, 1972.

TABLE I. - THRUSTER OPERATING CONDITIONS AND DESIGN REQUIREMENTS

\begin{tabular}{|c|c|c|}
\hline . & Nominal & Testing Range \\
\hline $\begin{array}{l}\text { Thrust } \\
\text { Chamber pressure } \\
\text { Mixture rstio (O/H) } \\
\text { Nozzle expansion ratio } \\
\text { Propellant inlet temperatures } \\
\text { Propellant inlet } \\
\text { presiure (Lo . } \\
\text { valve) } \\
\text { Total life capability } \\
\text { 'lotal number ot' "'irings } \\
\text { Minimum impulse bit (MIB) } \\
\text { Response (from siernal to 90\% thrust) } \\
\text { Specific impulse: } \\
\text { Steady-state } \\
\text { Pulsing (at NIB) } \\
\text { Reentry heating: } \\
\text { At nozzle } \\
\text { At chamber throat } \\
\text { Weight (of thruster assembly) } \\
\text { including valves }\end{array}$ & $\begin{array}{l}1500 \mathrm{lb} \\
300 \mathrm{psia} \\
4.0 \\
40: 1 \\
250^{\circ} \mathrm{R} \text {-hydrocen } \\
375^{\circ} \mathrm{R} \text {-oxyben } \\
400 \mathrm{psia} \text { - both } \\
\text { propellants } \\
50 \mathrm{hr} \\
500,000 \text { pulses, plus } \\
25,000 \text { full thermal cycles } \\
50 \text { 1b-sec } \\
50 \mathrm{milliseconds} \\
435 \text { sec } \\
400 \mathrm{sec} \\
30 \mathrm{minutes} \text { exposure/mission to } \\
\text { the following temperatures } \\
1800^{\circ} \mathrm{F} \\
1200^{\circ} \mathrm{F} \\
25 \text { lb }\end{array}$ & $\begin{array}{l}100-500 \text { psia } \\
3.0-5.0 \\
200-600^{\circ} \mathrm{R} \\
\text { Sat. }-600^{\circ} \mathrm{R}\end{array}$ \\
\hline
\end{tabular}

I'ABLE II. - IGNITION SYS'LEM UESICN REQUIIYEMENTS

Propellant inlet temperatures
Hydrogen
Oxygen
Propellant inlet pressures
Igniter body temperature
Igniter response
Environmentel pressure
Enercy input
Radio frequency interference (RFI)
Life
Operating life
Overall life
Cycle life.
Input voltage

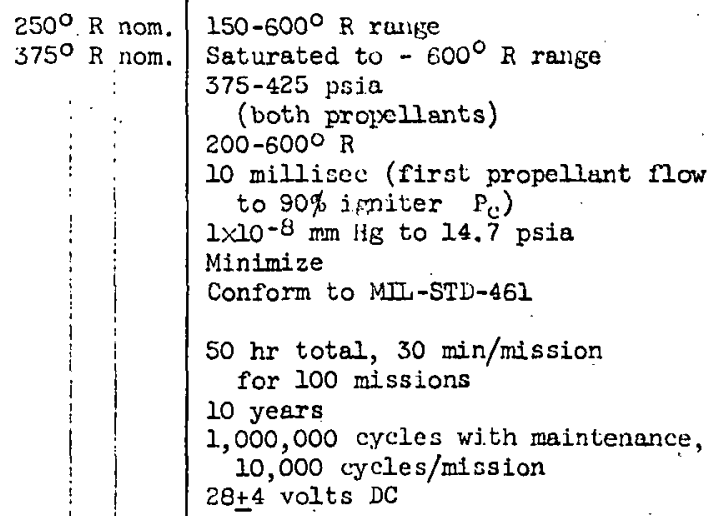


TABLE III. - SPARK/TORCH IGNITER/EXCITER NOMINAL CONDITIONS(14)

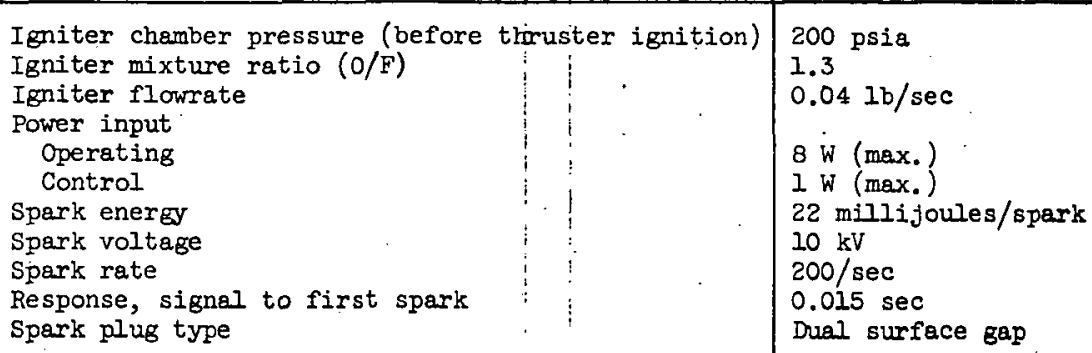

TABLE IV. - COMPARISON OF IGNITION SYSTEM (CONCEPT) PERFORMANCE

\begin{tabular}{|c|c|c|c|c|c|}
\hline \multirow{2}{*}{$\begin{array}{l}\text { Igniter } \\
\text { type }\end{array}$} & \multicolumn{5}{|c|}{ Character Istics } \\
\hline & $\begin{array}{l}\text { Spark } \\
\text { rate }\end{array}$ & $\begin{array}{l}\text { Igniter } \\
\text { response } \\
\text { (overall) }\end{array}$ & $\begin{array}{l}\text { Power } \\
\text { requirement }\end{array}$ & $\begin{array}{l}\text { R.F.I. } \\
\text { level }\end{array}$ & $\begin{array}{l}\text { Stage of } \\
\text { development }\end{array}$ \\
\hline $\begin{array}{l}\text { Spark plug }(15) \\
\text { torch }\end{array}$ & $\begin{array}{l}500 \mathrm{SPS}^{*} \\
\text { at } 20 \mathrm{kV}\end{array}$ & $\cong 10 \mathrm{~ms}$ & $\begin{array}{l}28 \text { V.D.C. } \\
\text { at } 3 \text { amps }\end{array}$ & $\begin{array}{l}\text { Meets } \\
\text { mil-STD- } \\
461 \mathrm{~A}\end{array}$ & Operational \\
\hline $\begin{array}{l}\text { Pulsed plasma (15) } \\
\text { torch }\end{array}$ & $\begin{array}{l}250 \mathrm{SPS} \\
\text { at } 5 \mathrm{kV}\end{array}$ & $\cong 10 \mathrm{~ms}$ & $\begin{array}{l}28 \text { V.D.C. } \\
\text { at } 3 \text { amps }\end{array}$ & $\begin{array}{l}\text { Meets } \\
\text { mil-STD- } \\
461 \mathrm{~A}\end{array}$ & $\begin{array}{l}\text { Advanced } \\
\text { R\&D }\end{array}$ \\
\hline $\begin{array}{l}\text { Catalytic (18) } \\
\text { torch }\end{array}$ & 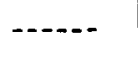 & $\cong 25 \mathrm{~ms}$ & $\ldots$ & -......... & $\begin{array}{l}\text { Advanced } \\
\text { R\&D }\end{array}$ \\
\hline $\begin{array}{l}\text { Direct S.P. (13) } \\
\text { type }\end{array}$ & $\begin{array}{l}250 \mathrm{SPS} \\
\text { at } \\
15-20 \mathrm{kV}\end{array}$ & $\cong 10 \mathrm{~ms}$ & 28 V.D.C. & $\begin{array}{l}\text { Not } \\
\text { tested }\end{array}$ & Operational \\
\hline $\begin{array}{l}\text { Resonance (14) } \\
\text { torch type }\end{array}$ & $-\ldots$ & $\cong 25 \mathrm{~ms}$ & - - & . & $R \& D$ \\
\hline
\end{tabular}

*SPS - sparks per secona.

Operating conditions: Ambient temperature propellants 350 psia chamber pressure. 
TABLE V. - PROPELIANT SHUTOFF VALVE DESIGN REQUIREMENTS

\begin{tabular}{|c|c|}
\hline $\begin{array}{l}\text { Valve type } \\
\text { Propellants } \\
\text { Operating temperature range } \\
\text { Propellant temperature range } \\
\text { Hydrogen } \\
\text { Oxygen } \\
\text { Propellant pressures at valve inlet } \\
\text { Pressure drop (maximums) } \\
\text { Fuel } \\
\text { Oxidizer } \\
\text { Actuation types } \\
\qquad \\
\text { Opening and closing } \\
\text { Response }\end{array}$ & 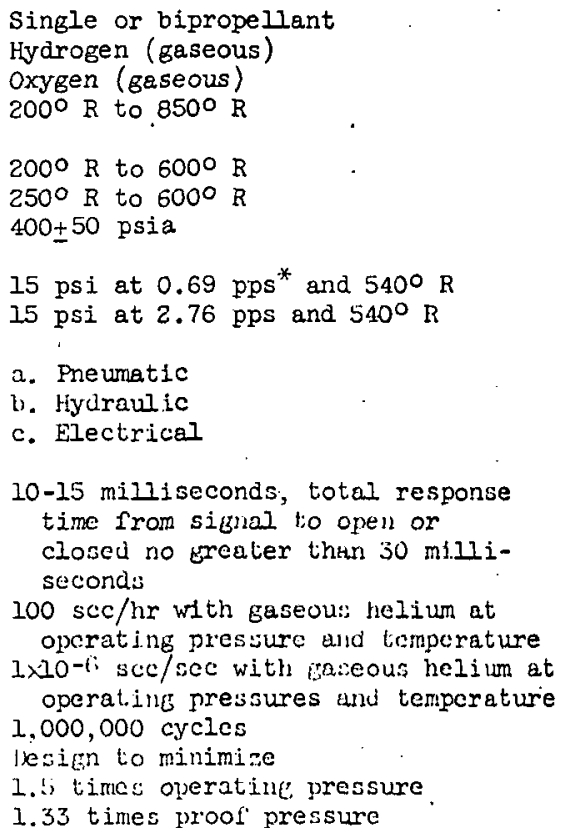 \\
\hline
\end{tabular}

*.pps - mass flow in pounds per second.

TABLE VI. - THRUSTER ASSEMBLY DESICN AND FERFORMANCE COMPARISON

\begin{tabular}{|c|c|c|c|c|c|c|}
\hline \multirow{2}{*}{$\begin{array}{l}\text { Thruster } \\
\text { types } \\
\\
\quad\end{array}$} & \multirow[b]{2}{*}{$\begin{array}{c}\text { Steady- } \\
\text { state } \\
\text { delivered } \\
\text { performance }\end{array}$} & \multicolumn{5}{|c|}{ Operatine characteristics } \\
\hline & & $\begin{array}{l}\text { Response } \\
\text { in } \\
\text { milliseconds } \\
\text { (0-90\% } \\
\text { thrust) }\end{array}$ & $\begin{array}{l}\text { M.I.B. } \\
\text { IL-sec }\end{array}$ & $\begin{array}{l}\text { Perf'ormance } \\
\text { at M.I.B. } \\
\left(I_{s p}\right)\end{array}$ & $\begin{array}{l}\text { Design } \\
\text { life } \\
\text { (a) critical } \\
\text { location } \\
\text { (b) life } \\
\text { (pulses) }\end{array}$ & $\begin{array}{l}\text { Demonstrated } \\
\text { (a) total mulses } \\
\text { (b) total time }\end{array}$ \\
\hline $\begin{array}{l}\text { Regenerative/ } \\
\text { dump }(10) \\
\text { (with coaxial } \\
\text { injector) }\end{array}$ & $\begin{array}{c}447 \\
1 b-5 c c / 1 b\end{array}$ & $40 \mathrm{~ms}$ & $48 \perp b-\sec$ & $\begin{array}{c}\approx 41 \mathrm{~d} \\
1 \mathrm{~b}-\sec / 1 \mathrm{~b}\end{array}$ & $\begin{array}{l}\text { (u) Tiroat-wall } \\
\text { transition } \\
\text { (b) } 0.0 \times 10^{6} \\
\text { pulses }\end{array}$ & $\begin{array}{l}\text { (4) } 2762 \text { pulses } \\
\text { (b) } 325 \mathrm{sec}\end{array}$ \\
\hline $\begin{array}{l}\text { Film/ } \\
\text { regenerative } \\
(1 i) \\
\text { (with premix } \\
\text { triplet in- } \\
\text { jector) }\end{array}$ & $\begin{array}{c}444 \\
1 b-50 c / 1 b\end{array}$ & $\begin{array}{l}\cong 50 \mathrm{mi} \\
.\end{array}$ & $5010-\sec$ & $\begin{array}{c}\simeq 350 \\
1 b-\sec / 1 b\end{array}$ & $\begin{array}{l}\text { (a) Throut } \\
\text { (u) } 10^{6} \text { pulsès }\end{array}$ & $\begin{array}{l}\text { (a) approx. } \\
281.3 \text { pulses } \\
\text { (b) approx. } \\
\text { ¿so sec }\end{array}$ \\
\hline $\begin{array}{l}\text { Film/(12) } \\
\text { dump (12) } \\
\text { (with triplet } \\
\text { injector) }\end{array}$ & $\begin{array}{c}432 \\
1 b-\sec / 1 b\end{array}$ & $\cong 45 \mathrm{~ms}$ & $\begin{array}{c}331 b-\sec \\
\vdots\end{array}$ & $\begin{array}{c}\cong 390 \\
1 \mathrm{~b}-\mathrm{sec} / 1 \mathrm{~b}\end{array}$ & $\begin{array}{l}\text { (a) Nozzle Div. } \\
\text { Section } \\
\text { (b) } 10^{6} \text { pulses }\end{array}$ & $\begin{array}{l}\text { (a) } 275 \text { pulses } \\
\text { (b) approx. } \\
300 \text { sec }\end{array}$ \\
\hline $\begin{array}{l}\text { Reverse } \\
\text { low } 13 \text { ) } \\
\text { (with vortex- } \\
\text { cup injector) }\end{array}$ & $\begin{array}{c}410 \\
1 b-5 e c / 1 b\end{array}$ & $\approx 30 \mathrm{~ms}$ & $\simeq 65 \mathrm{lb}-\mathrm{sec}$ & $N / A$ & $\begin{array}{l}\text { (a) Nozzle } \\
\text { liner } \\
\text { (b) } 900,000 \\
\text { pulses }\end{array}$ & $\begin{array}{l}\text { (a) } 3625 \text { pulses } \\
\text { (b) N/A }\end{array}$ \\
\hline \multicolumn{7}{|c|}{ 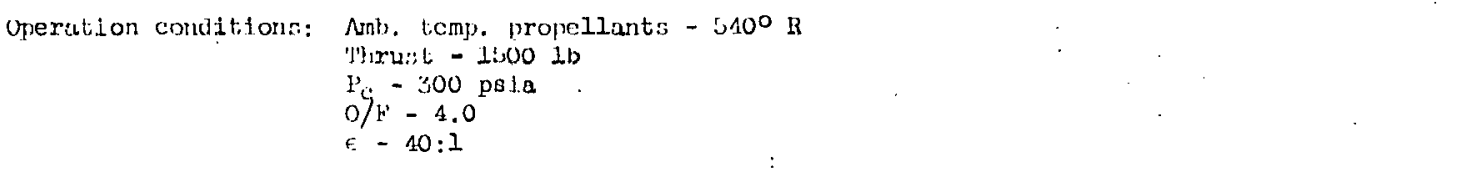 } \\
\hline
\end{tabular}




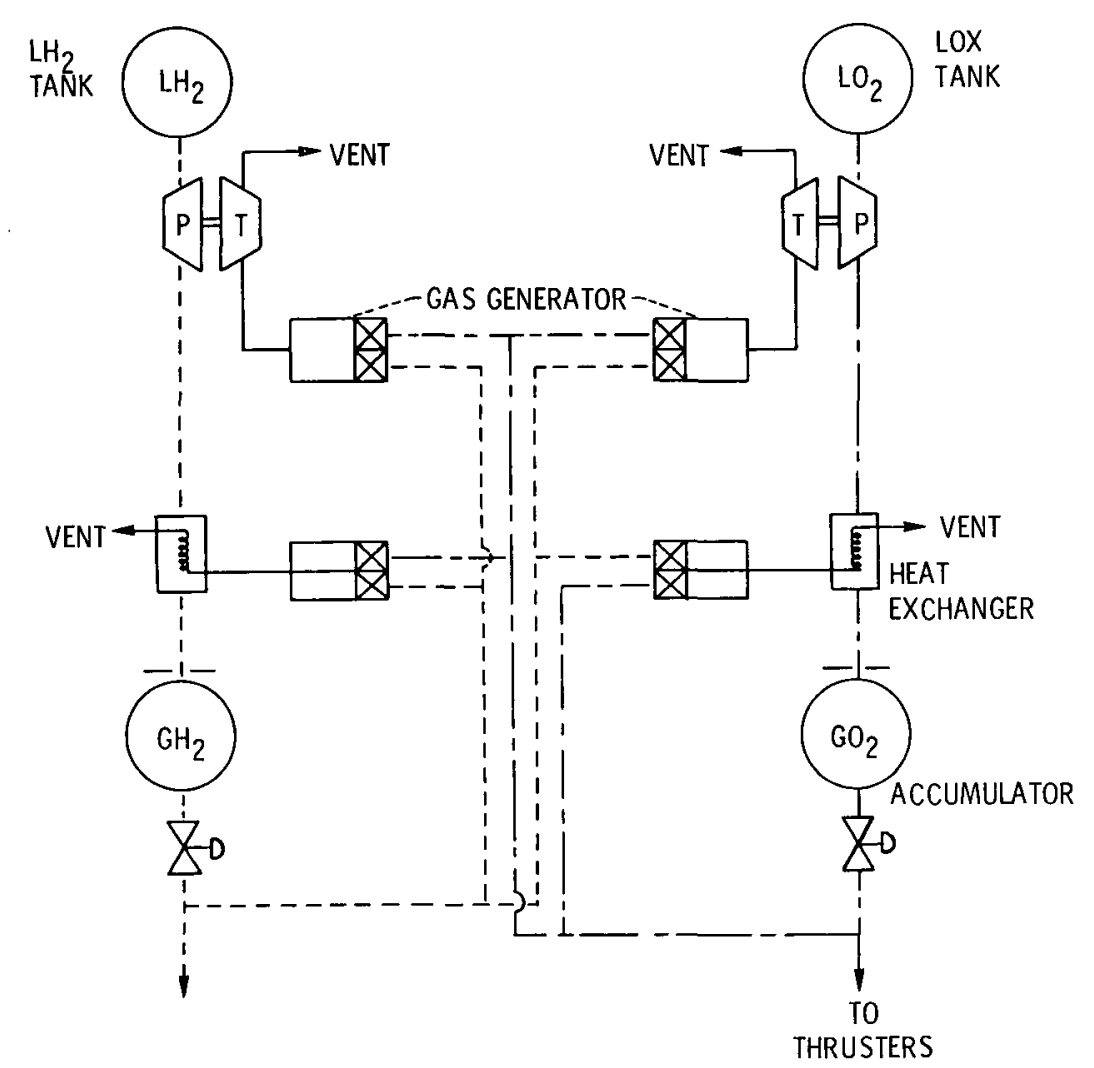

Figure 1. $-\mathrm{GO}_{2} / \mathrm{GH}_{2}$ system.

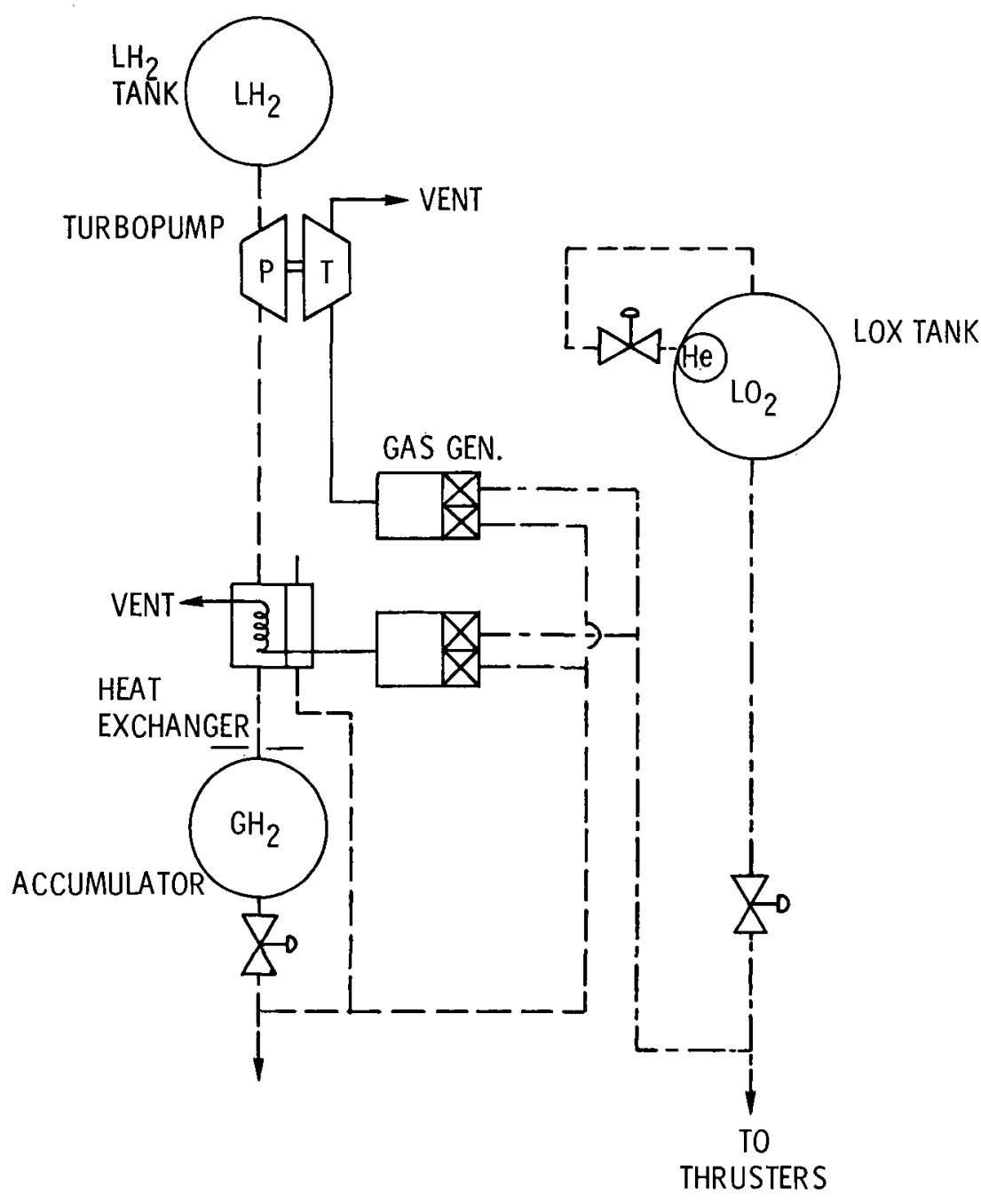

Figure 2. $-\mathrm{LO}_{2} / \mathrm{GH}_{2}$ system. 


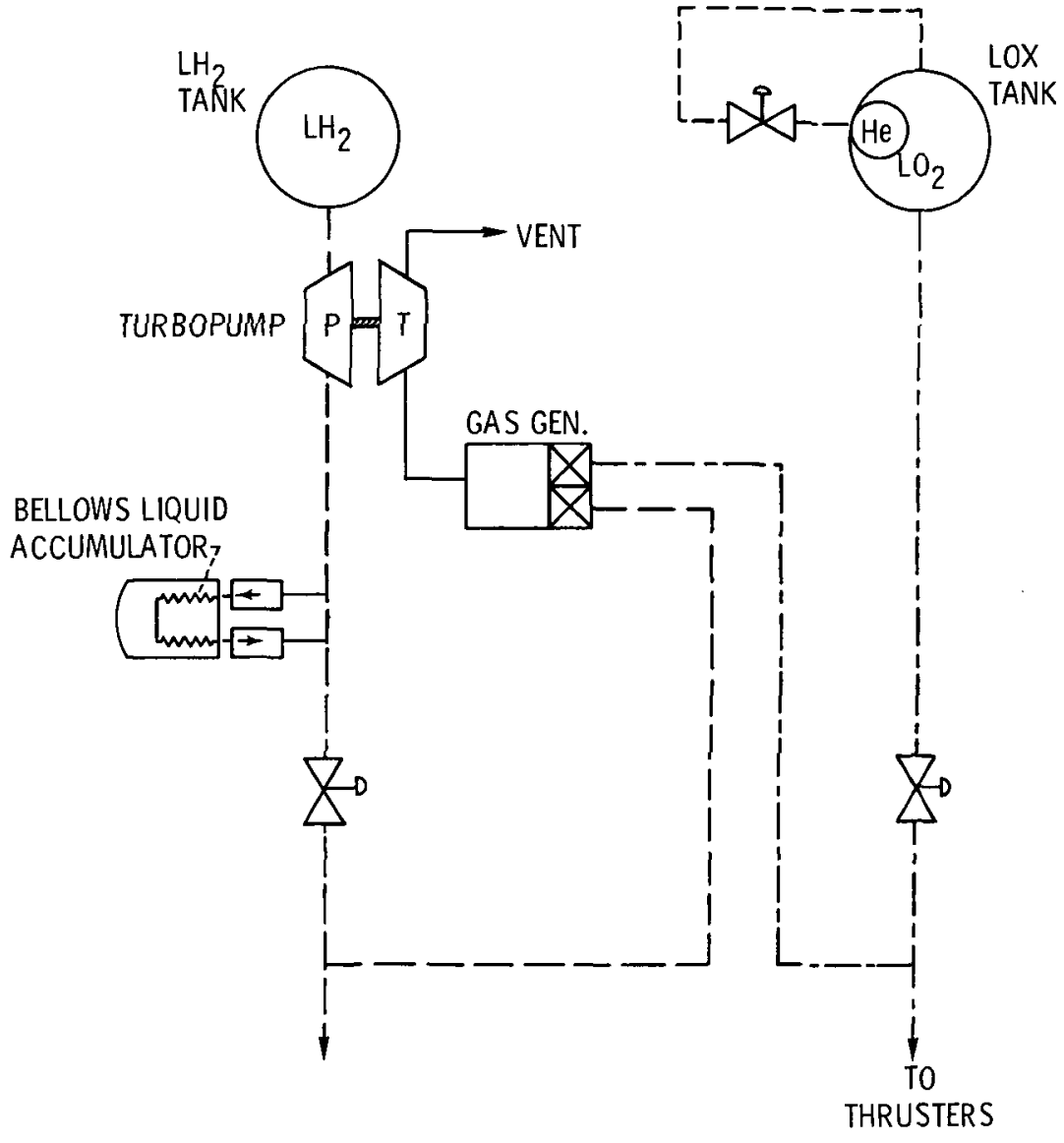

Figure 3. $-\mathrm{LO}_{2} / \mathrm{LH}_{2}$ system. 


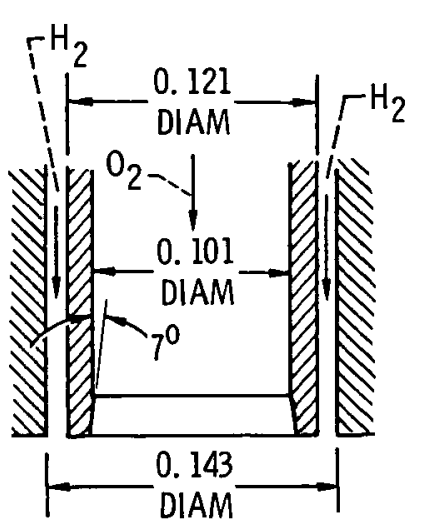

(a) COAXIAL.

咅

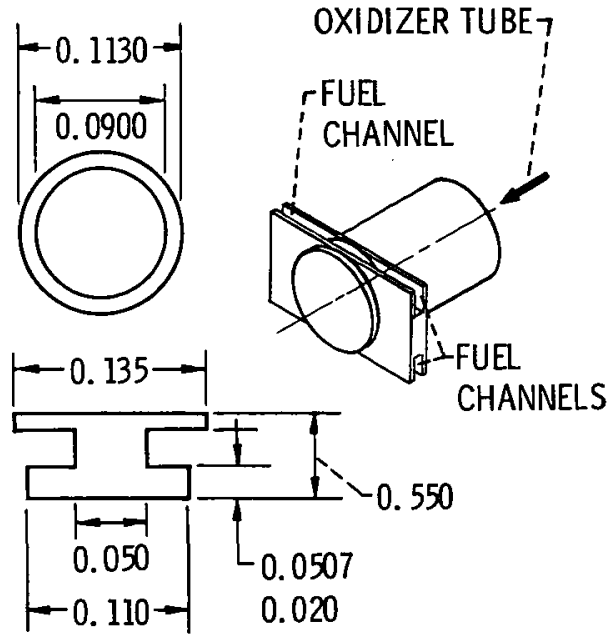

(b) PREMIX.
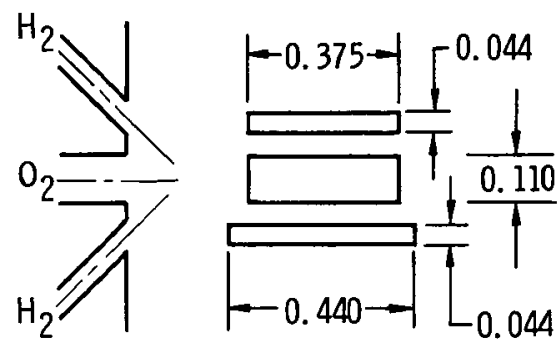

(d) TRISLOT (OUTER ROW).

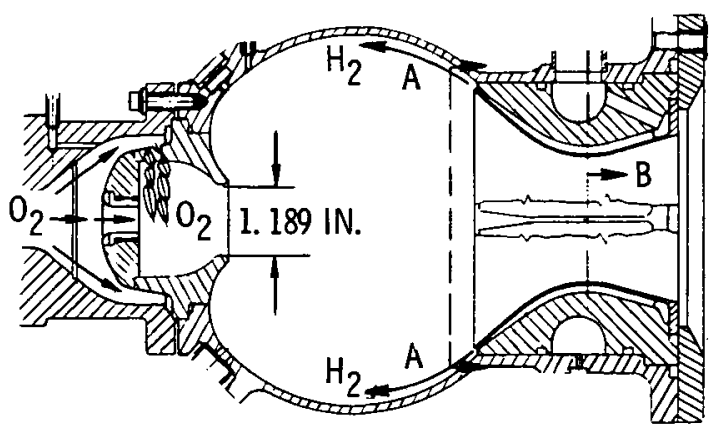

(e) REVERSE FLOW.

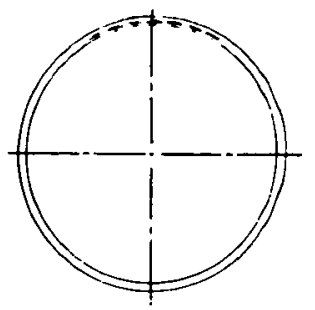

SECTION A-A

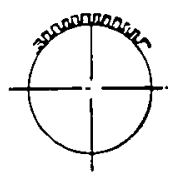

SECTION B-B

Figure 4. - Injector element details. 


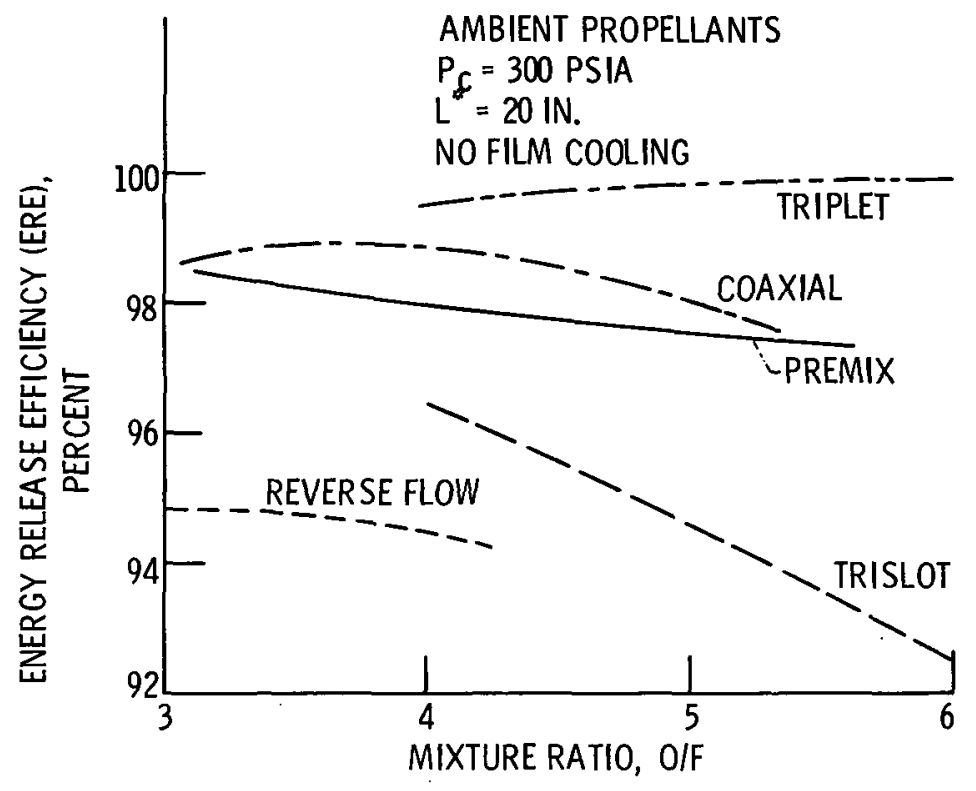

Figure 5. - Comparison of injector performance characteristics.

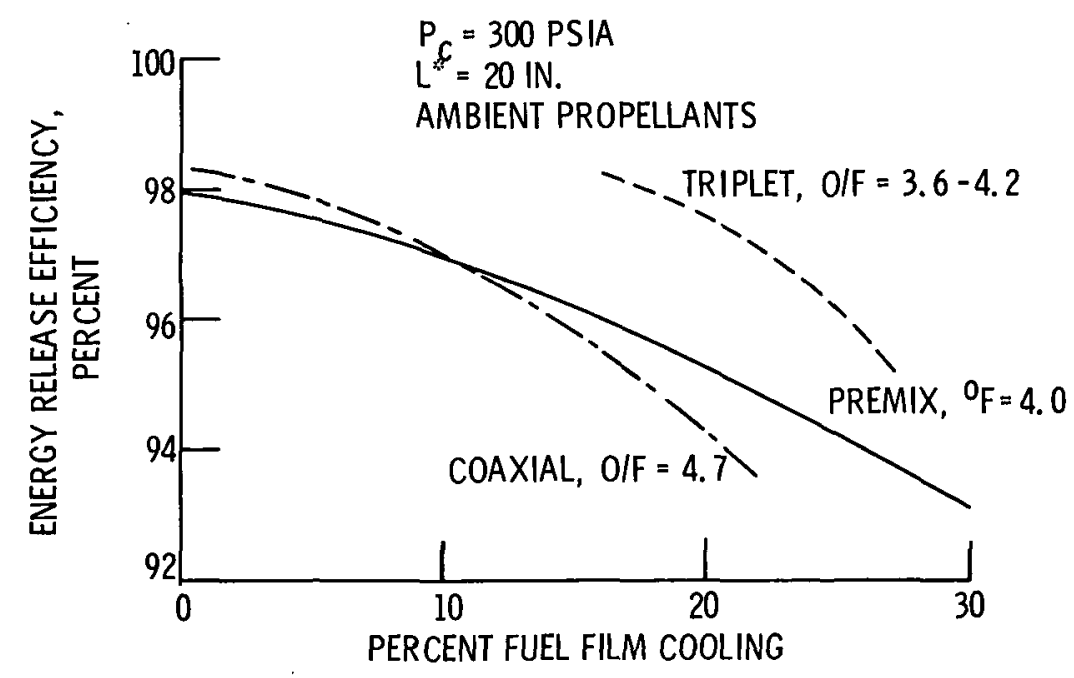

Figure 6. - Effect of film cooling on injector performance. 


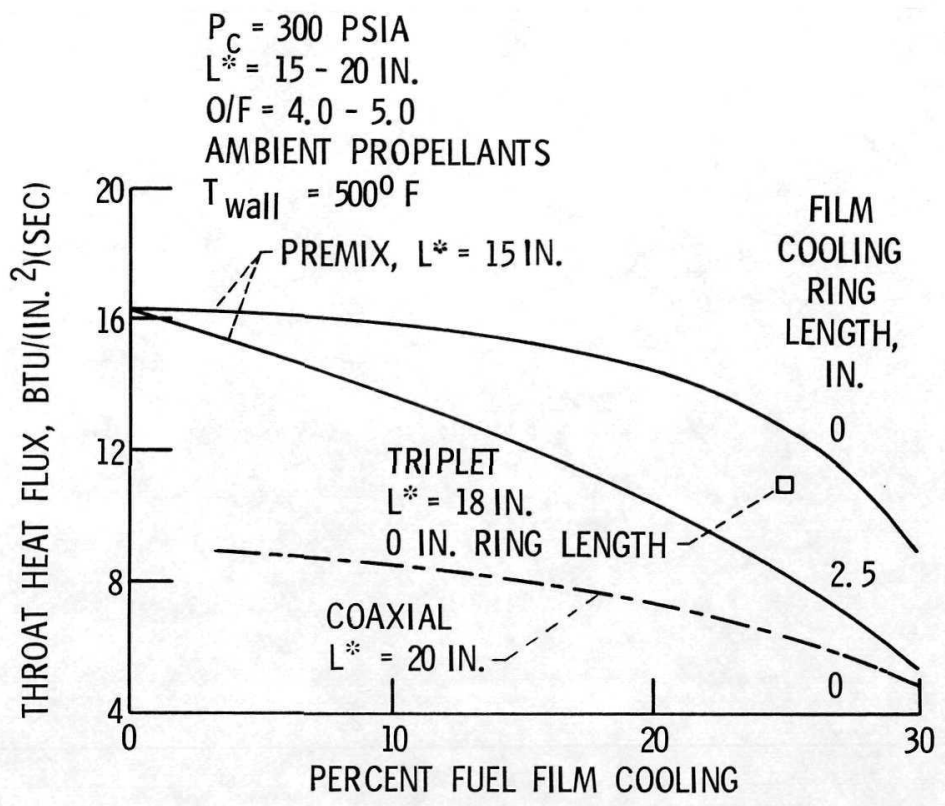

Figure 7. - Effect of film cooling on throat heat flux.

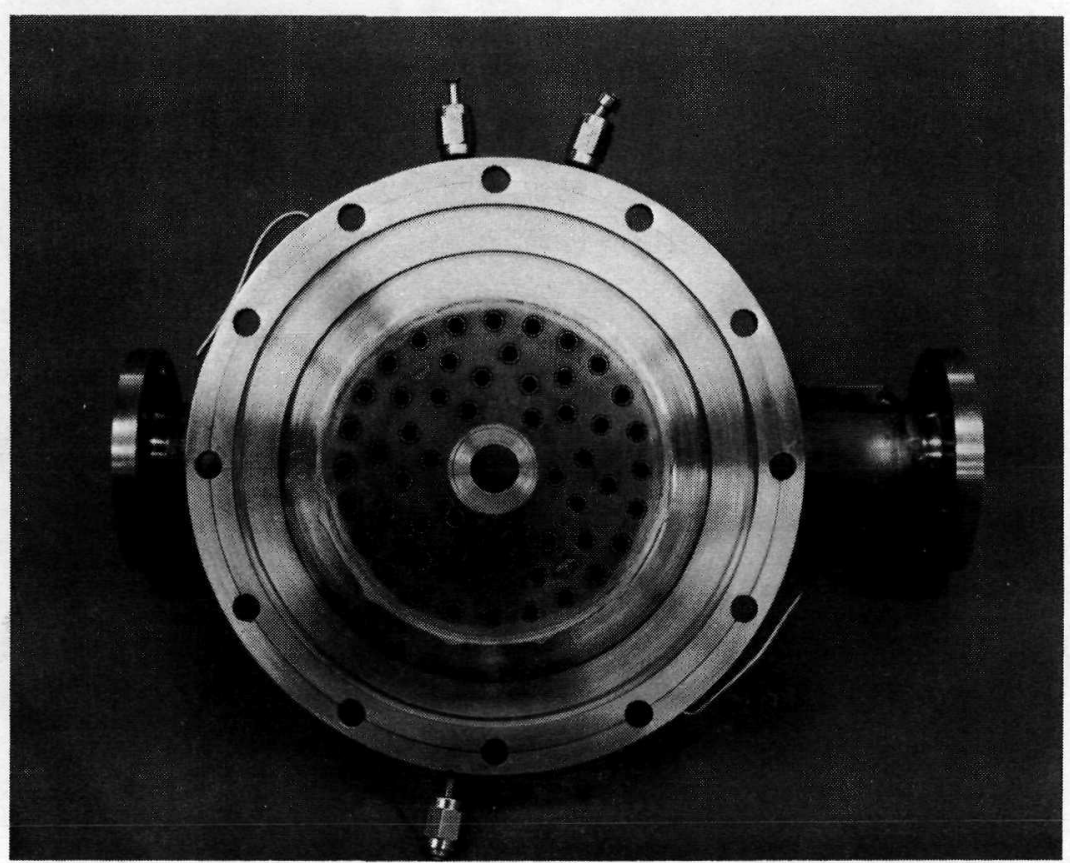

Figure 8. - Concentric tube (coaxial) injector. 
"I" TRIPLET ELEMENT CONFIGURATION
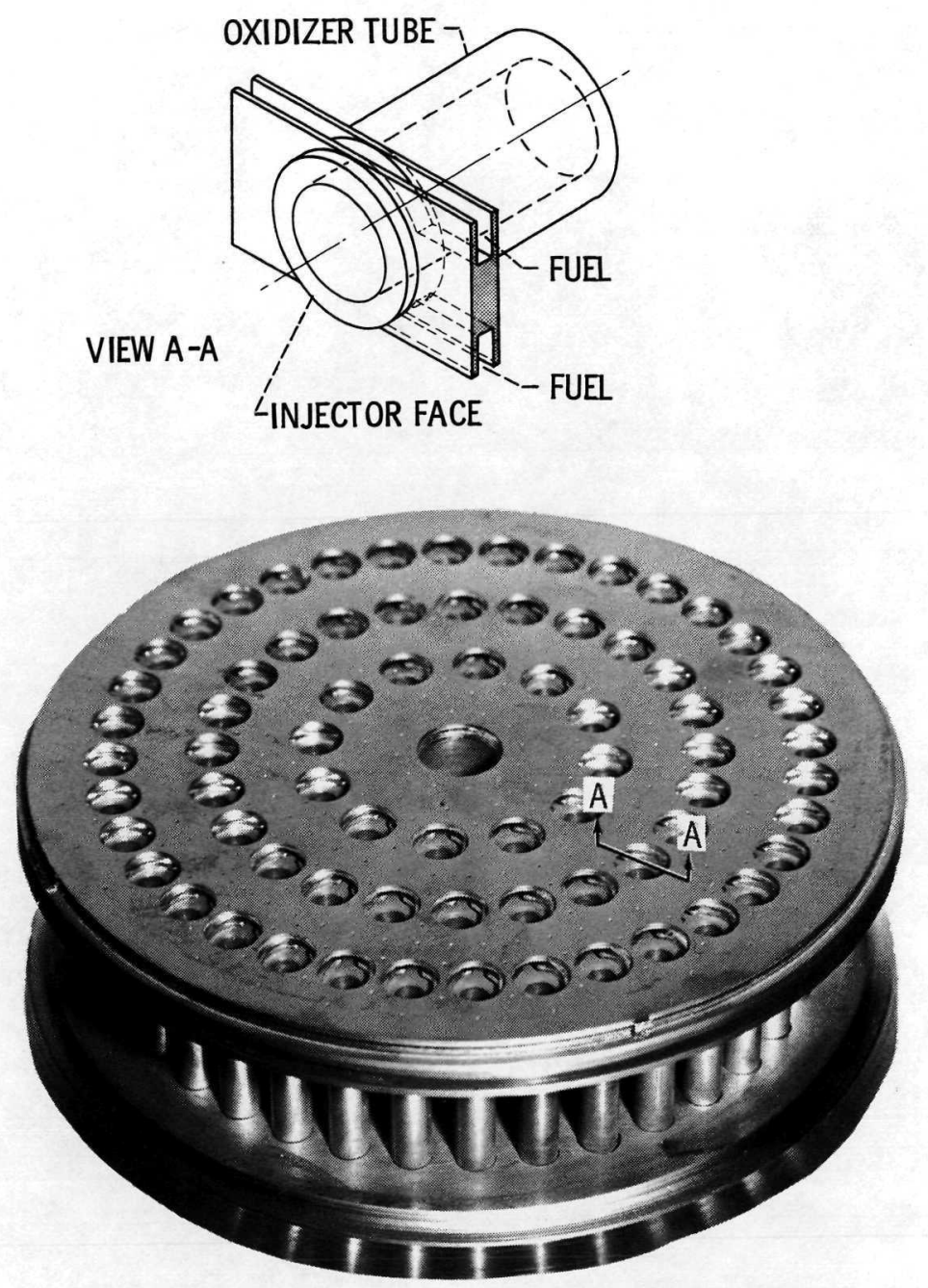

Figure 9. - Premix Injector assembly. 


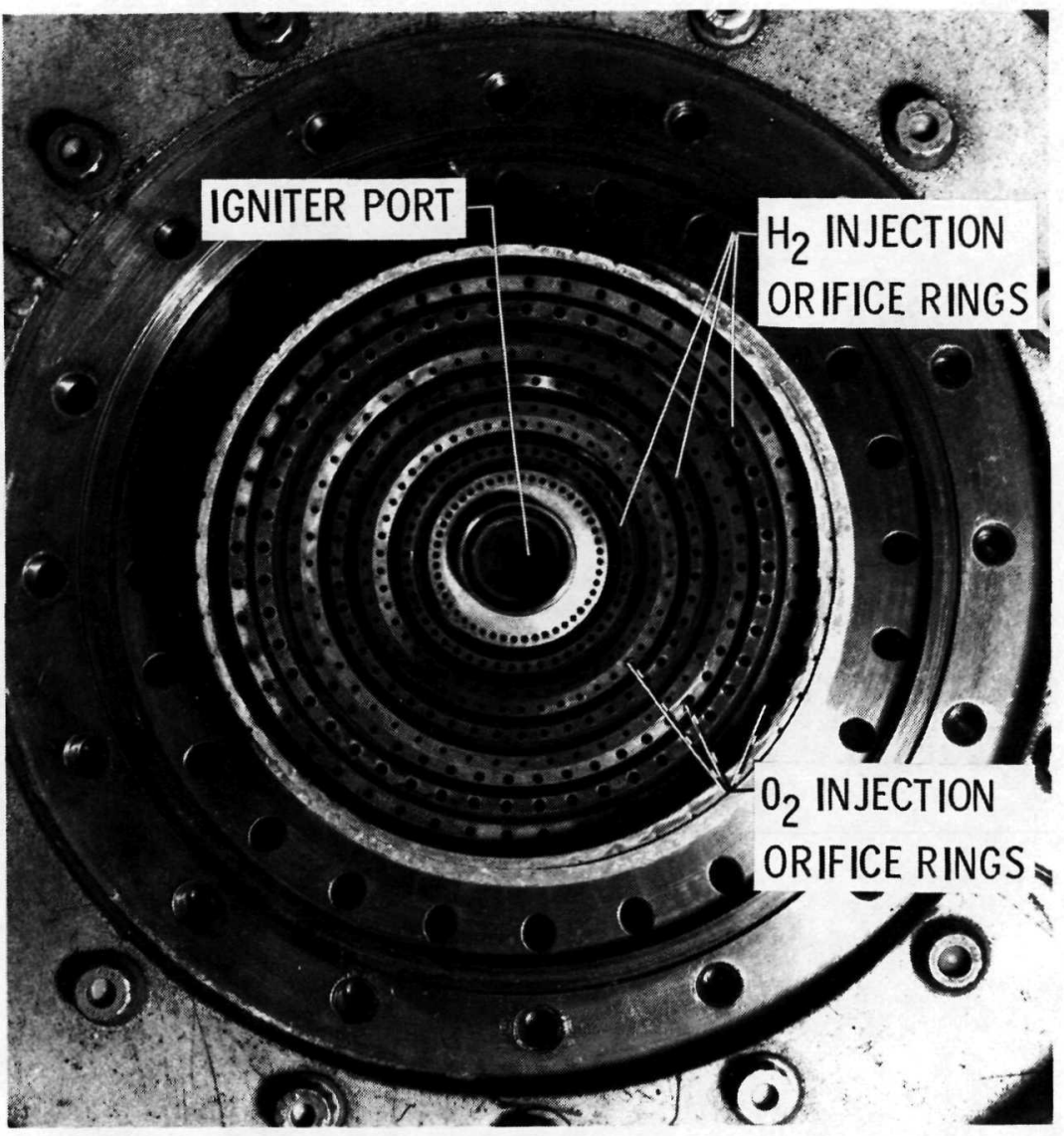

Figure 10. - Raised post triplet injector assembly.

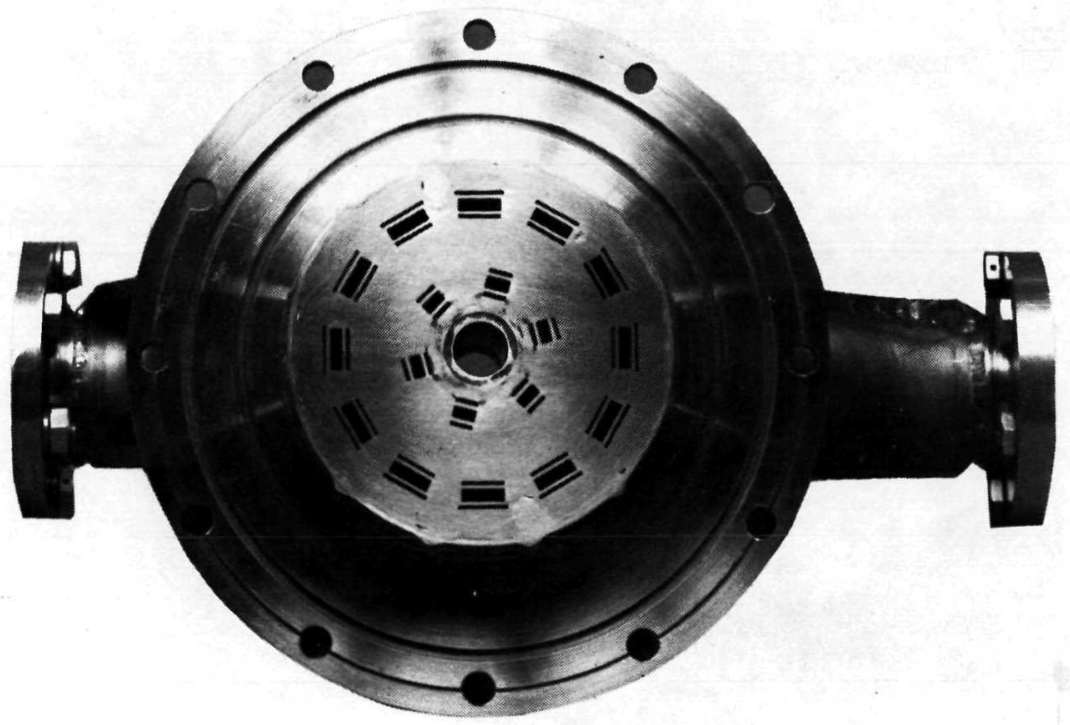

Figure 11. - Trislot injector assembly. 


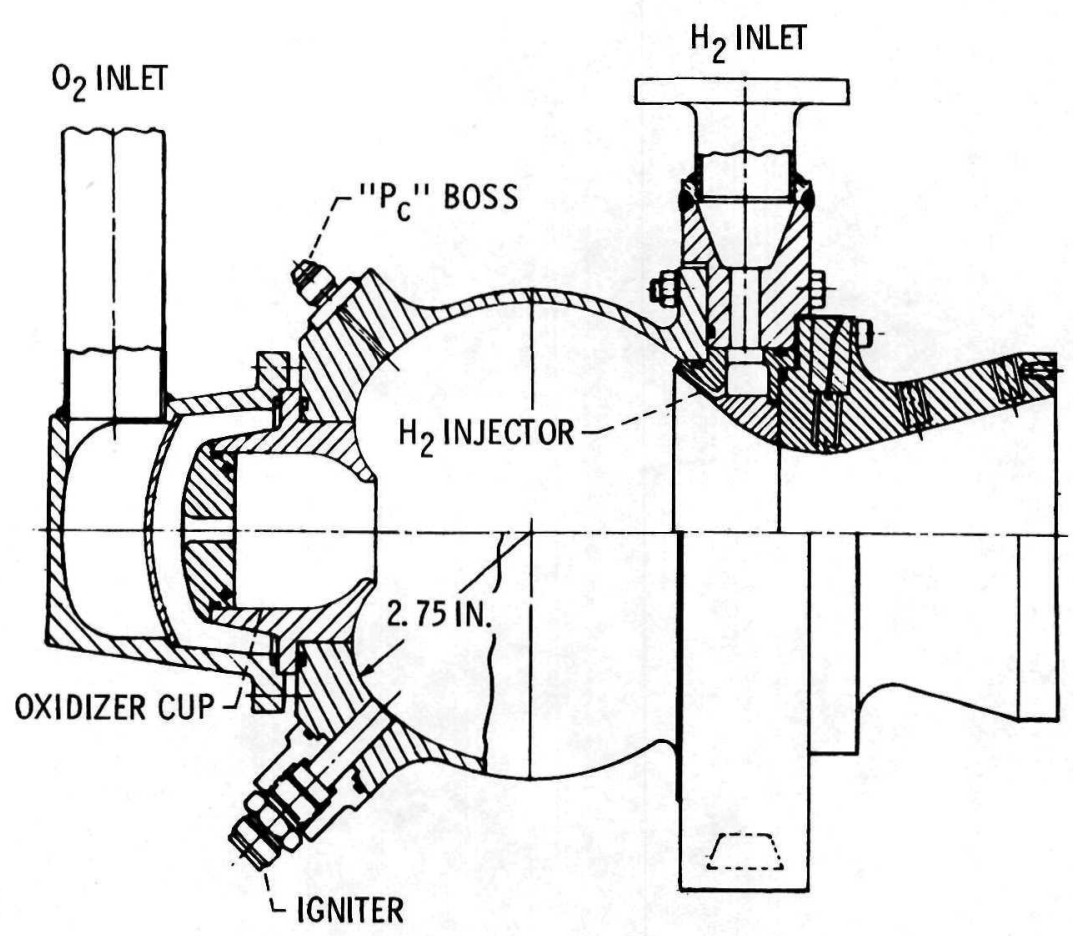

Figure 12. - Reverse Flow injector/thrust chamber assembly.

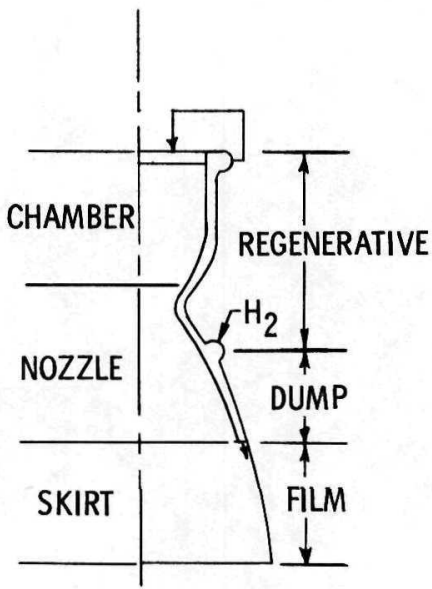

(a) REGENERATIVE/DUMP.

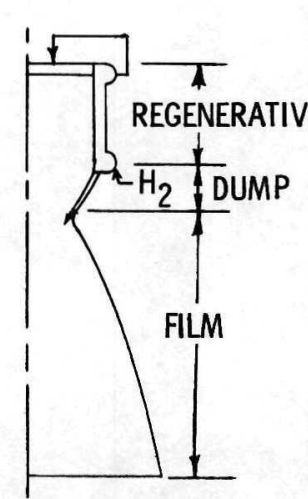

(d) FILM/REGENERATIVE.

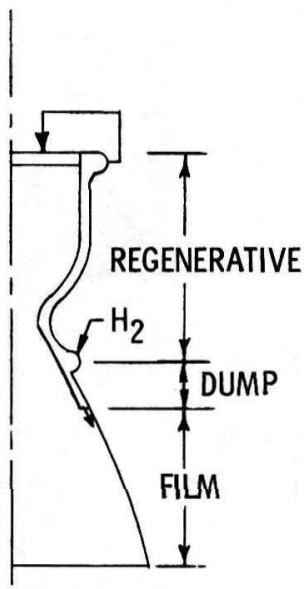

(b) REGENERATIVEIFILM.

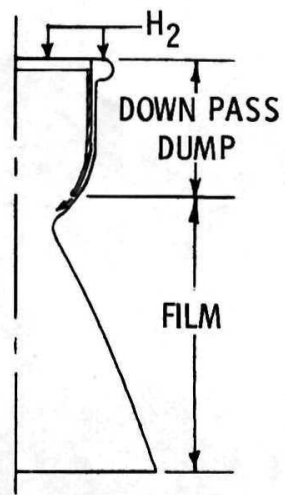

(e) FILM/DUMP.

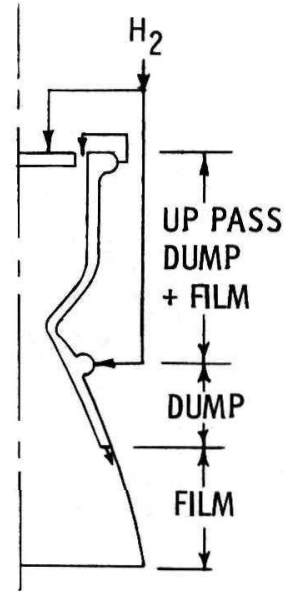

(c) DUMPIFILM.

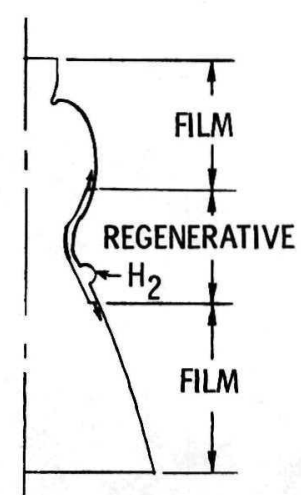

(f) REVERSE FLOW

(REGENERATIVEIFILM).

Figure 13. - Thrust Chamber Cooling methods. 


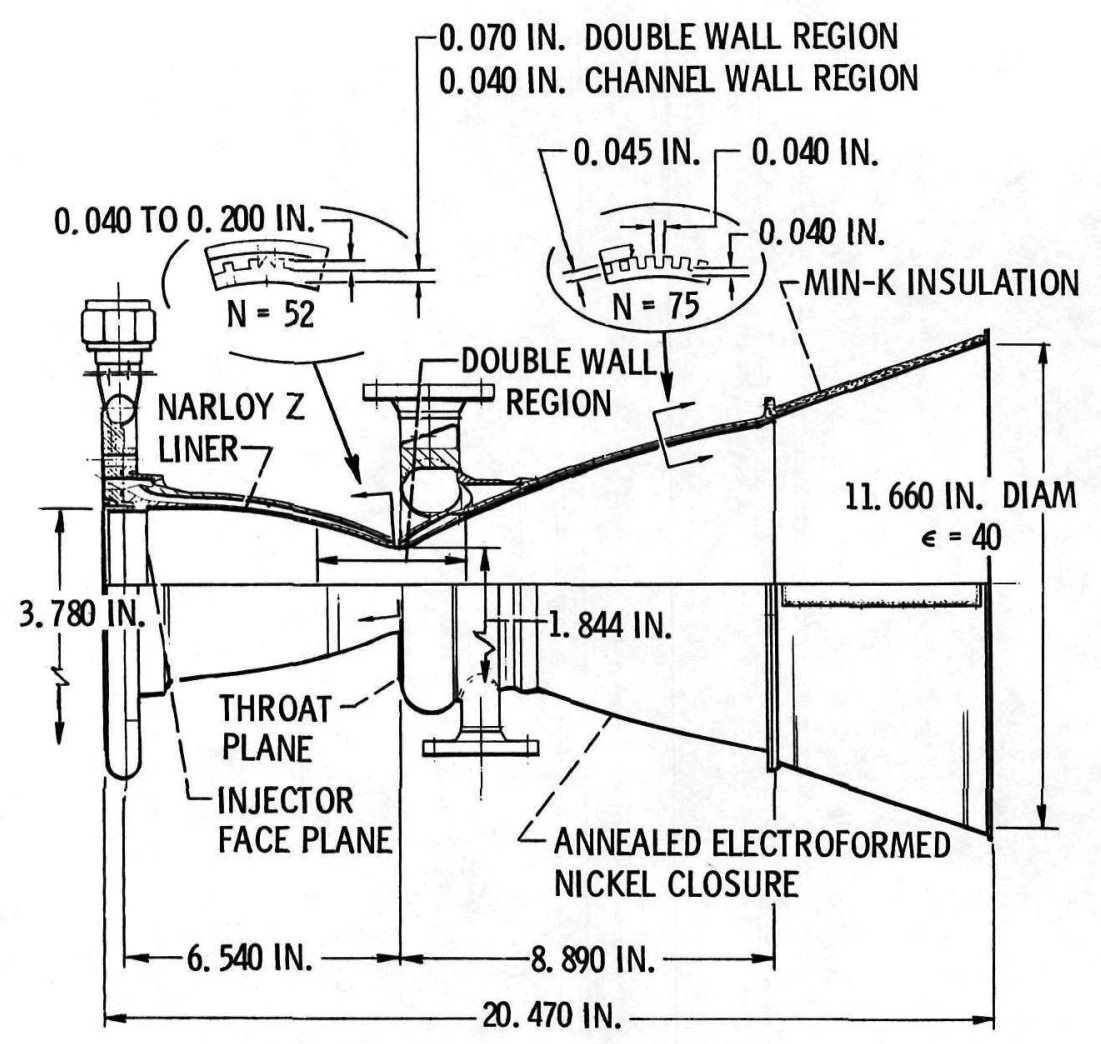

Figure 14. - Rocketdyne Regenerative/Dump Cooled thrust chamber.

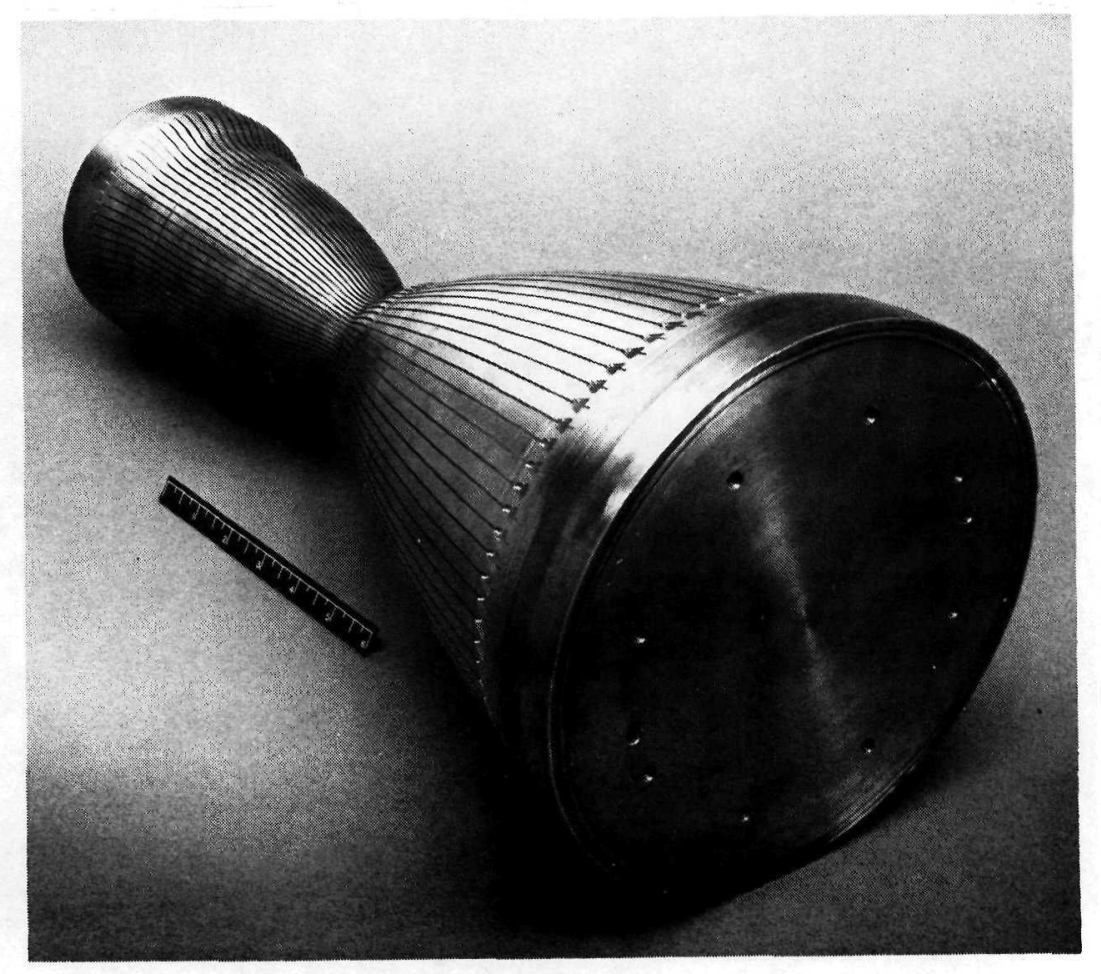

Figure 15. - Rocketdyne regenerative/dump cooled chamber Narloy-z-liner. 


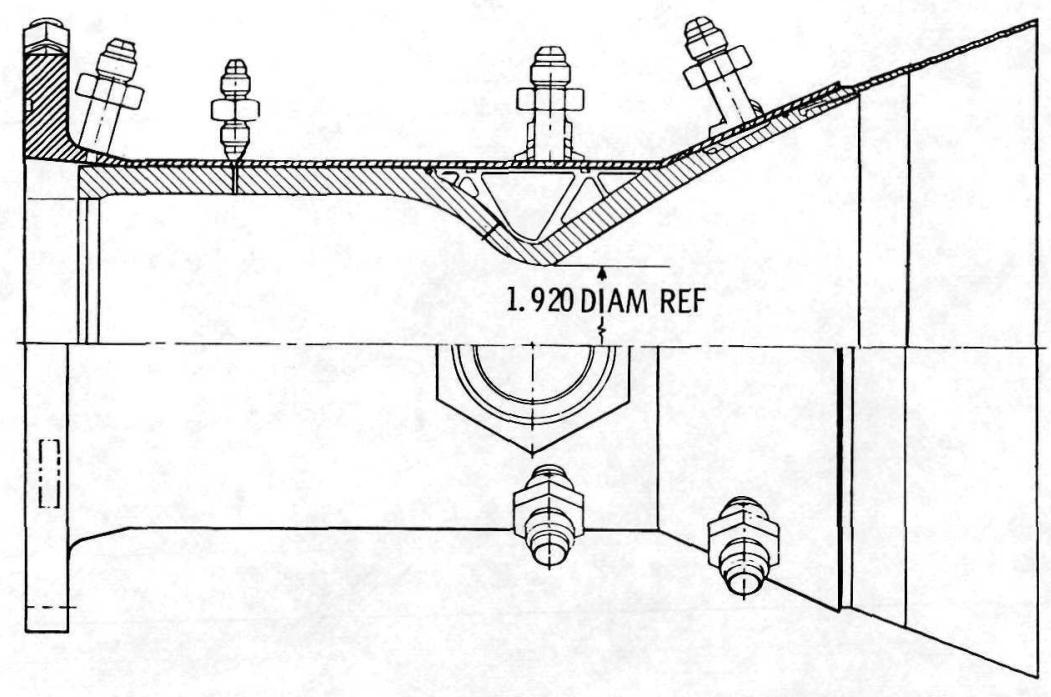

Figure 16. - Regenerative/Film cooled chamber section.

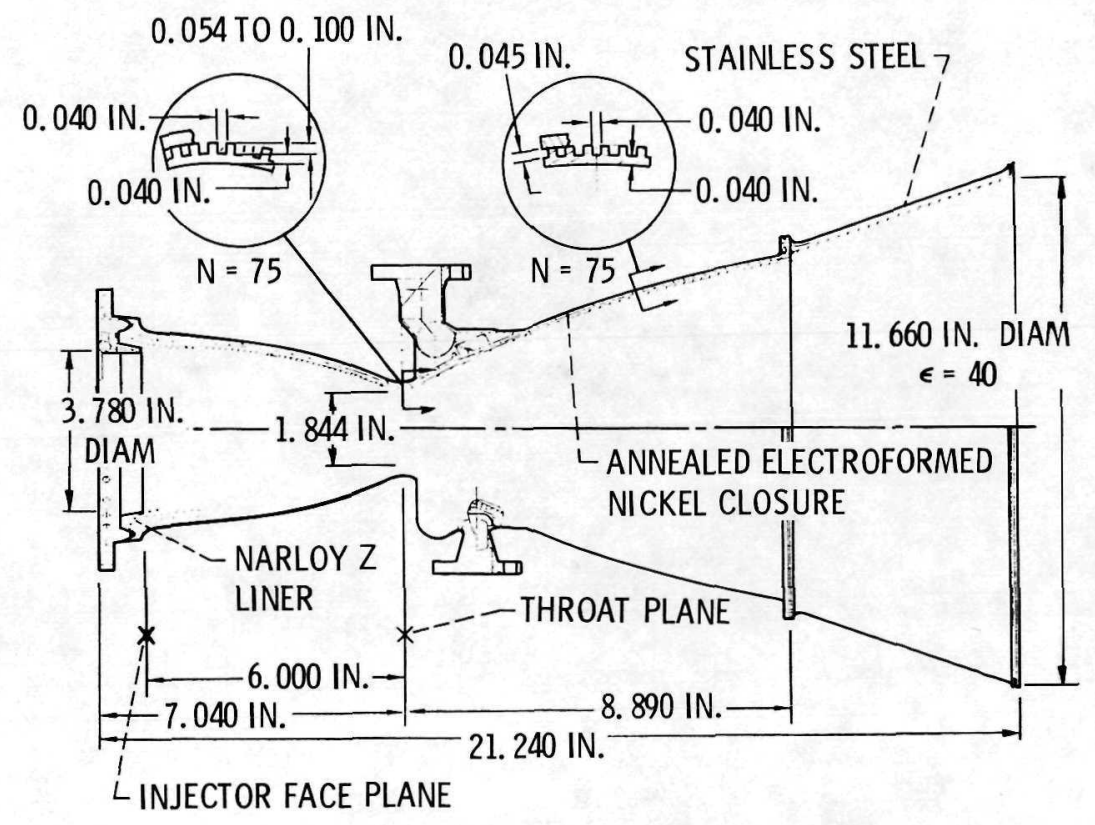

Figure 17. - Rocketdyne Dump/Film Cooled thrust chamber. 


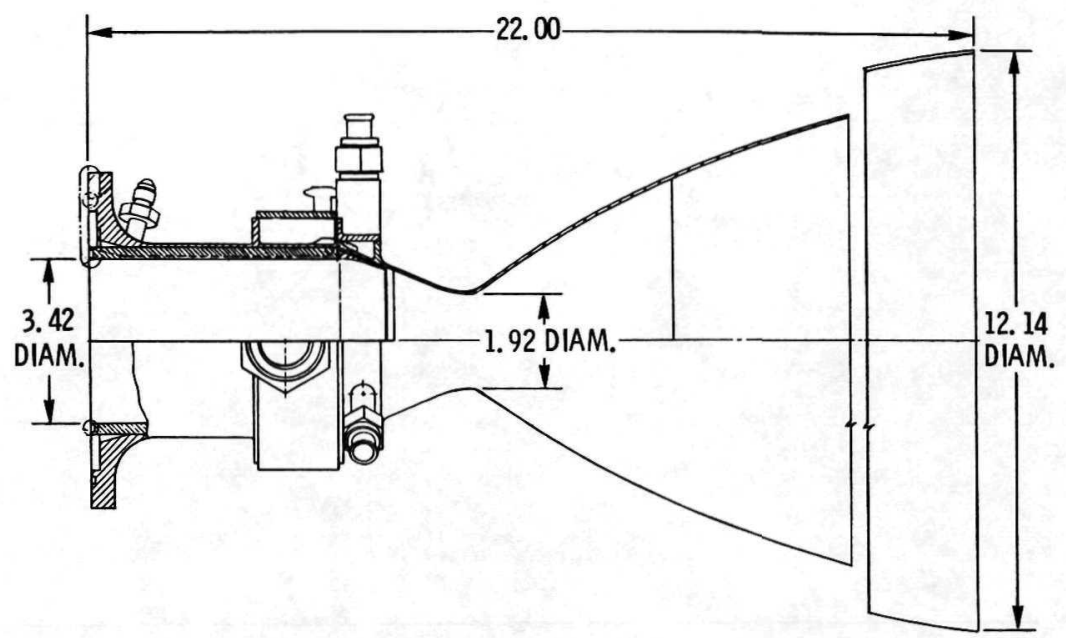

Figure 18. - Aerojet Film/Regenerative cooled thrust chamber.

곤

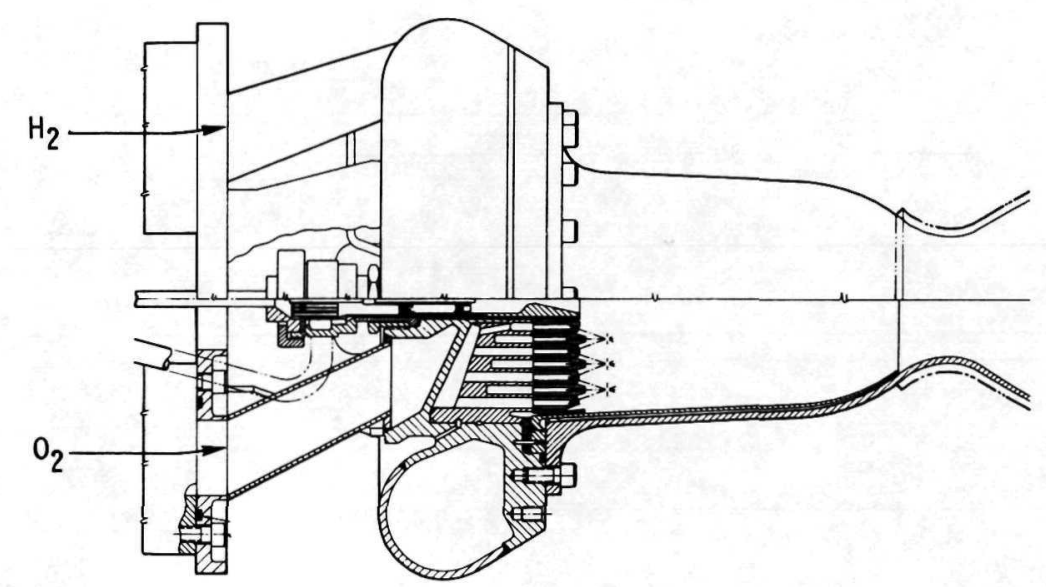

Figure 19. - TRW Film/Dump (Duct) cooled thrust chamber assembly. 


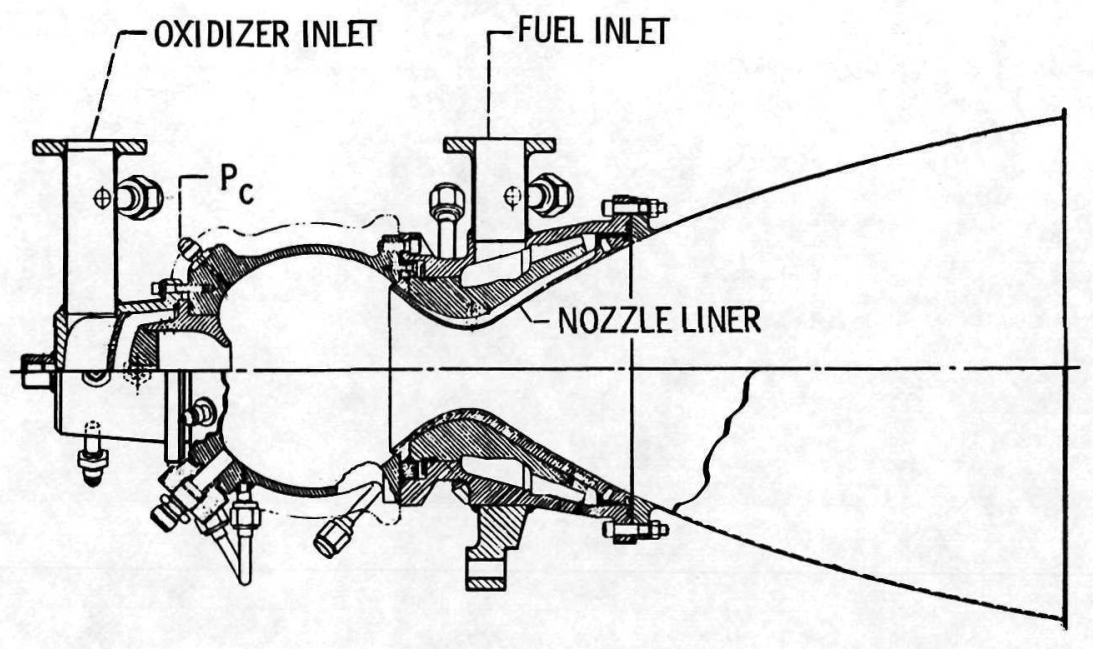

Figure 20. - Bell Reverse Flow thrust chamber assembly.

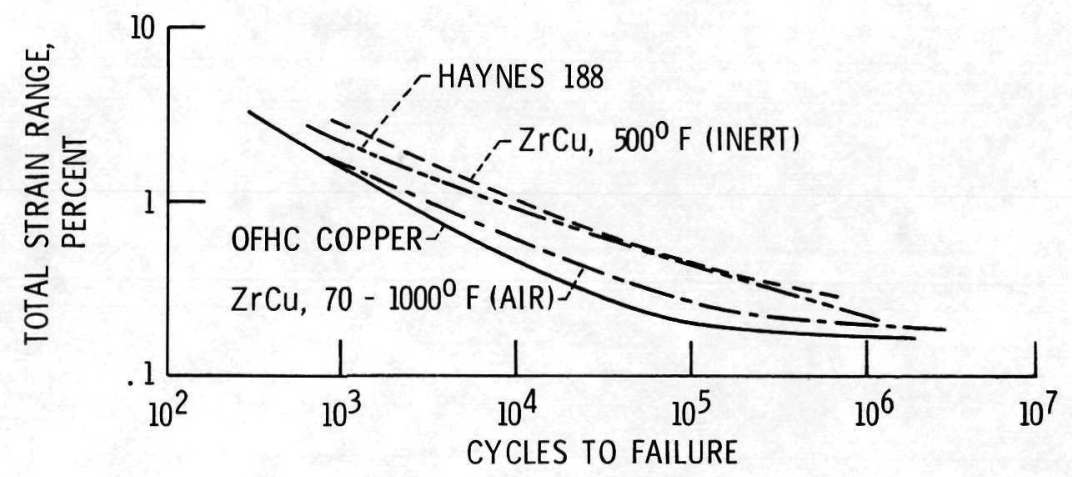

Figure 21. - Total strain versus fatigue life. 


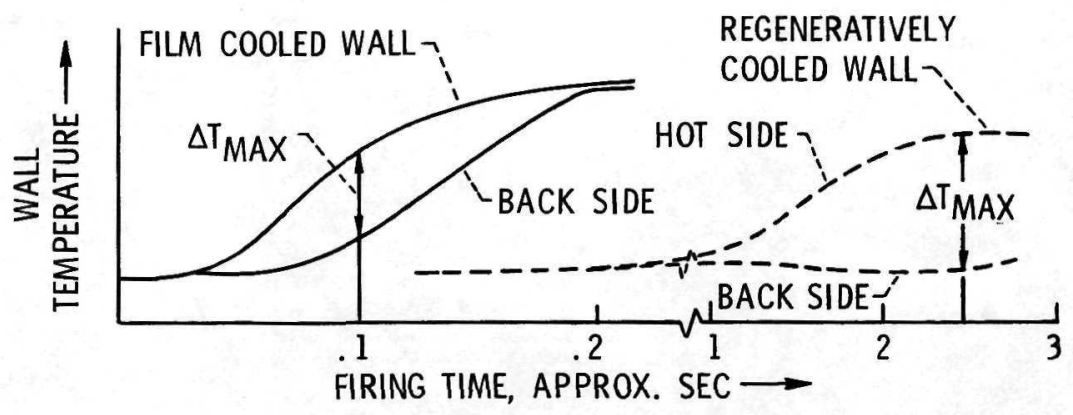

Figure 22. - Transient wall temperature behavior of film and regeneratively cooled chambers.

금

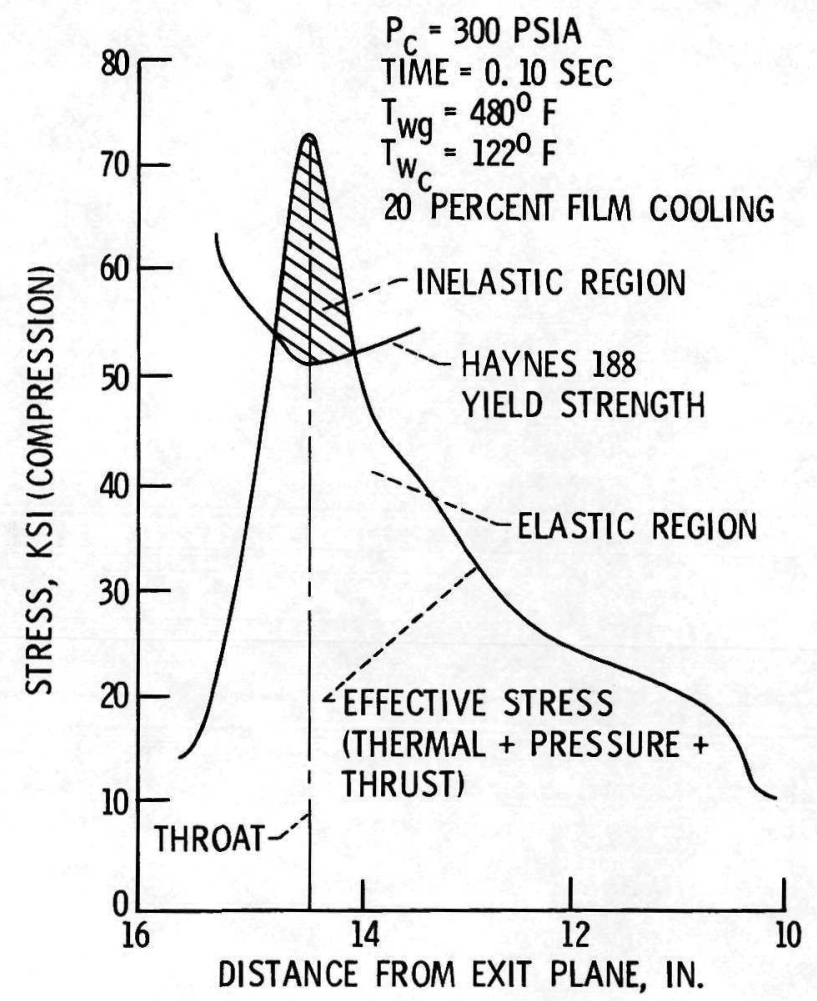

Figure 23. - Effective stress profile for film cooled chamber. 


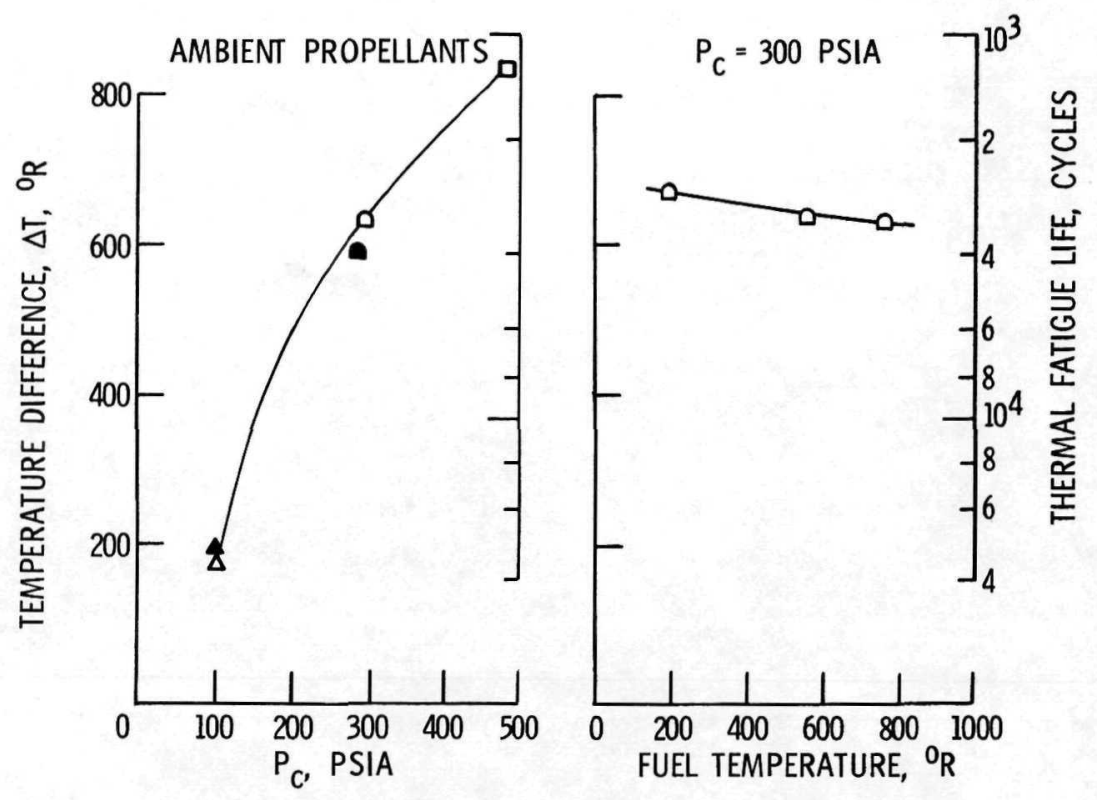

Figure 24. - Regenerative chamber life and wall temperature difference. Maximum temperature 0.6 inches upstream of throat.

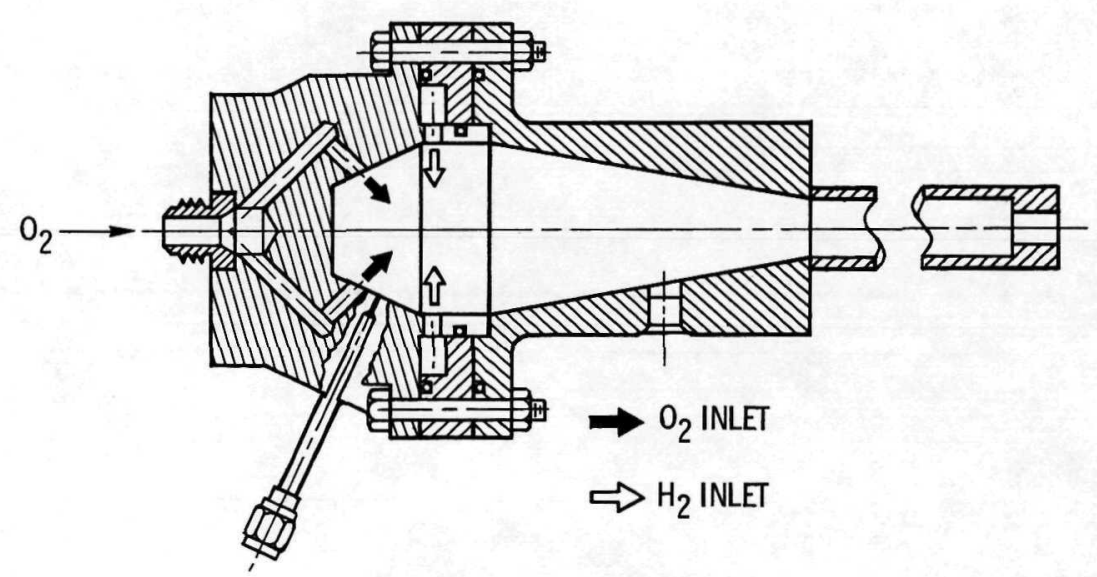

Figure 25. - Rocketdyne Spark/Torch igniter. 


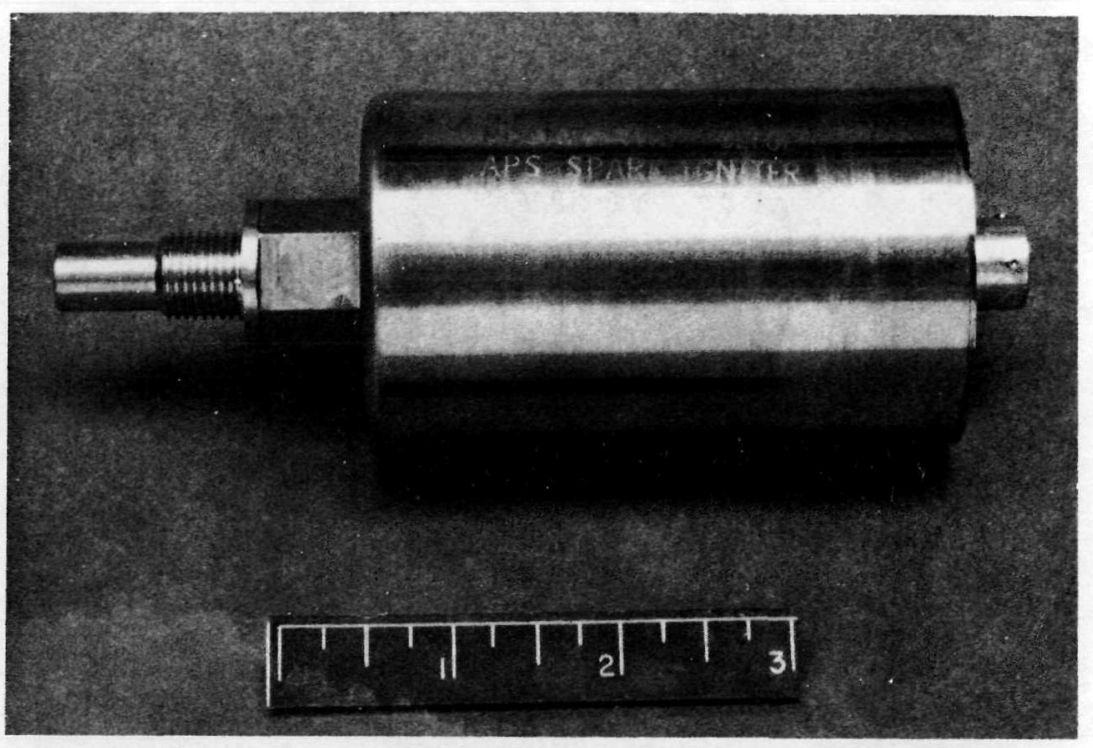

Figure 26. - Prototype integral sparkplug/exciter igniter assembly.

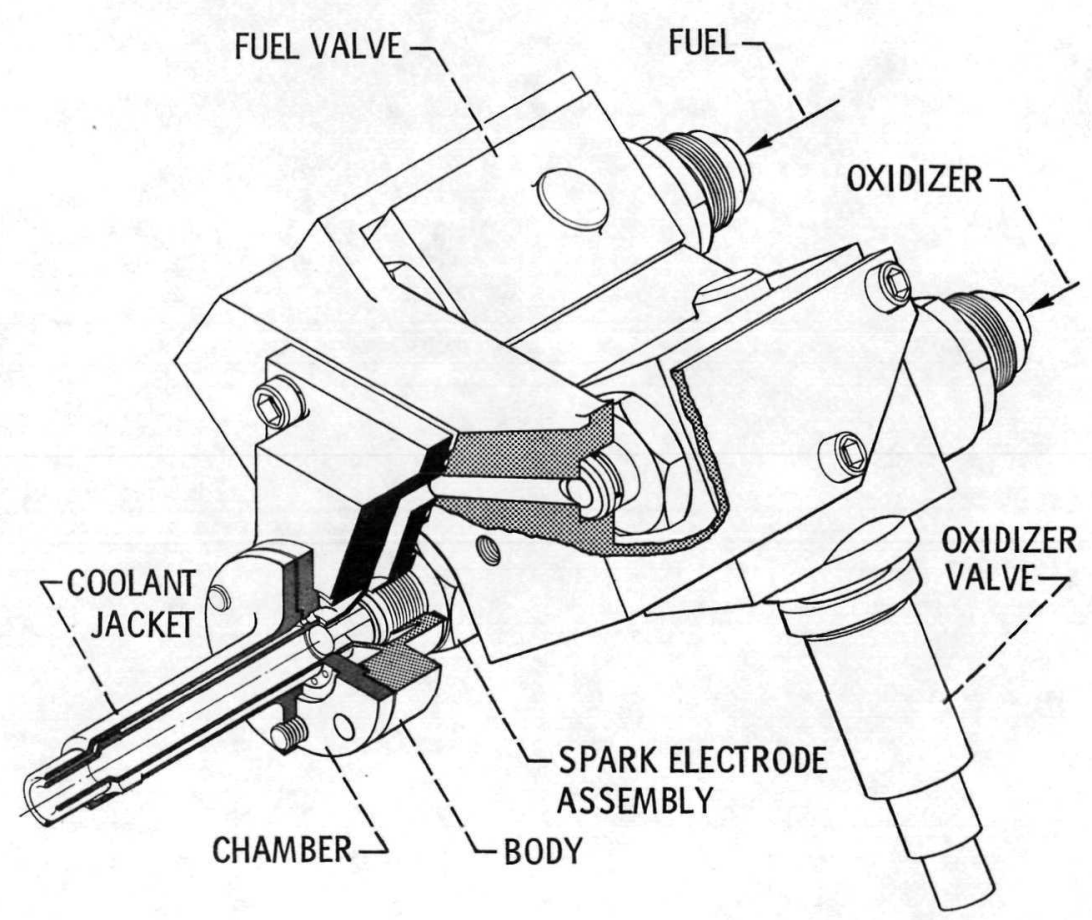

Figure 27. - Aerojet Spark/Torch igniter. 


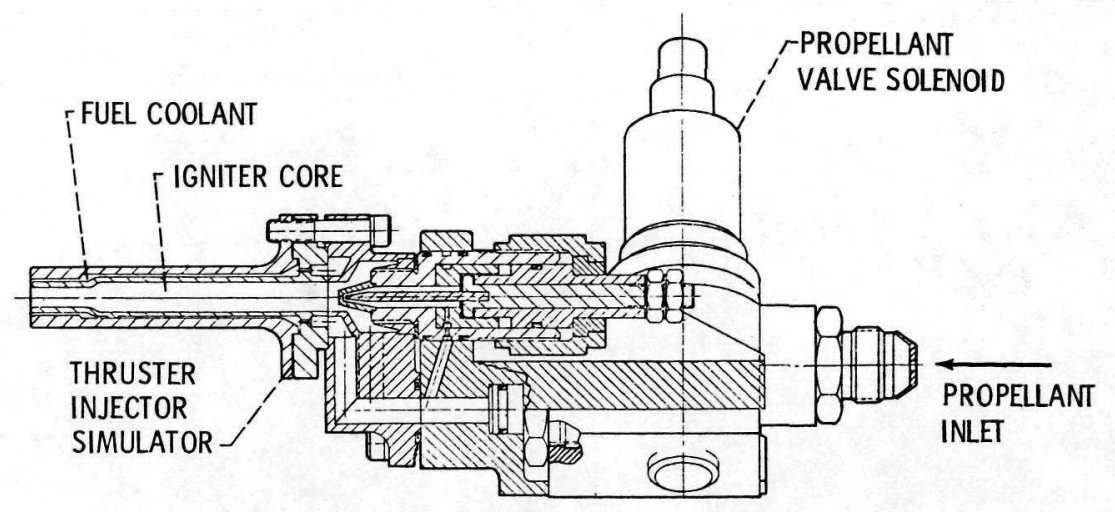

Figure 28. - Aerojet Plasma/Torch igniter.

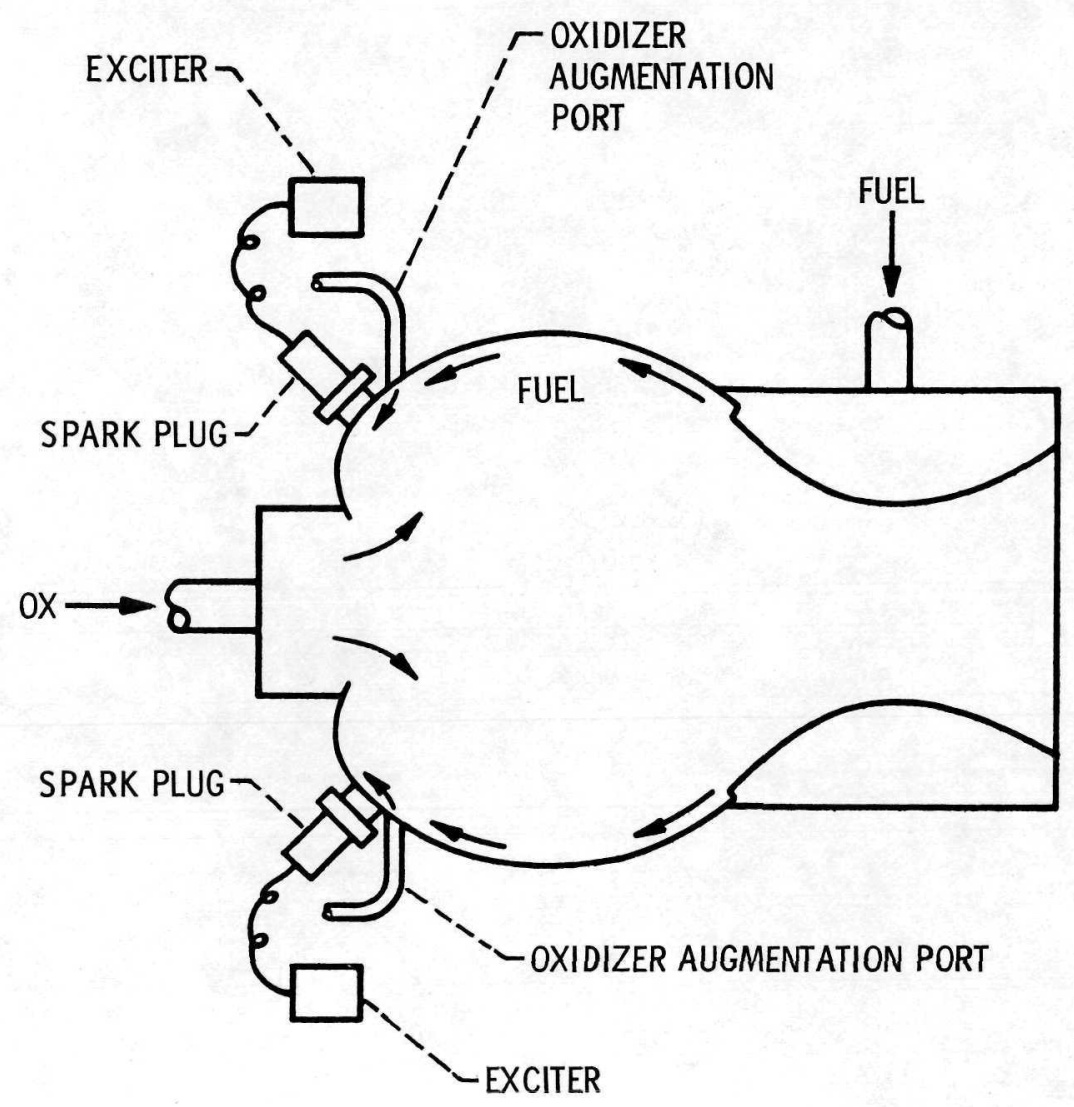

Figure 29. - Direct Spark Plug ignition. 


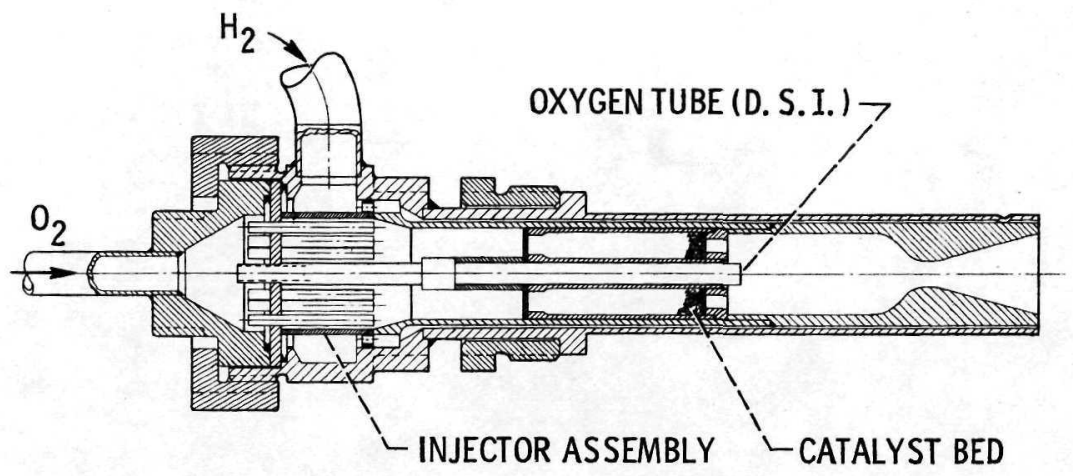

Figure 30. - TRW Catalytic igniter with downstream injection.

$\underset{7}{\stackrel{7}{N}}$

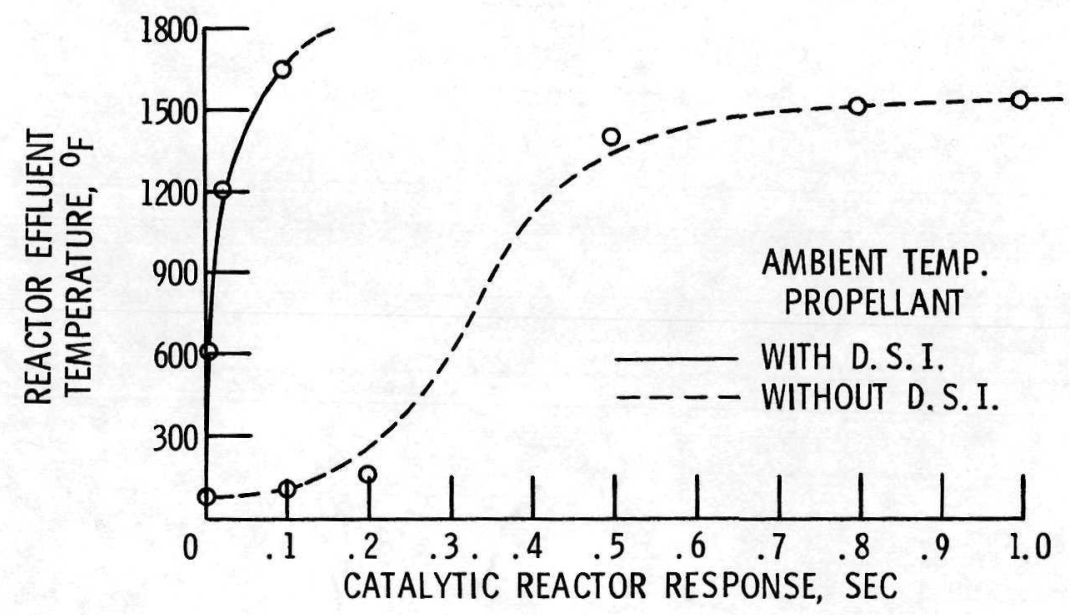

Figure 31. - Catalytic igniter response comparison. 

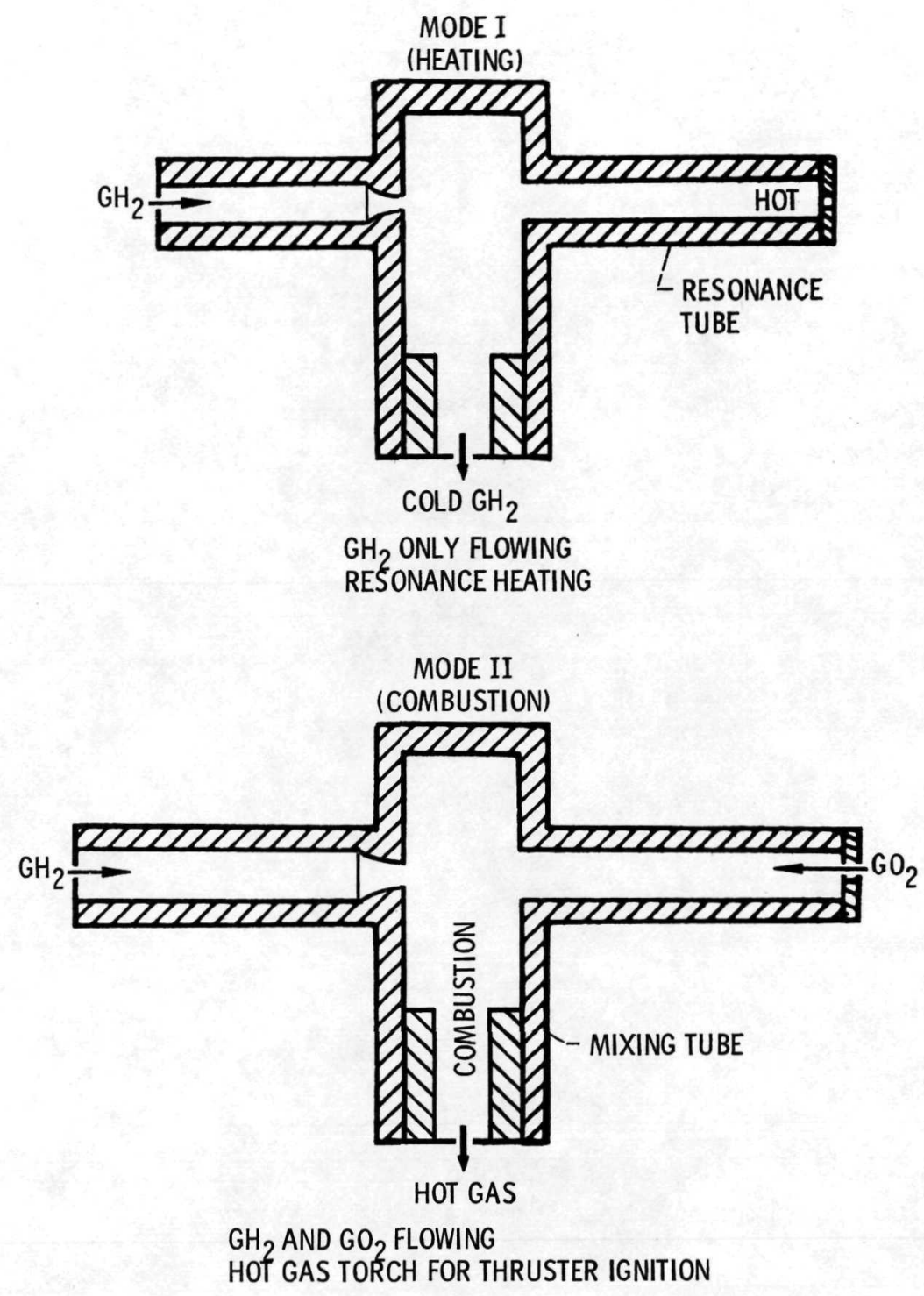

Figure 32. $-\mathrm{O}_{2} / \mathrm{H}_{2}$ Resonance igniter principle of operation. 


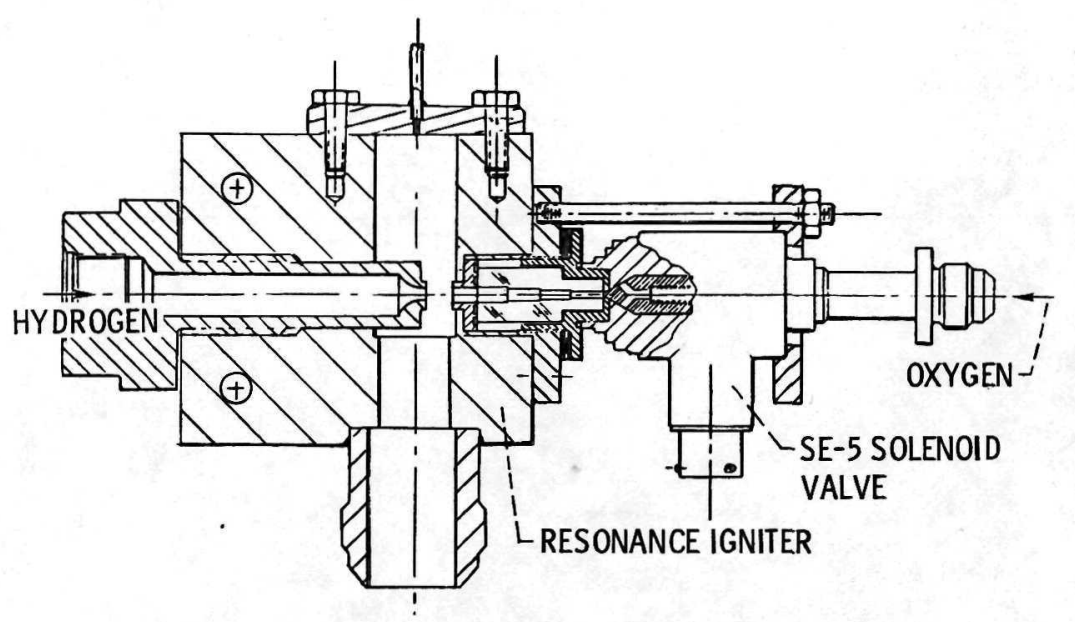

Figure 33. - Optimized Auto igniter and oxygen valve assembly.

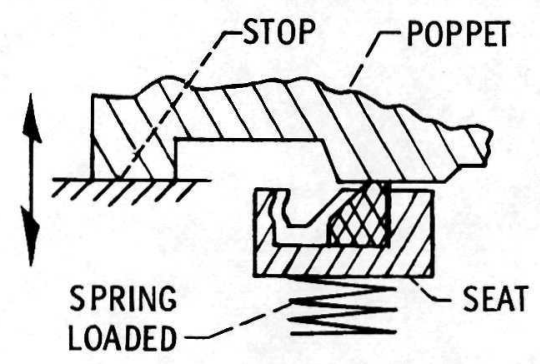

(a) POLYIMIDE SEAL.

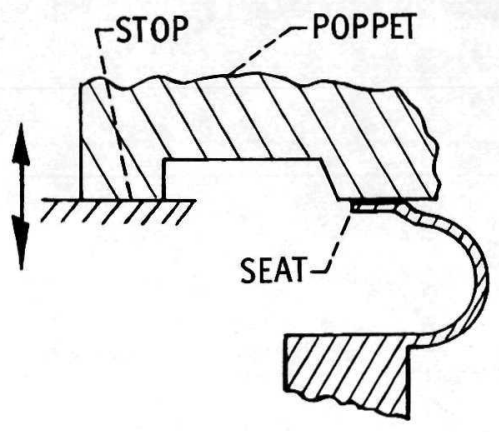

(b) GOLD PLATED LIP SEAL.

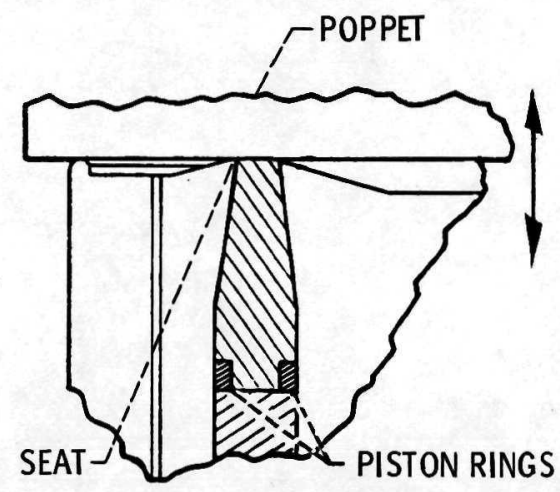

(c) CAPTIVE PLASTIC SEAL.

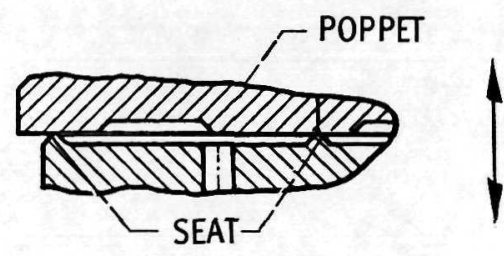

(d) HARD SHARP CARBIDE SEAL.

Figure 34. - Selected Valve Seal concepts. 

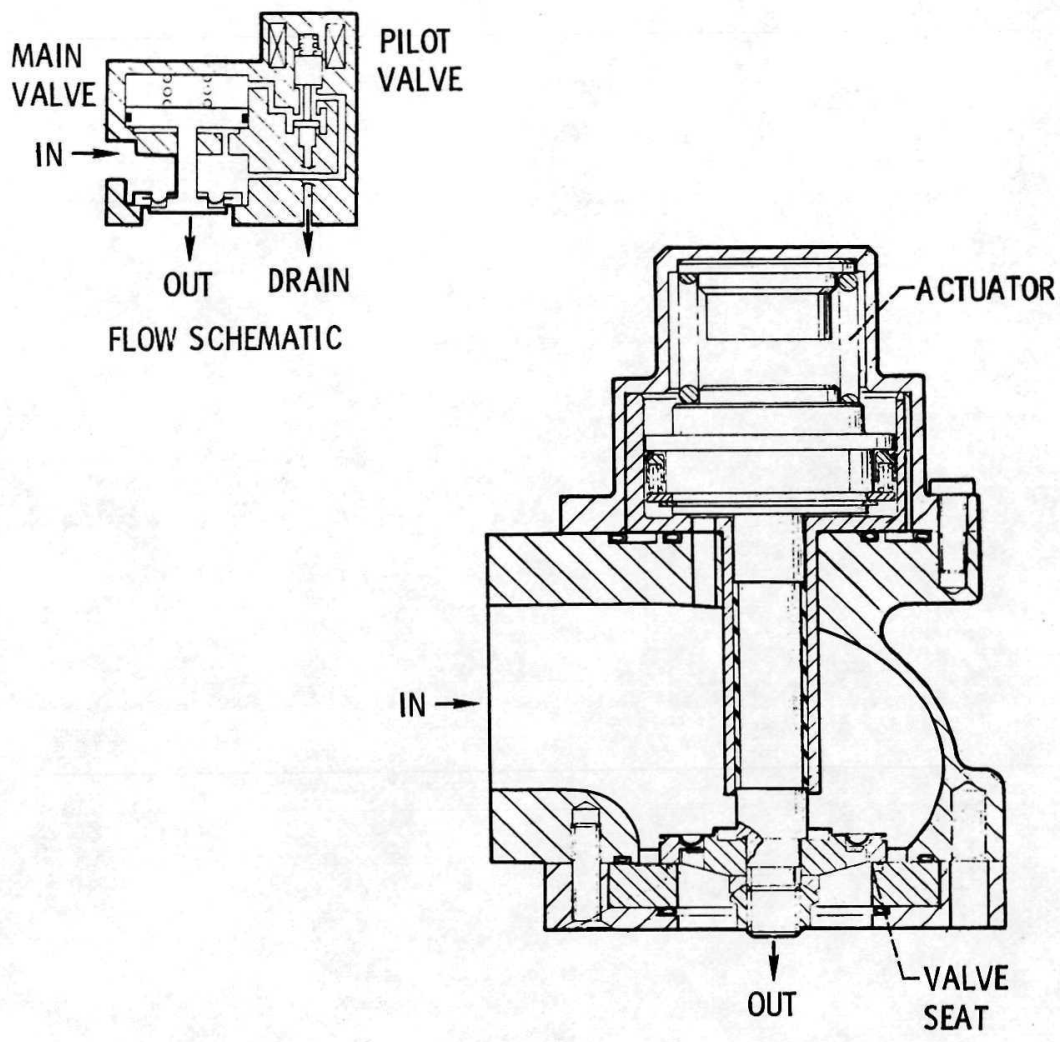

Figure 35. - Rocketdyne ACPS valve design.

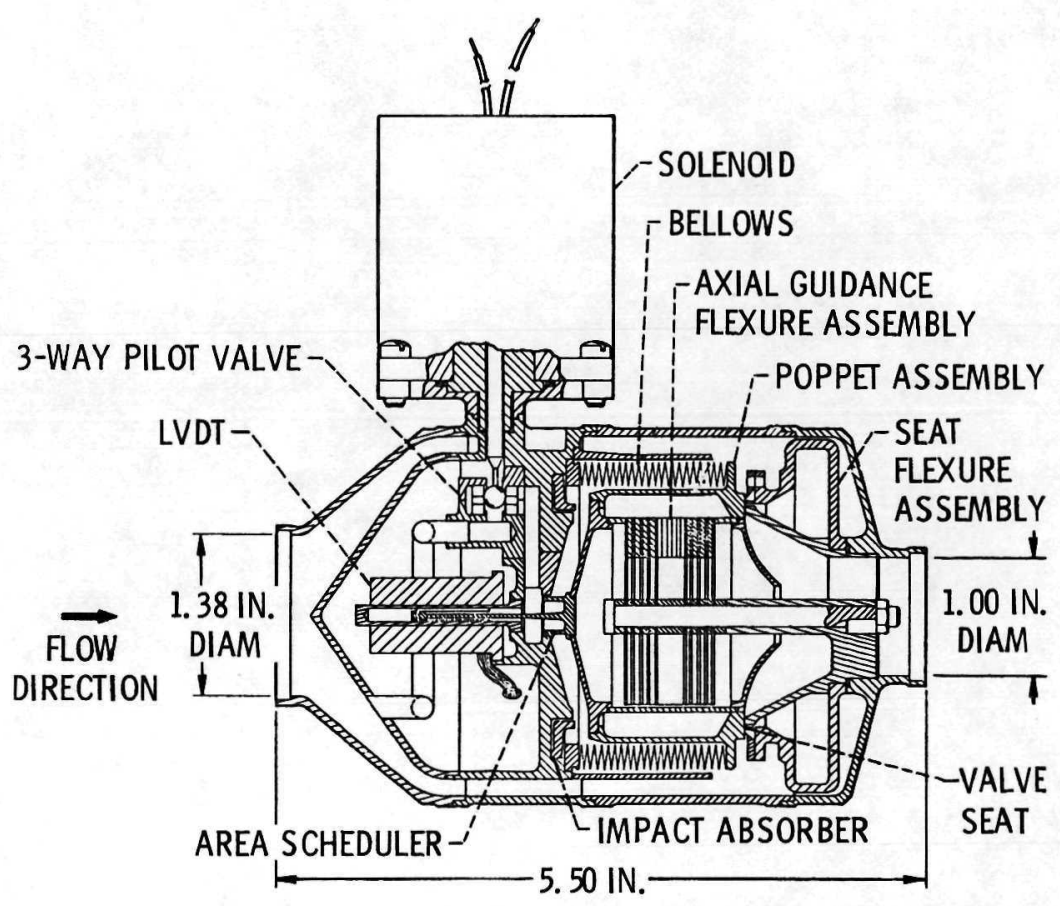

Figure 36. - Marquardt ACPS valve design. 


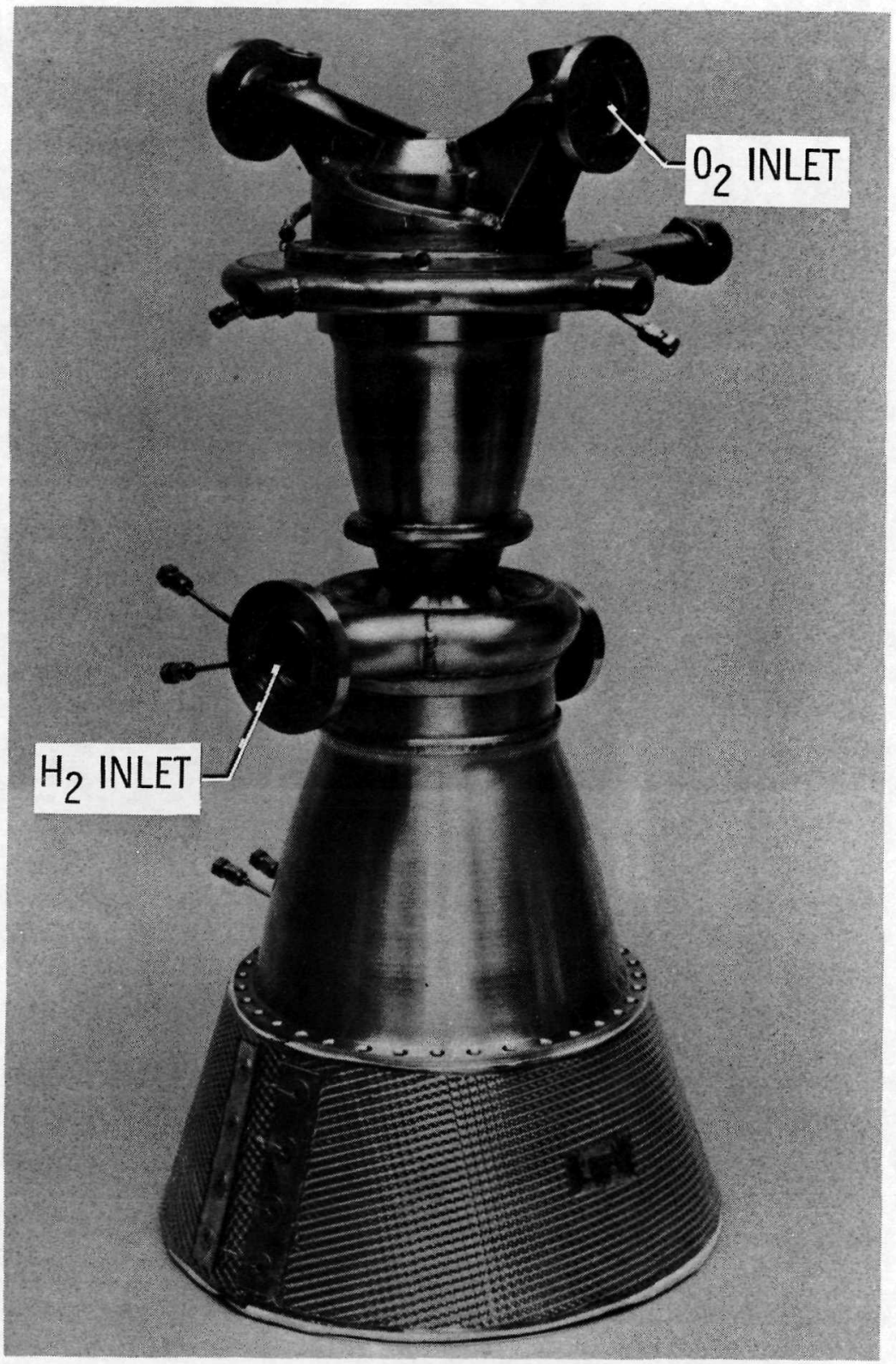

Figure 37. - Regenerative/dump cooled thruster assembly. 

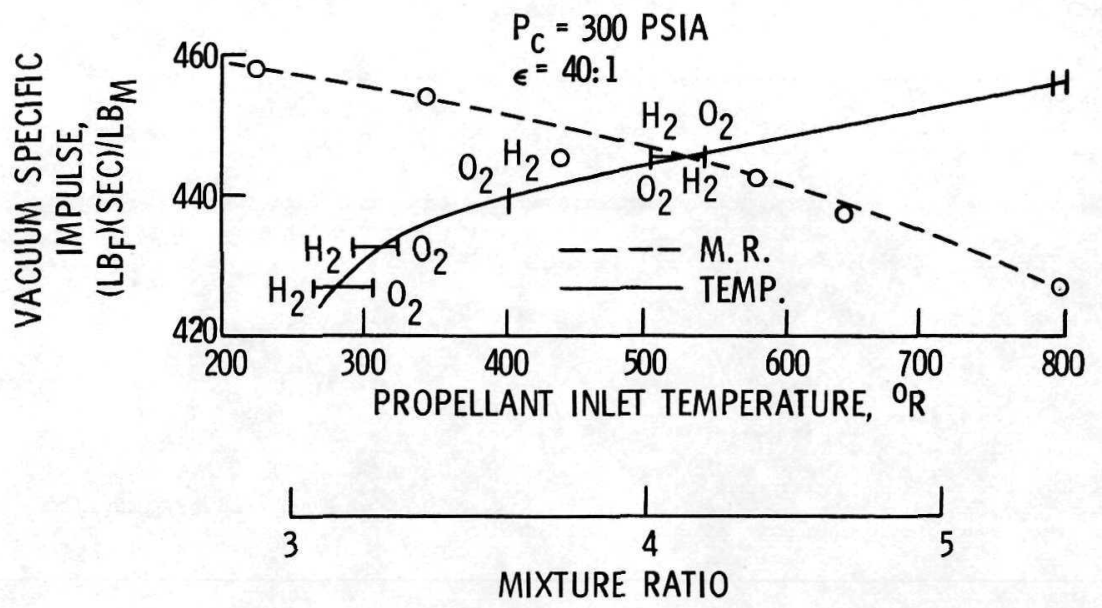

Figure 38. - Regenerative/dump cooled thruster performance characteristics.
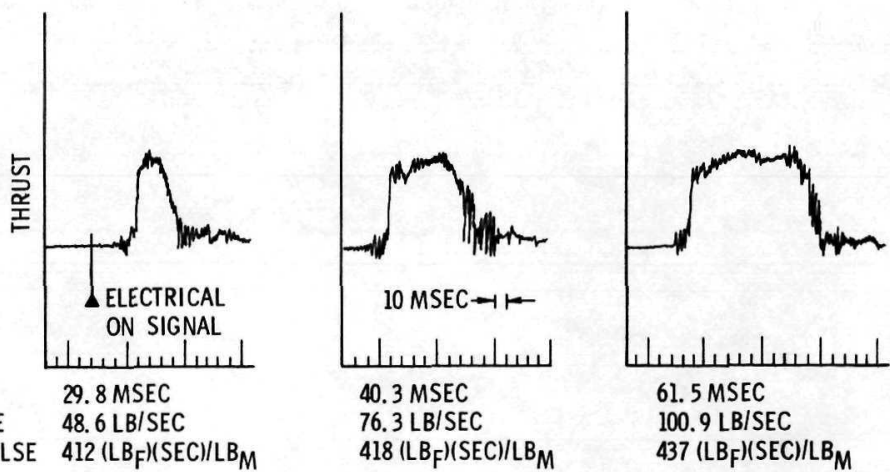

TOTAL IMPULSE

$412\left(\mathrm{LB} \mathrm{F}_{\mathrm{F}}\right)(\mathrm{SEC}) / \mathrm{LB}_{\mathrm{M}}$

40. 3 MSEC

76. $3 \mathrm{LB} / \mathrm{SEC}$

$418\left(\mathrm{LB}_{F}\right)(\mathrm{SEC}) / \mathrm{LB}_{M}$

100.9 LB/SEC

437 (LB $_{\mathrm{F}}$ )(SEC)/LB ${ }_{M}$

Figure 39. - Pulse performance data for regenerative/dump cooled thruster. 


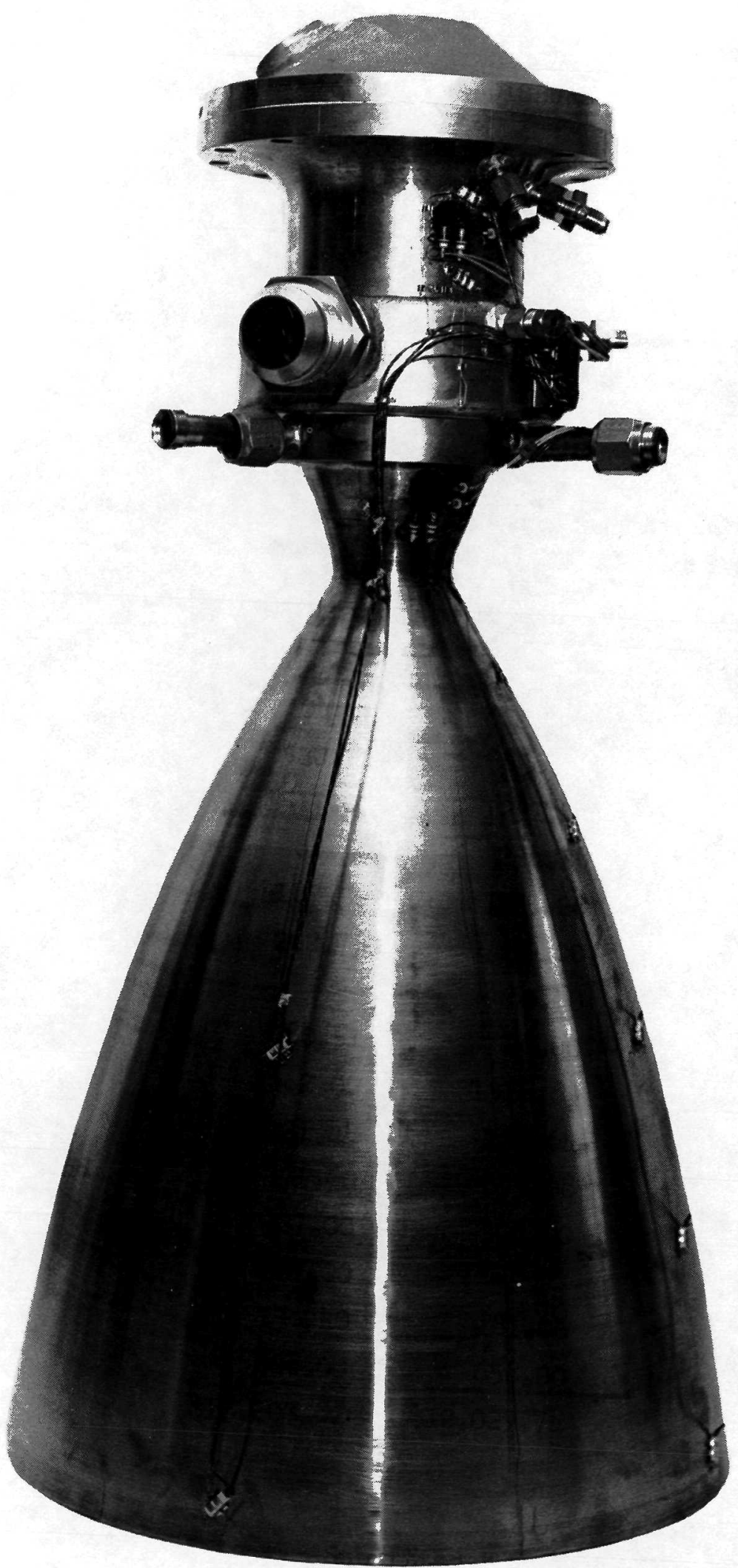

Figure 40. - Film/regenerative cooled thrust chamber. 


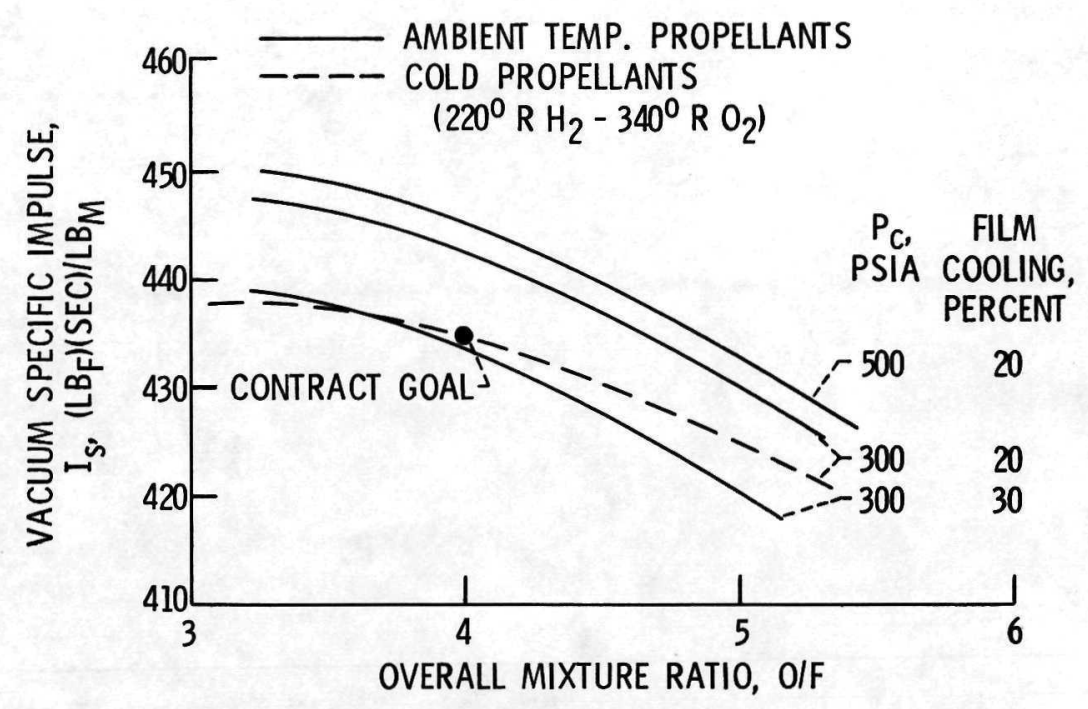

Figure 4l. - Vacuum specific impulse for film/regenerative thruster.

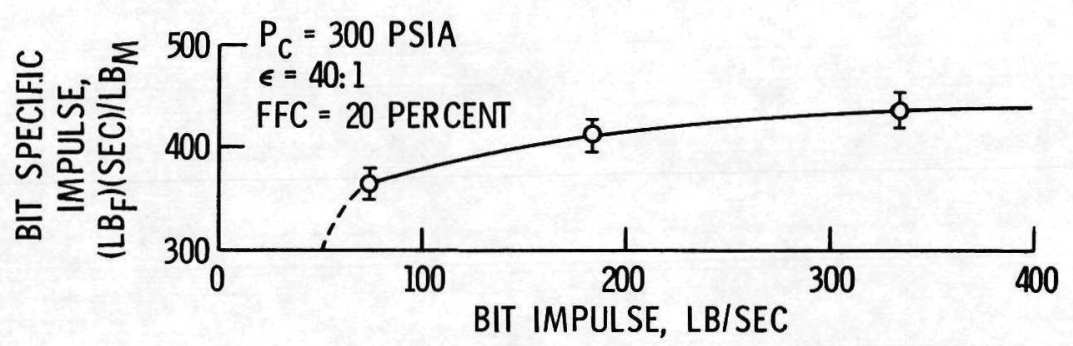

Figure 42. - Bit specific impulse versus pulse width, film/regenerative cooled chamber, ambient temperature propellants. 


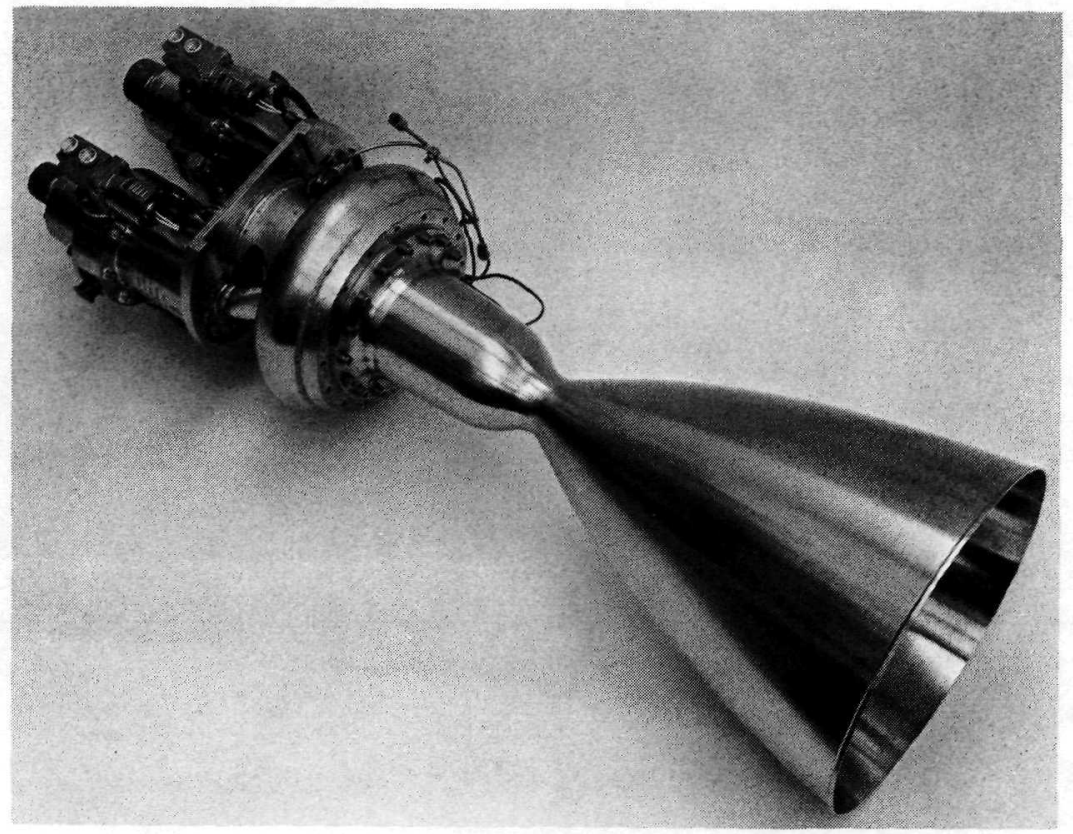

Figure 43. - TRW film/dump cooled thruster assembly.

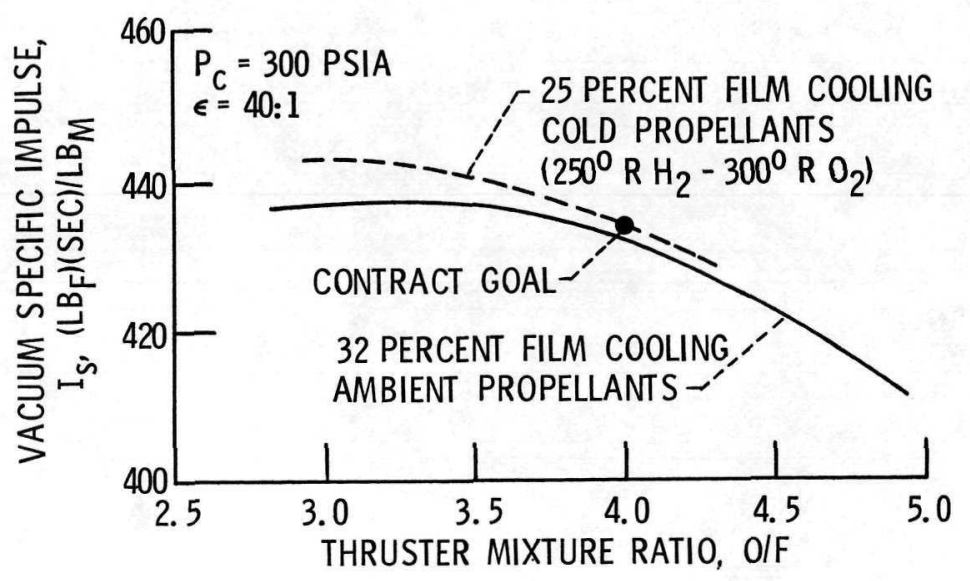

Figure 44. - Film/dump cooled thruster performance. 


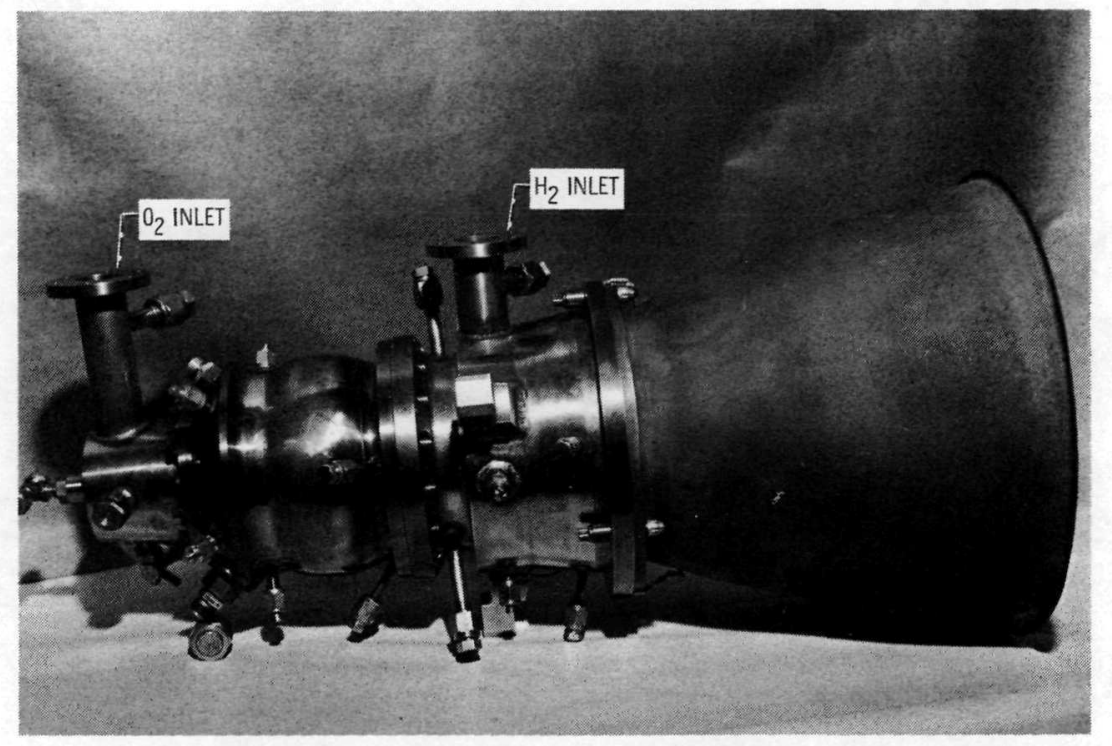

Figure 45. - Bell reverse flow thruster assembly.

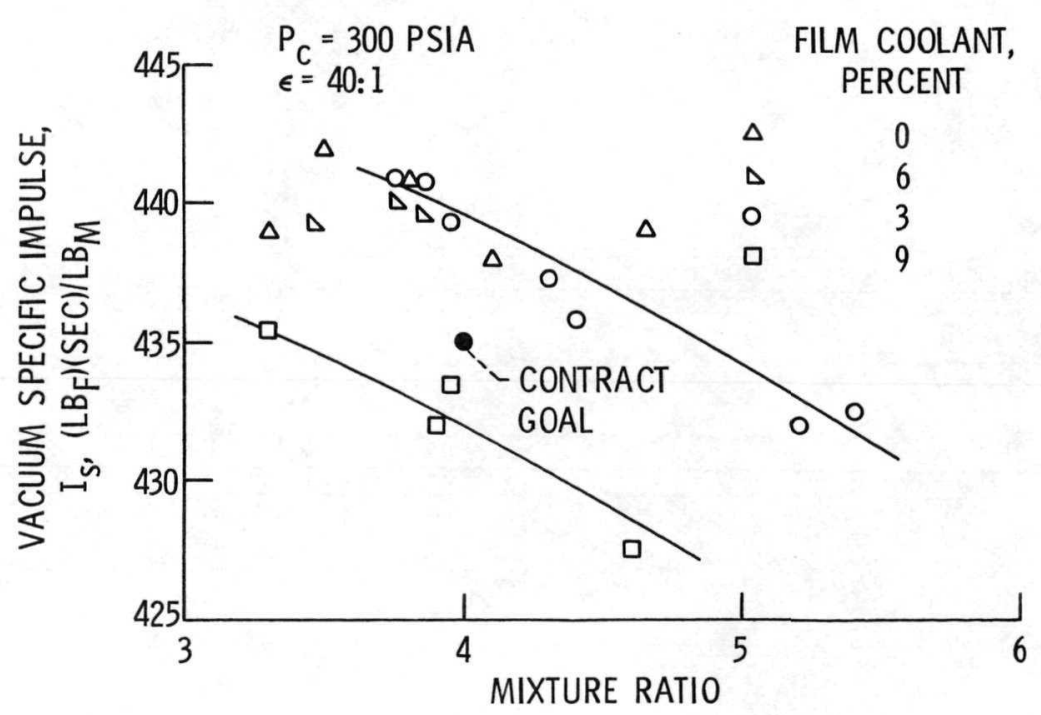

Figure 46. - Reverse flow thruster altitude performance as a function of mixture ratio at various nozzle film coolant flowrates. 


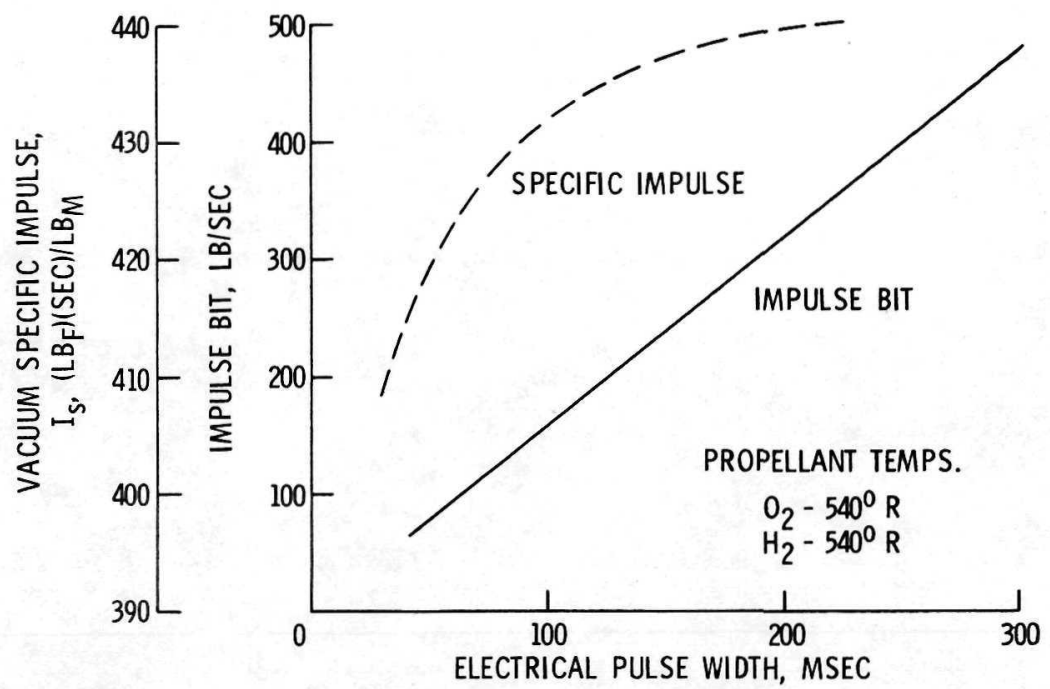

Figure 47. - Reverse flow thruster pulse mode performance.

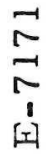

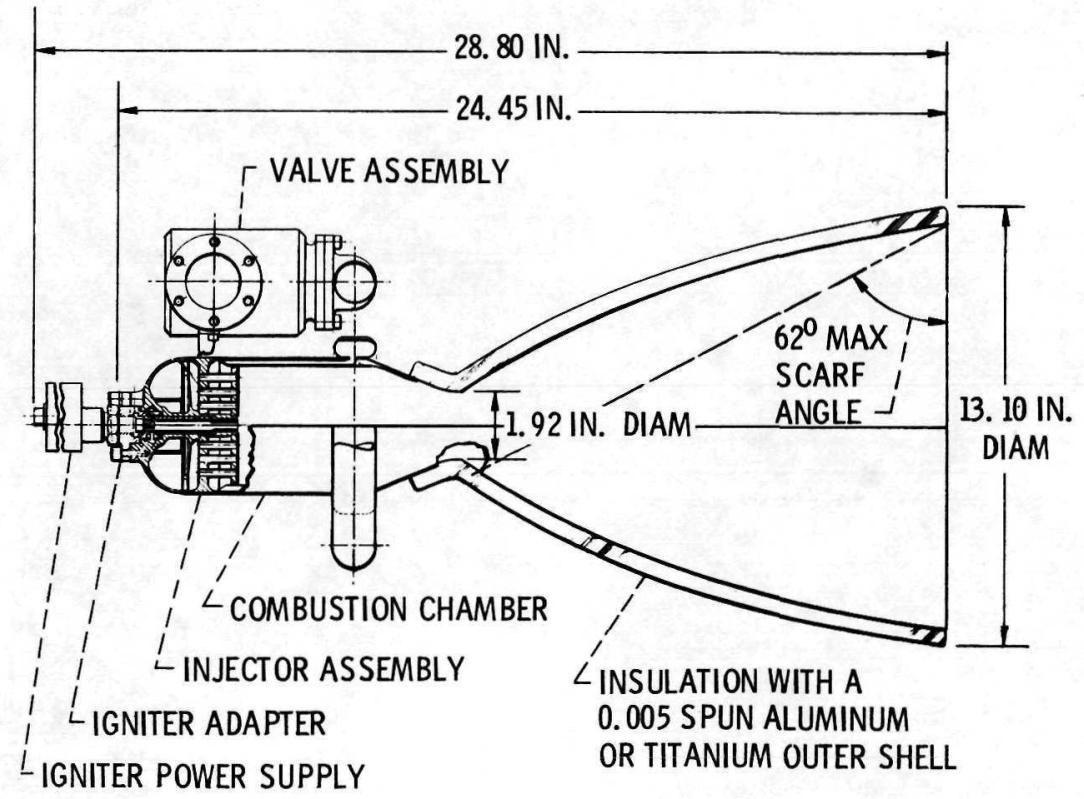

Figure 48. - Integrated Thruster Assembly. 